TEXAS TECH UNIVERSITY

Multidisciplinary Research in Transportation

\title{
Horizontal Cracking in Continuously Reinforced Concrete Pavements
}

Seong Cheol Choi, Moon C. Won

Texas Department of Transportation 


\section{NOTICE}

The United States Government and the State of Texas do not endorse products or manufacturers. Trade or manufacturers' names appear herein solely because they are considered essential to the object of this report 
Technical Report Documentation Page

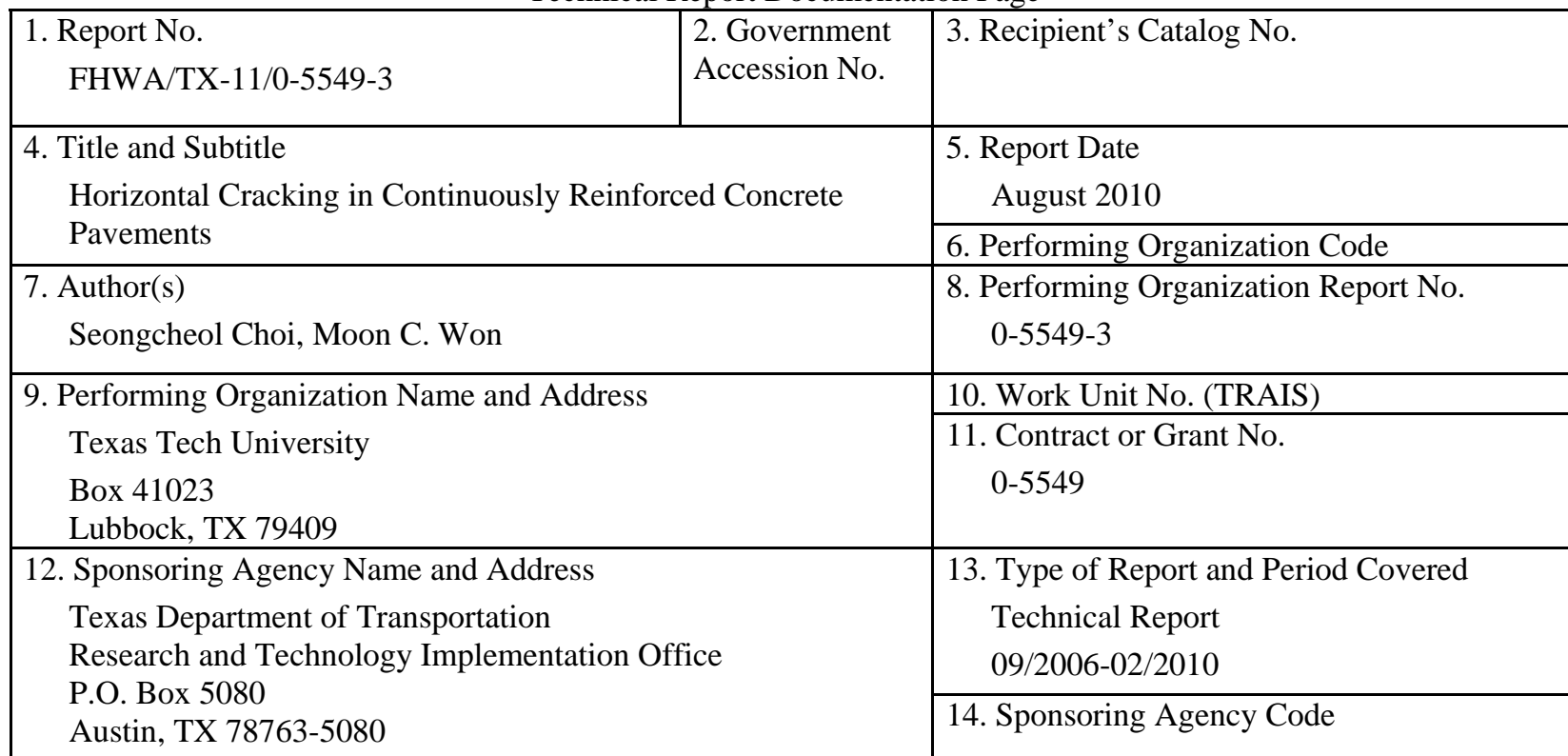
15. Supplementary Notes
Project performed in cooperation with the Texas Department of Transportation and the Federal Highway Administration.

16. Abstract

Horizontal cracking (HC) at the depth of longitudinal steel in CRCP was not known until 1999, when HC was observed in the section on IH 35 in the Waco District. At that time, no prior research was done on this topic and no reports published. Concerned about this type of cracking and its effect on the long-term performance of CRCP, TxDOT initiated this research study. The primary objective of this study was to identify the mechanism of HC in CRCP due to environmental loading (temperature and moisture variations). To this end, a numerical model was developed to predict the risk of HC in CRCP. Laboratory and field testing was also conducted to evaluate the actual behavior of concrete near longitudinal steel. The measured data was used to develop and validate a numerical model for the prediction of HC potential in CRCP. The mechanism of vertical stress development in concrete near longitudinal steel was investigated with a comprehensive numerical analysis. The results of the study indicate that pavement design, more specifically longitudinal steel design, concrete material properties such as coefficient thermal expansion (CoTE), modulus of elasticity, drying shrinkage and strength, and construction quality such as curing and temperature control, all have effects on HC development. Two-mat steel, lower values of CoTE and drying shrinkage and modulus, higher strength of concrete, good quality curing and temperature control will lower the potential for HC. Since there are almost an infinite number of combinations of design, materials and construction variables during the construction of CRCP, more general guidelines rather than prescriptive ones were developed. The guidelines cover three areas - pavement design, materials and construction quality. The implementation of the guidelines is expected to minimize the occurrence of horizontal cracking in CRCP.

\begin{tabular}{|l|l|}
\hline $\begin{array}{l}\text { 17. Key Words } \\
\begin{array}{l}\text { Horizontal cracking, CRCP, concrete, longitudinal } \\
\text { steel, environmental loadings }\end{array}\end{array}$ & $\begin{array}{l}\text { 18. Distribution Statement } \\
\text { No restrictions. This document is available to the } \\
\text { public through the National Technical Information } \\
\text { Service, Springfield, Virginia 22161; www.ntis.gov. }\end{array}$ \\
\hline
\end{tabular}

\begin{tabular}{|c|l|l|l|}
\hline $\begin{array}{c}\text { 19. Security Classif. (of report) } \\
\text { Unclassified }\end{array}$ & $\begin{array}{c}\text { 20. Security Classif. (of this page) } \\
\text { Unclassified }\end{array}$ & $\begin{array}{l}\text { 21. No. of pages } \\
92\end{array}$ & 22. Price \\
\hline
\end{tabular}

Form DOT F 1700.7 (8-72) Reproduction of completed page authorized 



\section{Horizontal Cracking in CRCP}

Seongcheol Choi

Moon Won

$\begin{array}{ll}\text { TechMRT Technical Report: } & 0-5549-3 \\ \text { Report Date: } & \text { August 2010 } \\ \text { Project: } & 0-5549 \\ \text { Project Title: } & \text { Horizontal Cracking in CRCP } \\ \text { Sponsoring Agency: } & \text { Texas Department of Transportation } \\ \text { Performing Agency: } & \text { The Center for Multidisciplinary Research in Transportation at Texas Tech } \\ & \text { University }\end{array}$

Project performed in cooperation with the Texas Department of Transportation and the Federal Highway Administration. 
Texas Tech Center for Multidisciplinary Research in Transportation 10th and Akron

Lubbock, TX 79409

http://www.depts.ttu.edu/techmrtweb/

Copyright (c) 2010

Center for Multidisciplinary Research

Texas Tech University

All rights reserved

Printed in the United States of America 


\title{
Disclaimers
}

Author's Disclaimer: The contents of this report reflect the views of the authors, who are responsible for the facts and the accuracy of the data presented herein. The contents do not necessarily reflect the official view or policies of the Federal Highway Administration or the Texas Department of Transportation (TxDOT). This report does not constitute a standard, specification, or regulation.

Patent Disclaimer: There was no invention or discovery conceived or first actually reduced to practice in the course of or under this contract, including any art, method, process, machine manufacture, design or composition of matter, or any new useful improvement thereof, or any variety of plant, which is or may be patentable under the patent laws of the United States of America or any foreign country.

\author{
Engineering Disclaimer \\ NOT INTENDED FOR CONSTRUCTION, BIDDING, OR PERMIT PURPOSES. \\ Project Engineer: Moon Won \\ Professional Engineer License State and Number: Texas No. 76918 \\ P. E. Designation: Research Supervisor
}




\section{Acknowledgments}

The authors express appreciation to the Project Director, Abbas Mehdibeigi, who provided valuable advice during the course of the research. Also, the support received from PMC members - Dar Hao Chen, Hua Chen, German Claros, Miles Garrison, Lisa Lukefahr, Noel Paramanantham, Billy Pigg, Zhiming Si, Min Tran and Dennis Warren - has been invaluable.

\section{Products}

This report does not include any products. 


\section{Table of Contents}

1. INTRODUCTION................................................................................................................ 1

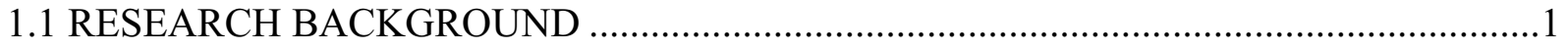

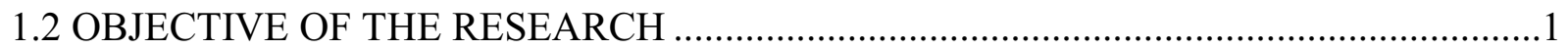

2. HORIZONTAL CRACKING IN CRCP .................................................................... 3

2.1 HORIZONTAL CRACKING PROBLEMS IN TEXAS.................................................

2.2 HORIZONTAL CRACKING IN OTHER STATES.......................................................

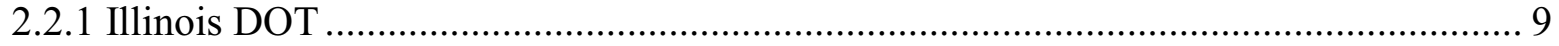

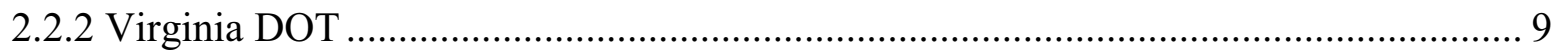

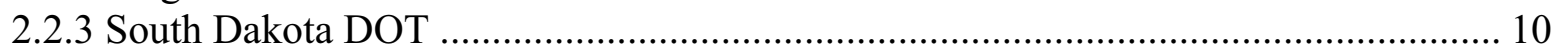

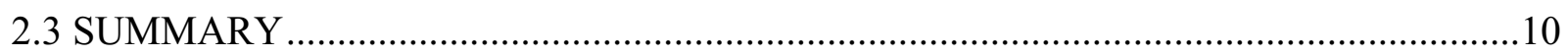

3. HORIZONTAL CRACKING MECHANISM ....................................................................... 12

3.1 NUMERICAL MODEL ………………………….............................................12

3.2 MECHANISM OF VERTICAL STRESS IN CONCRETE NEAR STEEL .........................15

4. LABORATORY TESTING ........................................................................................... 17

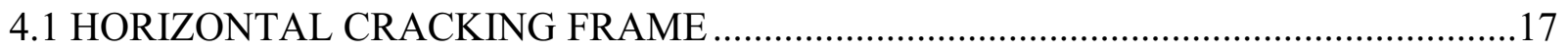

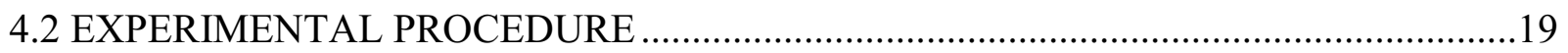

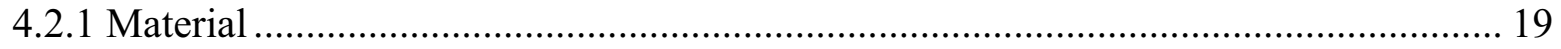

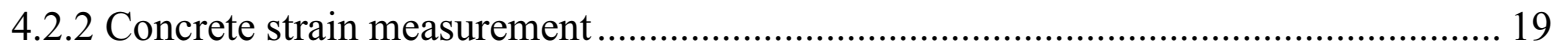

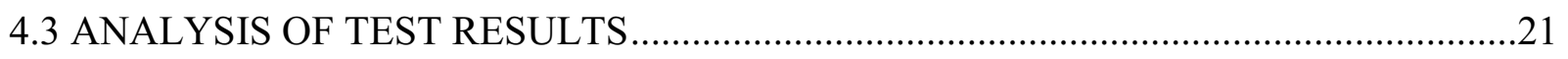

5. FIELD VALIDATION OF HORIZONTAL CRACKING MECHANISMS ..................... 23

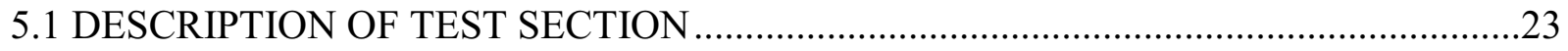

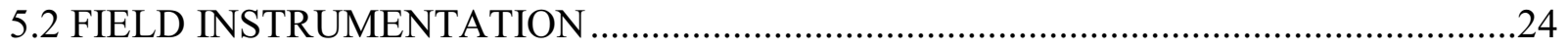

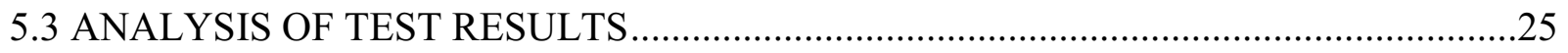

6. VERTICAL STRESS DEVELOPMENT OF CONCRETE NEAR STEEL

UNDER NONLINEAR TEMPERATURE GRADIENT ............................................................ 29

6.1 STRESS DEVELOPMENT DUE TO GENERAL NONLINEAR

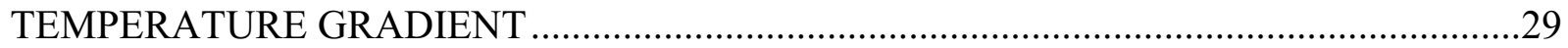

6.2 STRESS DEVELOPMENT DUE TO UNIFORM TEMPERATURE DROP AND

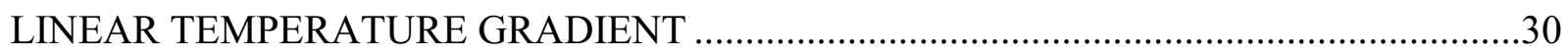

7. NUMERICAL PARAMETRIC STUDY ON HORIZONTAL CRACKING

POTENTIAL IN CRCP ........................................................................................................... 33

7.1 NUMERICAL STUDY ON HORIZONTAL CRACKING POTENTIAL IN CRCP .........33

7.2 FACTORIAL EXPERIMENT FOR ANALYSIS OF HC POTENTIAL …………..............36

7.3 GUIDELINES TO MINIMZIE HORIZONTAL CRACKING ...........................................43

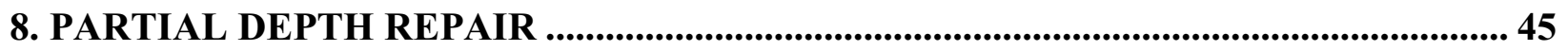

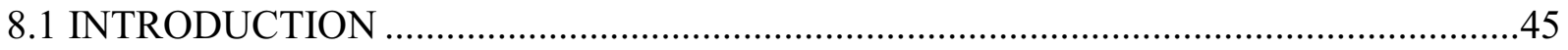

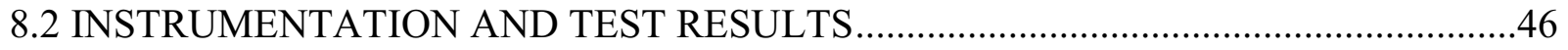

9. CONCLUSIONS ……….........................................................................................................5 50

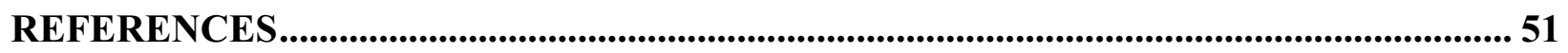


APPENDIX A. Vertical Stress Contour of Analysis Results per Factorial Experiment......52

APPENDIX B. Special Specifications for Partial Depth Repair .............................................. 76 


\section{List of Figures}

Figure 2.1: Horizontal cracking in CRCP (Phase I) on IH 35 in Waco District.......................... 3

Figure 2.2: CRCP distress caused by horizontal cracking ............................................... 4

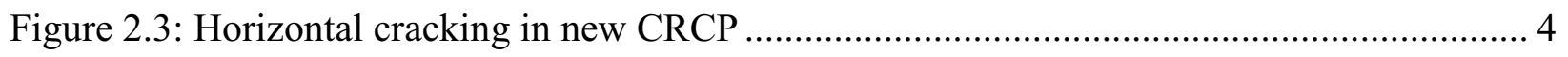

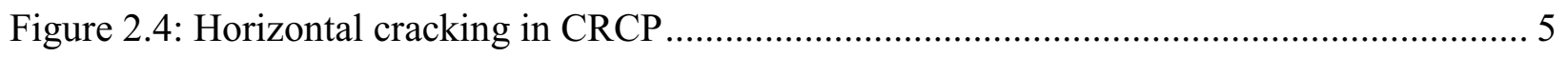

Figure 2.5: Horizontal cracks observed on the side of the slab ............................................ 6

Figure 2.6: Horizontal cracks in slabs removed from IH30 in Paris District ............................ 7

Figure 2.7: Surface distress caused by horizontal cracking ............................................ 7

Figure 2.8: No surface distress with fine horizontal cracking .............................................. 8

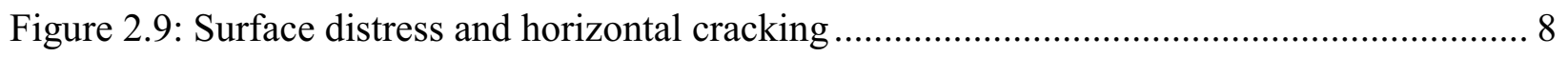

Figure 2.10: Horizontal crack in new pavement .......................................................... 9

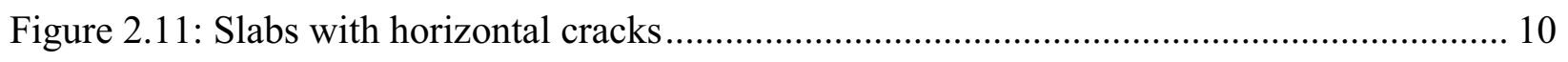

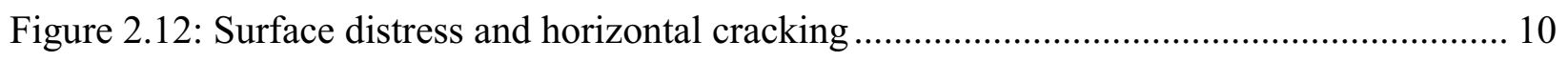

Figure 3.1: Finite element model for prediction of horizontal cracking in CRCP .................... 13

Figure 3.2: Finite element model for prediction of horizontal cracking in CRCP ................... 14

Figure 3.3: Restraint of steel on CRCP movement at transverse crack .................................. 16

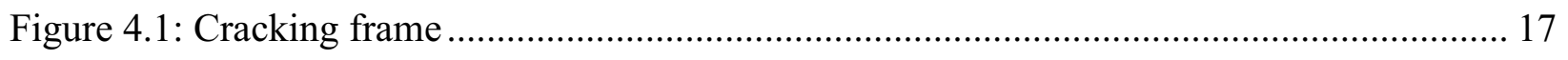

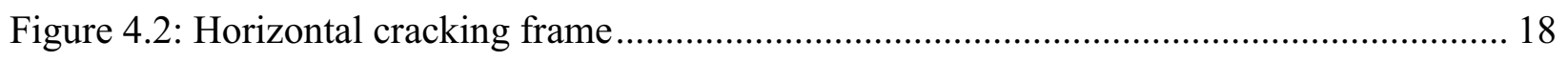

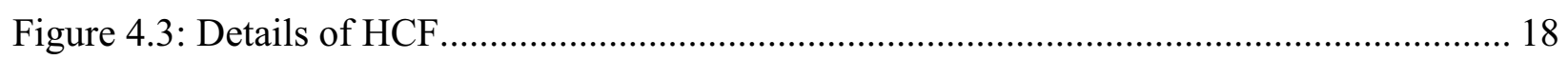

Figure 4.4: Installed VWSGs to measure transverse and horizontal cracks ........................... 20

Figure 4.5: Measured strain and temperature histories ................................................. 21

Figure 4.6: Measured coefficient of therma expansion ....................................................... 22

Figure 4.7: Variation of measured and predicted vertical strains ......................................... 22

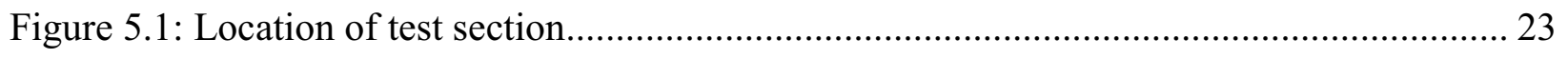

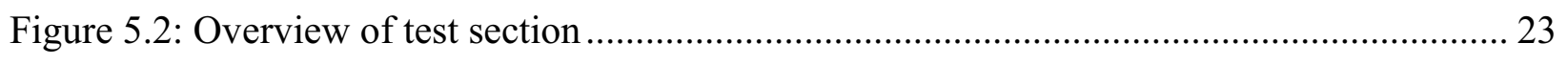

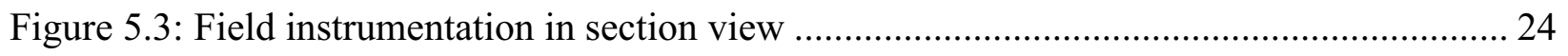

Figure 5.4: Installed strain gages in longitudinal and vertical direction.................................. 24

Figure 5.5: Measured strain and temperature histories in field testing .................................. 26

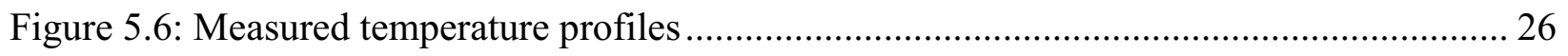

Figure 5.7: Measured vertical strains compared with predicted ones.................................... 27

Figure 5.8: Measured coefficient of thermal expansion in the field testing ............................. 27 
Figure 5.9: Measured elastic modulus of concrete material .............................................. 28

Figure 6.1: Decomposition of general nonlinear temperature gradient .................................... 29

Figure 6.2: Distribution of vertical stress in CRCP at transverse crack subject to general

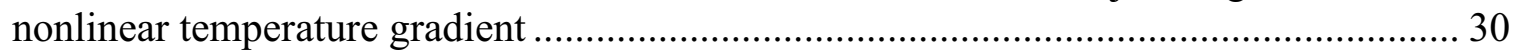

Figure 6.3: Effect of uniform temperature drop on vertical stress development ....................... 31

Figure 6.4: Effect of CoTE on vertical stress development................................................... 31

Figure 6.5: Effects of transverse crack spacing and number of steel layers on vertical

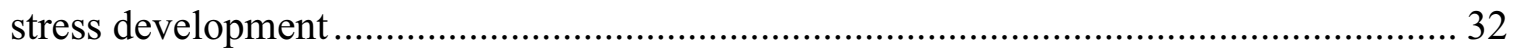

Figure 6.6: Effect of temperature difference on vertical stress developmen ............................. 32

Figure 7.1: Effect of elastic modulus and CoTE on vertical stress development ...................... 34

Figure 7.2: Nonlinear temperature gradient with different degree of nonlinearity..................... 35

Figure 7.3: Effect of degree of nonlinearity in temperature gradient on vertical stress

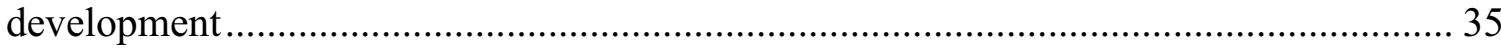

Figure 7.4: Distribution of vertical stress in CRCP at transverse crack ................................... 36

Figure 7.5: Analysis results in factorial experiment $\left(E_{c}=4 \times 10^{6} \mathrm{psi}, 2^{\text {nd }}\right.$ degree gradient,

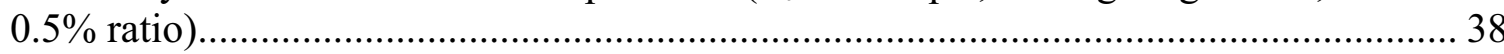

Figure 7.6: Analysis results in factorial experiment $\left(\mathrm{E}_{\mathrm{c}}=6 \times 10^{6} \mathrm{psi}, 2^{\text {nd }}\right.$ degree gradient, $0.5 \%$ ratio) 38

Figure 7.7: Analysis results in factorial experiment $\left(E_{c}=4 \times 10^{6} \mathrm{psi}, 4^{\text {th }}\right.$ degree gradient, $0.5 \%$ ratio) 39

Figure 7.8: Analysis results in factorial experiment $\left(\mathrm{E}_{\mathrm{c}}=6 \times 10^{6} \mathrm{psi}, 4^{\text {th }}\right.$ degree gradient, $0.5 \%$ ratio).

Figure 7.9: Analysis results in factorial experiment $\left(E_{c}=4 \times 10^{6} \mathrm{psi}, 2^{\text {nd }}\right.$ degree gradient, $0.6 \%$ ratio)

Figure 7.10: Analysis results in factorial experiment $\left(\mathrm{E}_{\mathrm{c}}=6 \times 10^{6} \mathrm{psi}, 2^{\text {nd }}\right.$ degree gradient, $0.6 \%$ ratio) 40

Figure 7.11: Analysis results in factorial experiment $\left(E_{c}=4 \times 10^{6} \mathrm{psi}, 4^{\text {th }}\right.$ degree gradient, $0.6 \%$ ratio).

Figure 7.12: Analysis results in factorial experiment $\left(E_{c}=6 \times 10^{6} \mathrm{psi}, 4^{\text {th }}\right.$ degree gradient, $0.6 \%$ ratio)

Figure 7.13: Analysis results in factorial experiment $\left(\mathrm{E}_{\mathrm{c}}=4 \times 10^{6} \mathrm{psi}, 2^{\text {nd }}\right.$ degree gradient, $0.7 \%$ ratio)

Figure 7.14: Analysis results in factorial experiment $\left(E_{c}=6 \times 10^{6} \mathrm{psi}, 2^{\text {nd }}\right.$ degree gradient, $0.7 \%$ ratio)

Figure 7.15: Analysis results in factorial experiment $\left(E_{c}=4 \times 10^{6} \mathrm{psi}, 4^{\text {th }}\right.$ degree gradient, $0.7 \%$ ratio). 
Figure 7.16: Analysis results in factorial experiment $\left(E_{c}=6 \times 10^{6} \mathrm{psi}, 4^{\text {th }}\right.$ degree gradient,

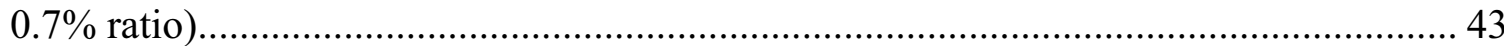

Figure 8.1: Distressed concrete slab with horizontal cracking ........................................... 45

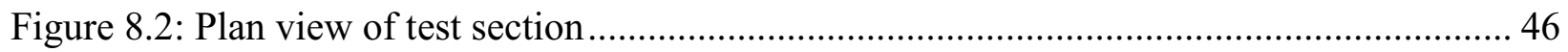

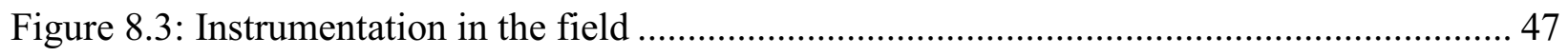

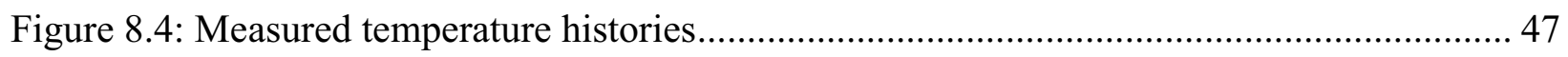

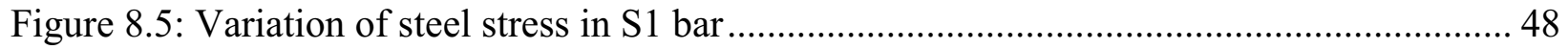

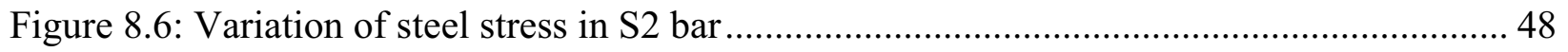

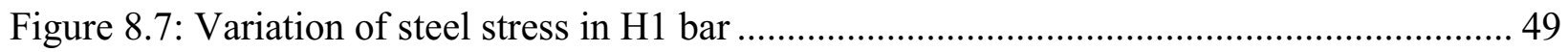

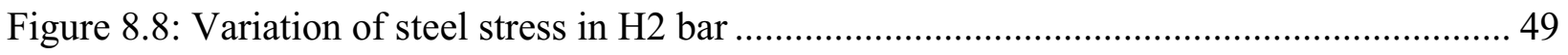




\section{List of Tables}

Table 2.1: Details of Phase I and II Sections ............................................................... 3

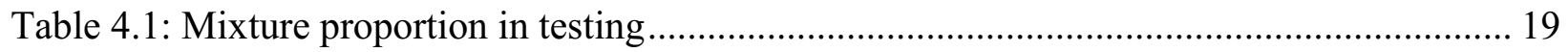

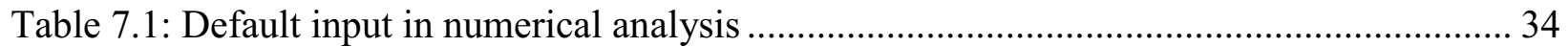

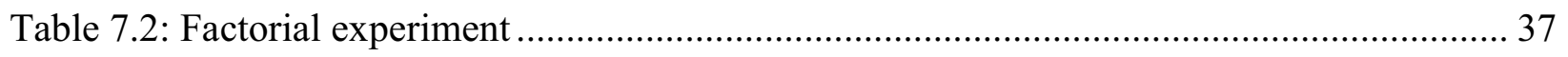




\section{INTRODUCTION}

\subsection{RESEARCH BACKGROUND}

Cracks in jointed Portland cement concrete (PCC) pavement, whether transverse or longitudinal, are considered undesirable and efforts are made to prevent or minimize them by the use of adequate slab thickness and proper joint spacing along with adequate slab support. On the other hand, in continuously reinforced concrete pavement (CRCP), transverse cracks are intentional and do not necessarily develop into distress primarily because they are held quite tight by longitudinal reinforcement. As a matter of fact, transverse cracks at adequate spacing are desirable in CRCP because they provide flexibility to the pavement system that can accommodate volume changes in the subgrade. On the other hand, longitudinal cracks are not intentional nor desirable because the steel amount provided is not sufficient enough to hold longitudinal cracks tight. To prevent longitudinal cracks, longitudinal joints are provided every $12-\mathrm{ft}$ or at most $15-\mathrm{ft}$. If these joints are working properly, longitudinal cracks do not develop. As discussed above, transverse and longitudinal cracks are the only two types of cracks known to exist in CRCP and proper design and construction techniques and features were developed to make transverse cracks harmless and to keep longitudinal cracks from developing. In 1999, a different type of cracking in CRCP was observed on IH 35 in Hillsboro in the Waco District. At that time, CRCP section was under construction and being evaluated due to curing-related issues. During the pavement evaluation, horizontal cracking (HC) was observed at the depth of the longitudinal steel. At that time, HC was not known to exist in CRCP. Since the section was still under construction and not open to traffic, except for occasional construction traffic, it was considered that $\mathrm{HC}$ was caused by environmental loading (temperature and moisture variations), not by wheel loading. What was not known at that time was whether $\mathrm{HC}$ will eventually develop into distress, and if it does, how long it will take before distress develops. Concerned about the unknown nature of $\mathrm{HC}$ and its effect on long-term performance of CRCP, TxDOT initiated this research study.

During the course of this research study, HC was discovered at the depth of longitudinal steel in punchouts in CRCP with coarse aggregate that has low coefficient of thermal expansion (CoTE) and modulus of elasticity. Concrete with low CoTE and modulus of elasticity is considered to have lower potential for HC from environmental loading. Also, the CRCP with HC discovered during punchout repair was old and had slab thickness of 6 to 8 inches. Theoretical analysis conducted in TxDOT research project 0-5832 indicated strong interactions between longitudinal steel and concrete due to wheel loading applications. It is considered that $\mathrm{HC}$ could develop from either environmental loading or wheel loading applications, or from a combination of environmental loading and wheel loading applications. When this research study was initiated, it was not known that wheel loading can cause HC. As a result, the scope of this research was limited to $\mathrm{HC}$ development due to environmental loading only and what could be done to prevent or minimize $\mathrm{HC}$ occurrence.

\subsection{OBJECTIVE OF THE RESEARCH}

The objective of this study was to identify the mechanism of HC in CRCP due to environmental loading and develop recommendations to design standards, materials and/or construction specifications to prevent or minimize HC. To this end, a comprehensive numerical model was 
developed to represent the behavior of CRCP under environmental loadings. The stress distribution of concrete at the depth of steel, where the horizontal crack generally occurs, was analyzed in the model. The mechanism of $\mathrm{HC}$ was identified through the numerical model. Laboratory and field testing was also performed, where the developed numerical model was validated with measured data from testing. The variation of strain in concrete during temperature changes was measured and compared with the result predicted by numerical analysis. The development of vertical stress in concrete near steel was also estimated. Based on experimental and numerical study results, a comprehensive factorial experiment was developed, and the $\mathrm{HC}$ potential was assessed for the factors related to the materials, design and construction of CRCP. 


\section{HORIZONTAL CRACKING IN CRCP}

\subsection{HORIZONTAL CRACKING PROBLEMS IN TEXAS}

There are numerous cases of horizontal cracking failure in CRCP in Texas. The HC problem has been observed in the following districts: Atlanta, Beaumont, Dallas, Houston, Paris, Waco, and Wichita Falls. This type of distress could exist in other districts as well and just hasn't been identified to date. A few selected cases are presented here.

In 1999, the Waco District was constructing 14-in CRCP on IH-35 in Hillsboro. The coarse aggregate used was limestone gravel. As described in the previous chapter, during the field evaluation of the pavement for curing issues, $\mathrm{HC}$ was observed at the depth of the longitudinal steel, as shown in Figure 2.1. This evaluation included coring in vertical and horizontal directions to identify the extent of the horizontal cracking. There were two phases in this project, and Table 2.1 summarizes the differences between the two phases.

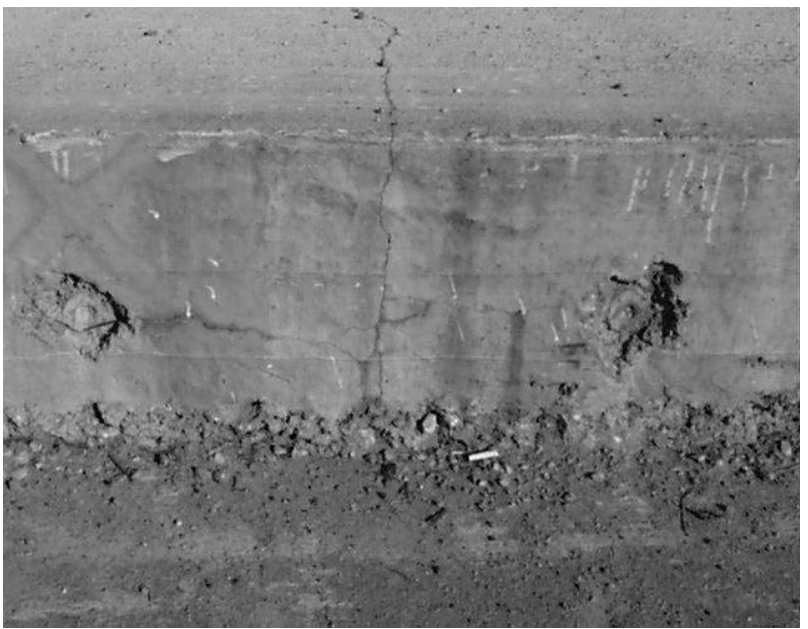

(a)

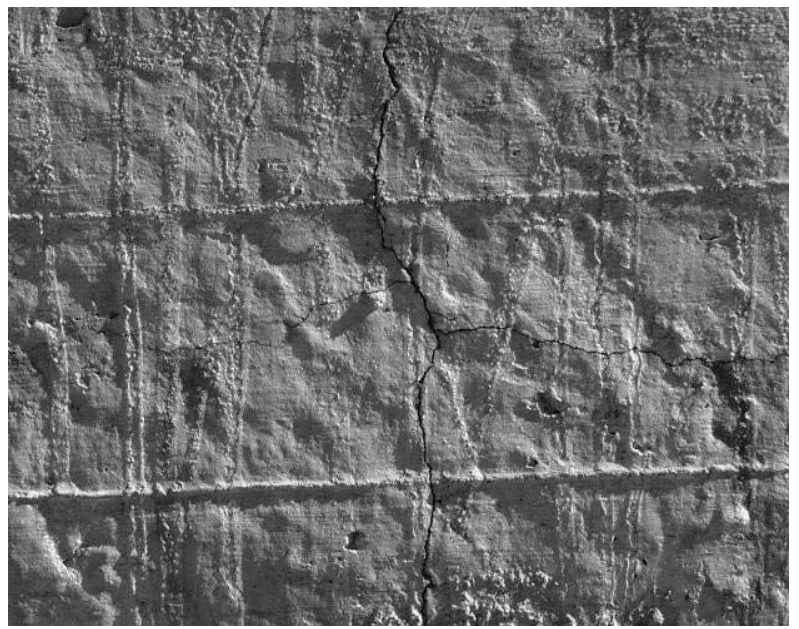

(b)

Figure 2.1: Horizontal cracking in CRCP (Phase I) on IH 35 in Waco District

Table 2.1: Details of Phase I and II Sections

\begin{tabular}{ccc}
\hline Phase & I & II \\
\hline \hline Slab thickness (in) & 14 & 14 \\
\hline Layer of longitudinal steel & $1 \mathrm{mat}$ & $2 \mathrm{mat}$ \\
\hline Rebar size & $\# 7$ & $\# 6$ \\
\hline Bar spacing (in) & 6.5 & 9.5 (double layer) \\
\hline Steel Reinforcement $(\%)$ & 0.66 & 0.66 \\
\hline $\begin{array}{c}\text { Min air temperature during three days } \\
\text { after concrete placement }\left({ }^{\circ} \mathrm{F}\right)\end{array}$ & 29 & 56 \\
\hline
\end{tabular}

The major differences between the two phases are the number of steel layer and minimum air temperature during the first three days after concrete placement. HC was observed in the Phase I 
section, and none in the Phase II section. It appears that the number of steel mats and temperature condition played a role in $\mathrm{HC}$ development. Distresses resembling traditional puchouts were first observed in 2009, 10 years after the concrete placement. Figure 2.2-(a) shows a typical distress observed in the Phase I section in 2009, and Figure 2.2-(b) confirms the existence of $\mathrm{HC}$ in the distressed area.

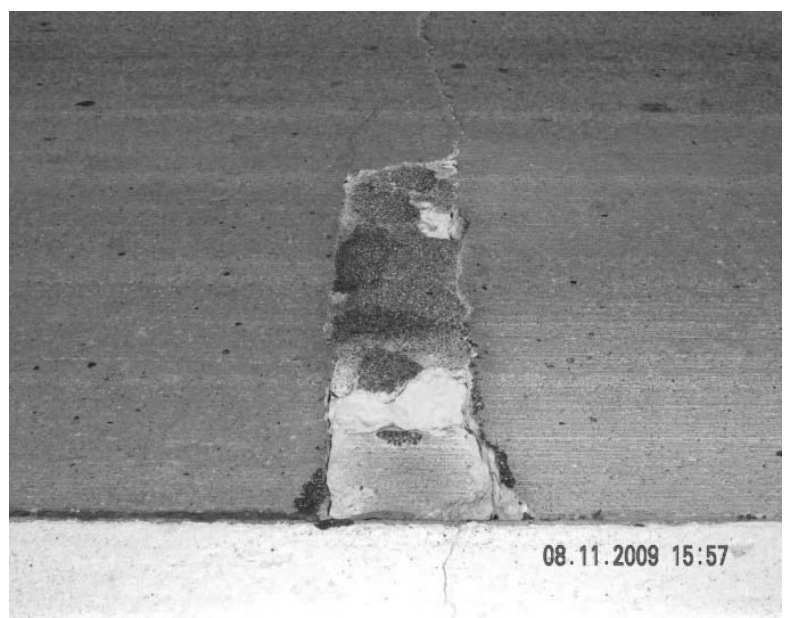

(a)

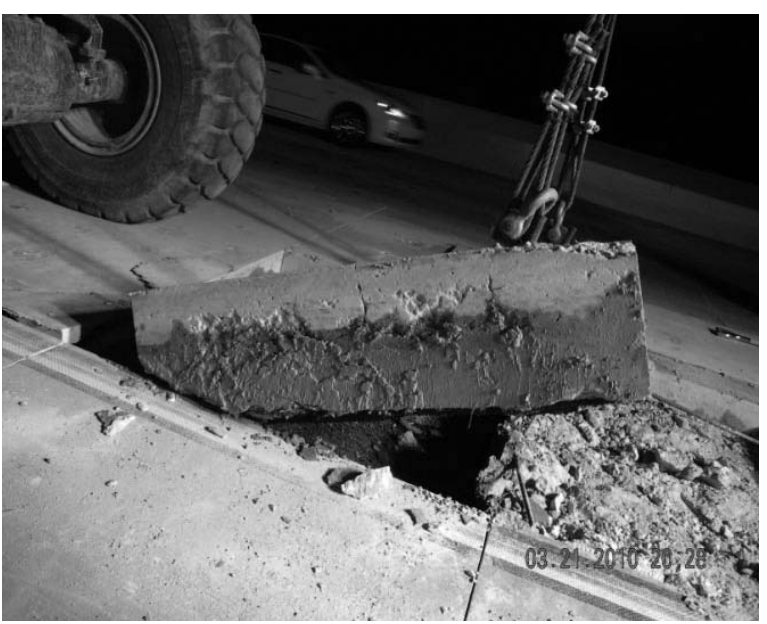

(b)

Figure 2.2: CRCP distress caused by horizontal cracking

In 2001, the Atlanta District constructed CRCP on US 59 in Cass County. During the field evaluation for low concrete strength problems, horizontal cracking was observed as shown in Figure 2.3. Figure 2.3-(a) shows HC on the side of the pavement edge, and 2.3-(b) shows a horizontal crack at the steel depth in a core taken in the middle of the lane. This pavement was new and was not open to traffic at the time this picture was taken, which indicates that this horizontal cracking was caused by factors other than wheel loading. The coarse aggregate used was siliceous river gravel.

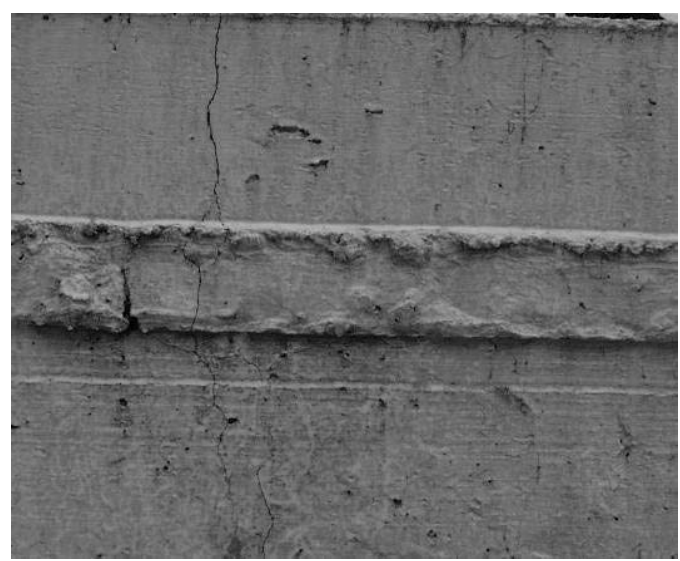

(a)

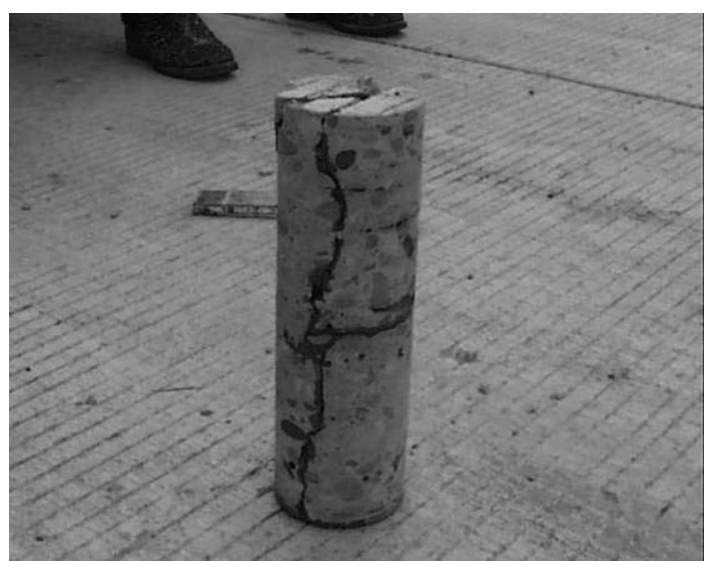

(b)

Figure 2.3: Horizontal cracking in new CRCP 
In 2001, the Dallas District repaired pavement distresses on a CRCP section on IH-35W in Denton County. This CRCP section was built in the mid-1960's and scheduled for an asphalt concrete (AC) overlay. Before the overlay, the district was repairing distresses. During the repair of what appeared to be punchout, horizontal cracking was observed in the slab taken out from the pavement, as shown in Figure 2.4. It shows that there were delaminations at the depth of steel. The slab was 8-in thick, siliceous river gravel was used as the coarse aggregate and soilcement was the subbase type used. It is not known whether this $\mathrm{HC}$ was due to environmental loading or a combination of environmental and wheel loading applications.

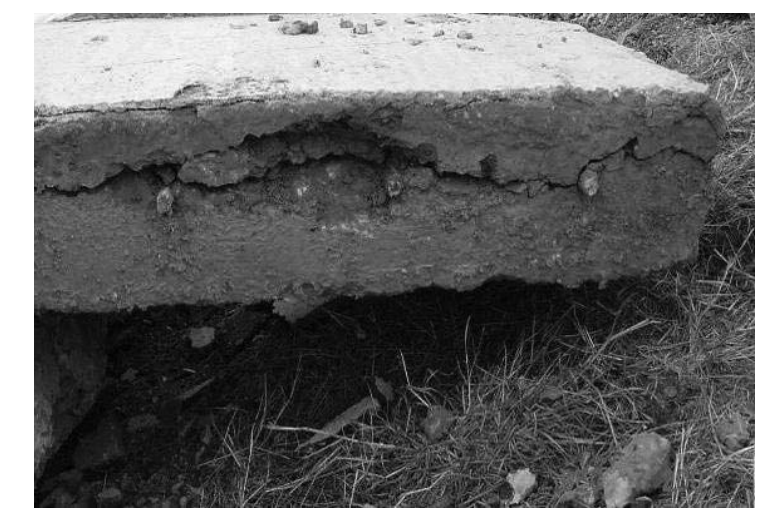

Figure 2.4: Horizontal cracking in CRCP

The CRCP section on US 290 in the Hempstead area of the Houston District was completed in 1995. Siliceous river gravel was used as the coarse aggregate in the east bound lanes, while crushed limestone was used in the west bound lanes. The slab was 10-in thick, which was placed on top of a 1-in AC bond breaker over a 6-in cement stabilized subbase. A condition survey of these sections done in 2001 showed no distress, except for minor to moderate spalling in the east bound lanes (siliceous river gravel section). This roadway provided an excellent opportunity to evaluate whether coarse aggregate type has an effect on HC. In 2001, the side of the concrete shoulder was exposed at the transverse crack area and the side of the pavement was evaluated for $\mathrm{HC}$. Figure 2.5 shows the $\mathrm{HC}$ at the mid-depth of the slab in the east bound lanes. However, no horizontal cracks were observed in the west bound lanes. As discussed, siliceous river gravel was used in the east bound and limestone was used in the west bound lanes. This might indicate the effect of coarse aggregate type on HC. Concrete with limestone aggregate has, in general, lower CoTE and modulus of elasticity compared with concrete containing siliceous river gravel. Accordingly, it appears that concrete with higher CoTE and modulus is more prone to HC. A condition survey conducted as recently as February 2010 under TxDOT's rigid pavement database project indicated no pavement distress resulting from $\mathrm{HC}$ in both westbound and eastbound lanes. Continued monitoring of the condition of this pavement section will provide important information on whether horizontal cracks will necessarily result in distresses. 

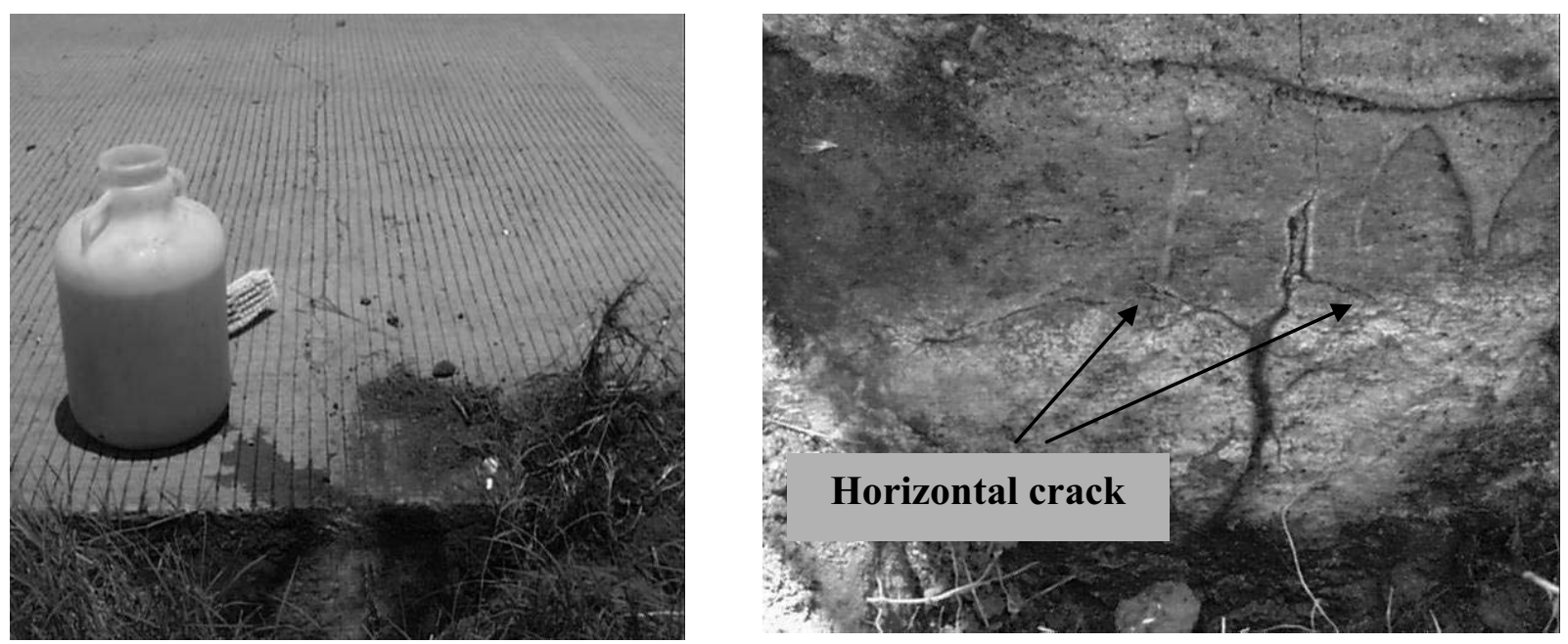

Figure 2.5: Horizontal cracks observed on the side of the slab

In the late 1990's, Sulphur Springs Area Office in the Paris District noticed distresses in CRCP on IH-30. The pavement was built in the mid-1980s. The slab is 13-inch thick and sandstone was used as the coarse aggregate. The concrete slab was placed over old jointed concrete pavement, with an AC bond breaker. Therefore, this pavement can be classified as unbonded overlay. The Area Office hired a contractor to repair distresses with full-depth repair. During the removal of the distressed slabs, it was noted that the slabs had horizontal cracks at the middepth, as shown in Figure 2.6-(a). In 2001, the site was visited where the contractor stored removed slabs, and it was noticed that most of the slabs had horizontal cracks at the mid-depth as shown in Figure 2.6-(b). 


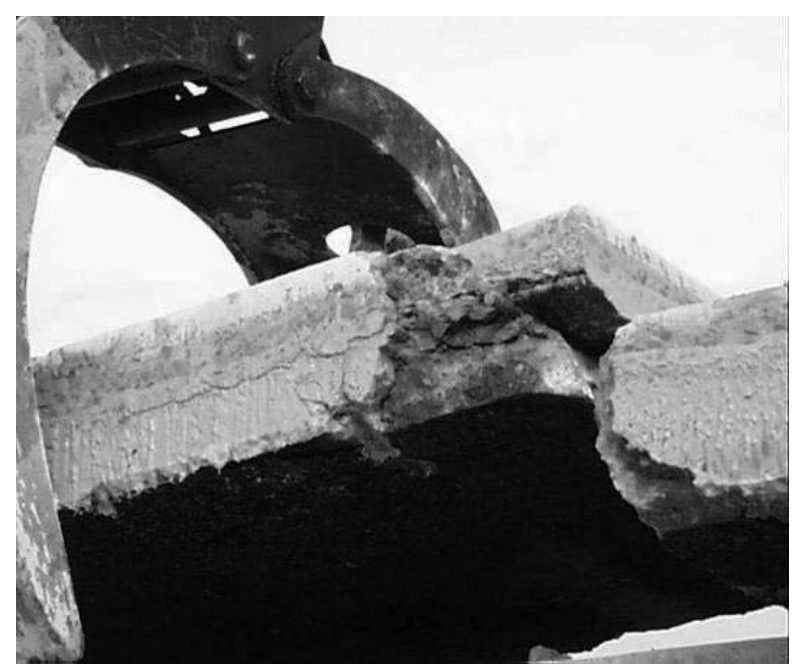

(a)

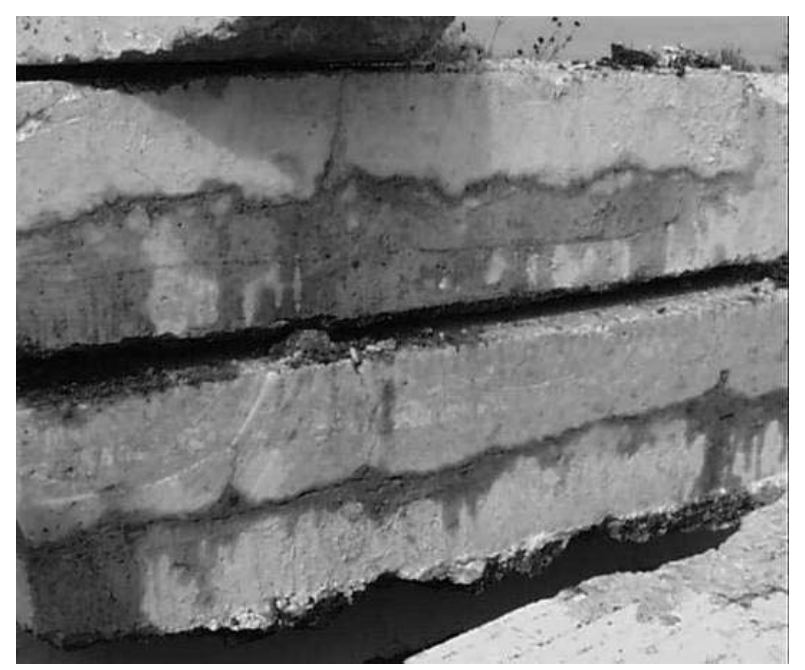

(b)

Figure 2.6: Horizontal cracks in slabs removed from IH30 in Paris District

Despite the repair of the pavement, the Area Office noticed that the distresses continued to develop and in 2001, contacted TxDOT's Construction Division, Materials \& Pavements Section (CSTMP) for an in-depth forensic study. The purpose of the study was to evaluate the pavement condition and make recommendations regarding the best rehabilitation option. During the forensic study, two areas were investigated - one with apparent surface distress, and the other with no surface distress. Figure 2.7-(a) shows the surface distress and 2.7-(b) shows a slab segment taken out from the distressed area. It clearly shows horizontal cracking at the mid-depth of the slab. It also shows that longitudinal cracks developed over the longitudinal steel, did not propagate below the middle of the slab depth where horizontal crack developed.

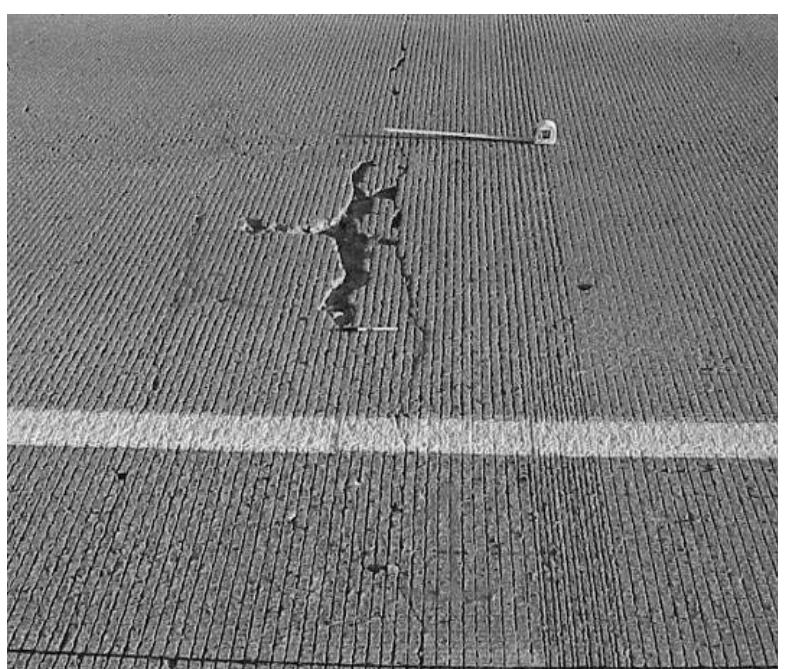

(a)

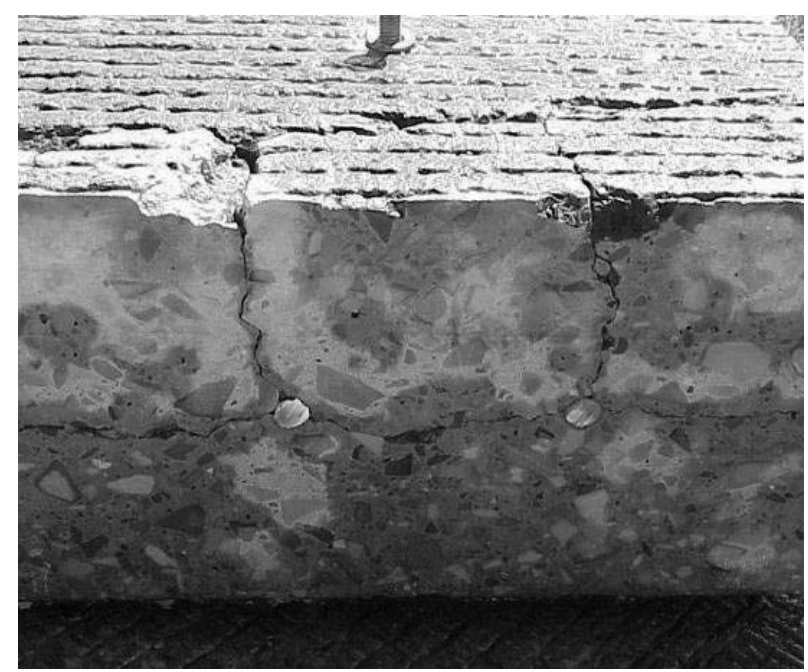

(b)

Figure 2.7: Surface distress caused by horizontal cracking 
The investigation of an area with no surface distress shows that even though there was no apparent distress on the pavement surface, fine horizontal cracking existed at the depth of longitudinal steel. The pavement surface and fine horizontal cracking are shown Figure 2.8.

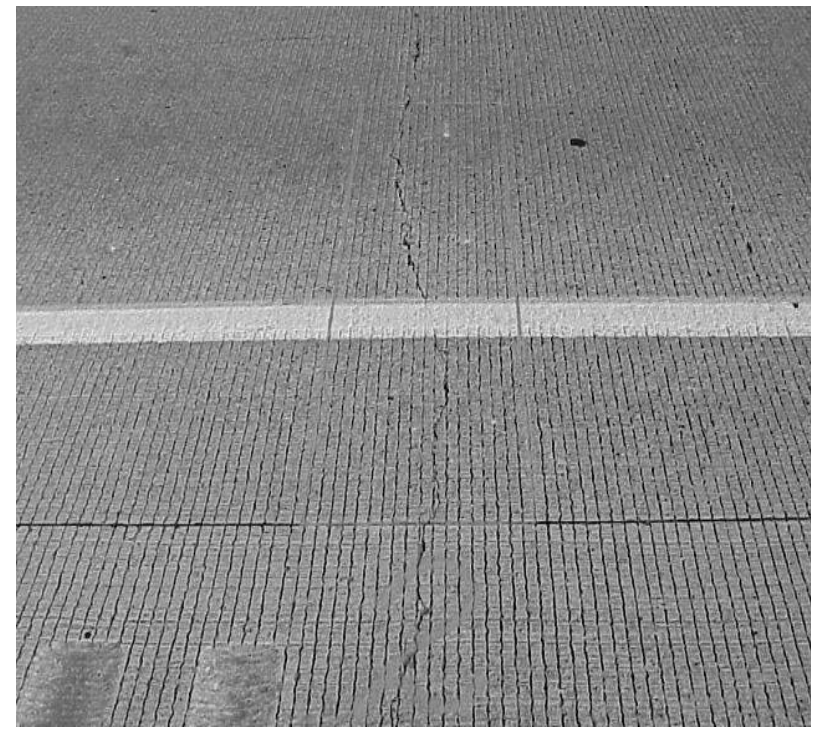

(a)

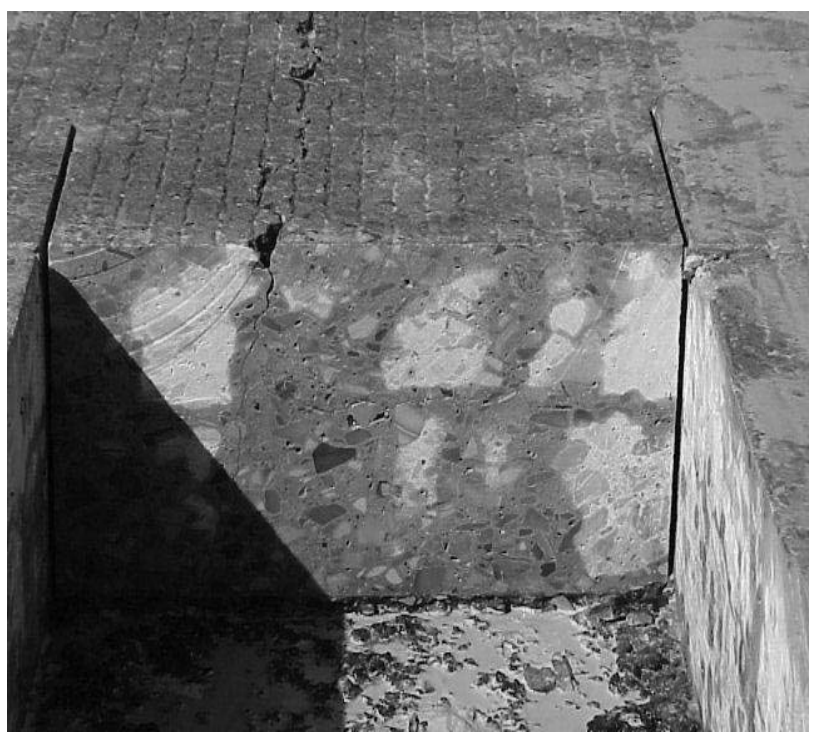

(b)

Figure 2.8: No surface distress with fine horizontal cracking

In 2002, a major full-depth repair of concrete pavement was underway on US 281 in the Wichita Falls District for the preparation of a 4-in bonded overlay. The existing pavement was built in the early 1960's. Limestone was the coarse aggregate type used. The slab was 6-in thick over natural soil. The major distress type in this pavement was surface distress that resembles punchout as shown in Figure 2.9-(a). Upon removal of the distressed slab segment, it was noted that there was $\mathrm{HC}$, which was over longitudinal steel as shown in Figure 2.9-(b). Since limestone was used as coarse aggregate, $\mathrm{HC}$ in this section might have been due to wheel loading applications.

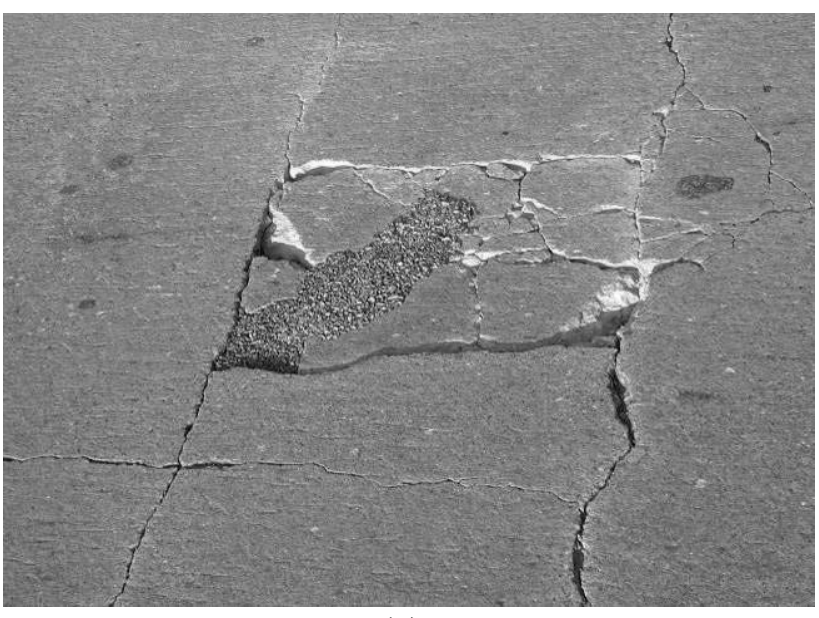

(a)

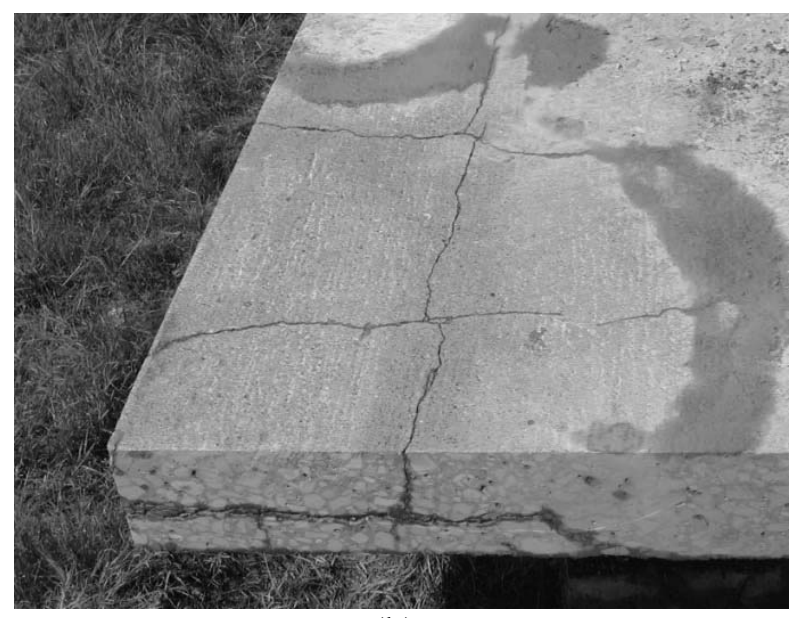

(b)

Figure 2.9: Surface distress and horizontal cracking 
Figure 2.10 shows HC on US 59 southbound lane in Sugarland in the Houston District. This pavement was constructed in 2003 and not opened to traffic when this picture was taken, indicating that this horizontal cracking occurred quite early. In other words, traffic loading may not be a factor; rather, this cracking was caused by the combined effects of environmental loading and concrete material properties, and possibly steel design. The slab was 10 -in thick, siliceous river gravel was used as the coarse aggregate, and the subbase was 1-in AC bond breaker on top of 6-in cement stabilized subbase.

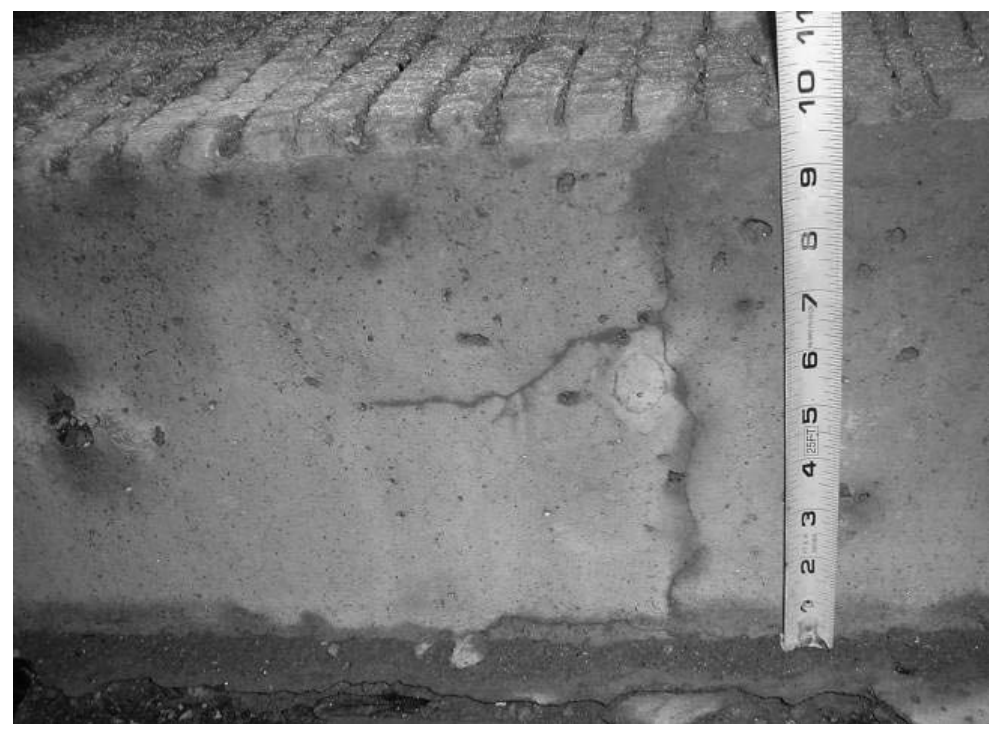

Figure 2.10: Horizontal crack in new pavement

\subsection{HORIZONTAL CRACKING IN OTHER STATES}

\subsubsection{Illinois DOT}

The most extensive use of CRCP in the nation after Texas is in Illinois. Matt Mueller of Illinois DOT (formerly pavement research engineer for Illinois DOT) and David Lippert (acting Materials and Research Engineer) were contacted. Both of them stated that they haven't seen horizontal cracks in Illinois.

\subsubsection{Virginia DOT}

Virginia DOT started using CRCP a few years back and has gained experience in the design/construction and performance of CRCP. Mohamed Elfino (Assistant State Materials Engineer of Virginia DOT) was contacted for Virginia DOT's experience with horizontal cracking. He stated that Virginia DOT has had distresses due to horizontal cracking. However, the distresses were confined to transverse construction joints where additional longitudinal steel was used. Figure 2.11 shows the slabs with $\mathrm{HC}$ at the level of longitudinal steel. To minimize horizontal cracking, Virginia DOT was considering the use of thicker slabs. 


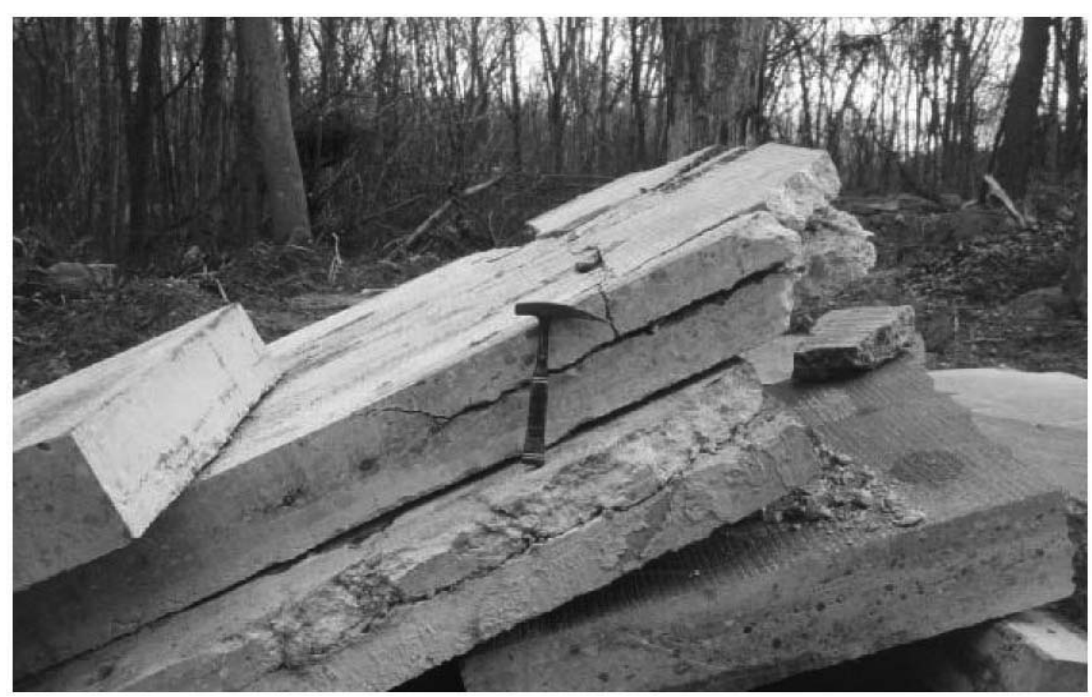

Figure 2.11: Slabs with horizontal cracks

\subsubsection{South Dakota DOT}

Ms Andrea Talley of CRSI (Concrete Reinforcing Steel Institute) provided pictures of horizontal cracking in South Dakota. Mr. Brian Raecke of the South Dakota DOT (Surfacing Plans Engineer) was contacted for further information. Mr. Raecke stated that horizontal cracks in South Dakota are limited to steel lap areas. He provided a Powerpoint presentation file he developed. Figure 2.12 shows the pavement failure due to $\mathrm{HC}$ and the slab taken out, which shows delamination at the steel depth. TxDOT experienced this type of failure in the past when the steel splicing was not properly staggered. Since then, TxDOT revised steel splicing standards and this type of failure has been eliminated in Texas. Mr. Raecke stated that the South Dakota DOT is revising steel splicing standards to prevent HC problems.

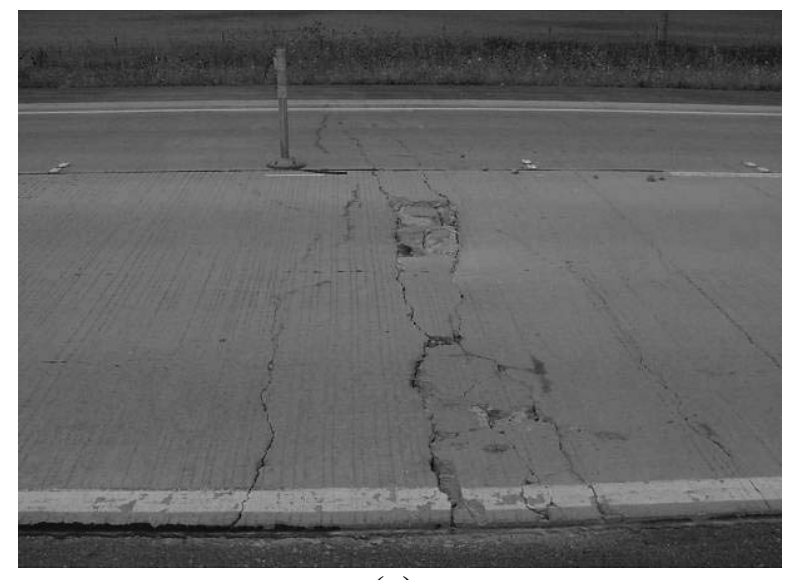

(a)

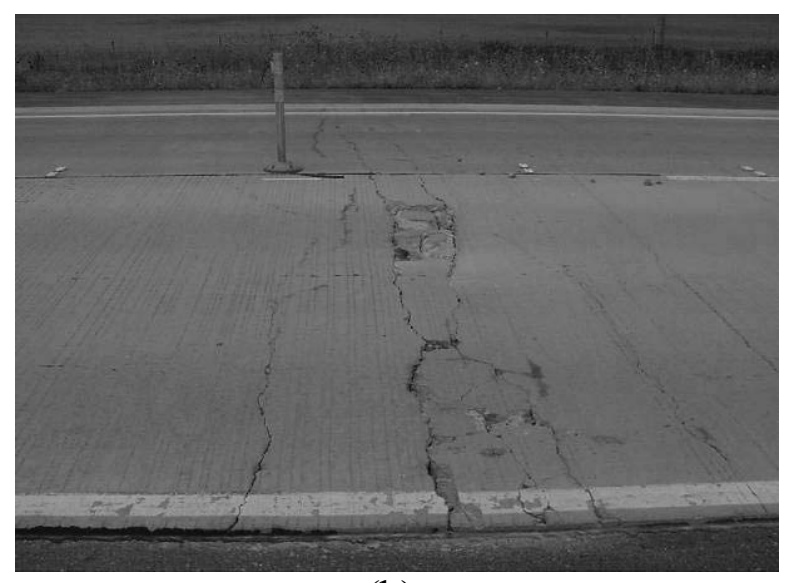

(b)

Figure 2.12: Surface distress and horizontal cracking 


\subsection{SUMMARY}

Horizontal cracking and associated distresses have been observed in CRCP in a number of districts in Texas as well as in Virginia and South Dakota. However, Illinois DOT reports no horizontal cracking in their CRCP. In Texas, they occurred in slabs with various thicknesses, ranging from as thin as 6-in to as thick as 14-in. They also occurred in pavement structures with or without stabilized subbases and tied concrete shoulders. It appears that, in some projects, HC occurred due to environmental loading only whereas in other projects, wheel loading applications contributed to HC development. Horizontal cracking problems in Virginia and South Dakota appear to be related to additional steel at construction joints or inadequate longitudinal steel splicing. 



\section{HORIZONTAL CRACKING MECHANISM}

\subsection{NUMERICAL MODEL}

Cracking in concrete takes place when the stress exceeds the strength. In order to identify the appropriate horizontal cracking mechanism, it is required to accurately predict the distribution of strain and stress fields in concrete at the depth of reinforcement. The state of stress in concrete near the reinforcement can be analyzed through a two-dimensional finite element method. Environmental loadings due to changes in temperature and moisture were considered in the numerical analysis. Figure 3.1-(a) shows the finite element model for prediction of horizontal cracking in CRCP. If CRCP is subject to environmental loading, the CRCP behavior can be assumed to be symmetric with respect to the center of the two adjacent transverse cracks. Therefore, one-half of the slab was considered in the numerical model. The concrete slab and longitudinal steel were modeled using two-dimensional plane strain and frame elements, respectively. The boundary conditions of the finite element model should be defined to obtain the correct prediction of structural behavior under environmental loadings. At the transverse crack, it is assumed that no restraint was applied to the concrete. Longitudinal and rotational displacements were fixed at the point of the reinforced bar at the transverse crack interface. At the center of the slab, a vertical degree of freedom existed and longitudinal and rotational displacements were restrained due to symmetry.

The bond-slip relation between concrete and longitudinal steel bars was considered through the interface element with horizontal springs. The frictional slip that occurs at the interface between the bottom of the concrete slab and the base layer was considered through the horizontal spring element. A vertical tensionless spring was used to properly consider the curling effect. The vertical tensionless spring stiffness per unit area in this study was $300 \mathrm{psi} /$ in. Figure 3.1 -(b) indicates the frictional stress-slip relationship between concrete and subbase [1]. Horizontal stiffness for the interface between the concrete and subbase was assumed to be $150 \mathrm{psi} / \mathrm{in}$. In order to predict the strain of tie bar, the bond stress-slip relationship in Figure 3.1-(c) was used [1]. The vertical stiffness of structural interface for bond-slip, which will be discussed later with experimental data, was $1 \times 10^{7} \mathrm{psi} / \mathrm{in}$. The finite element program DIANA [2] was used in the numerical analysis. 


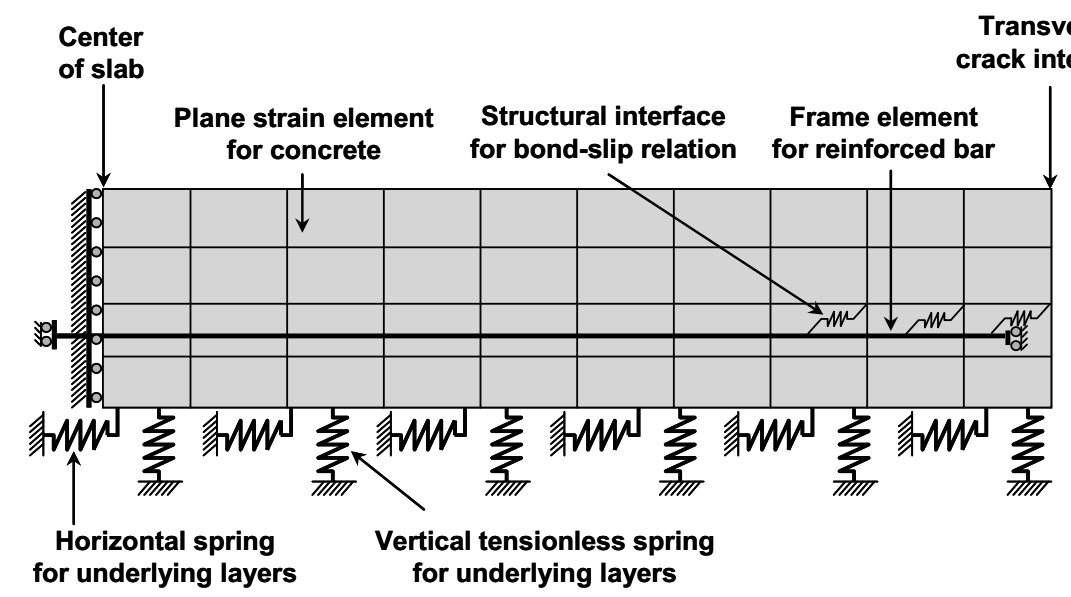

(a)

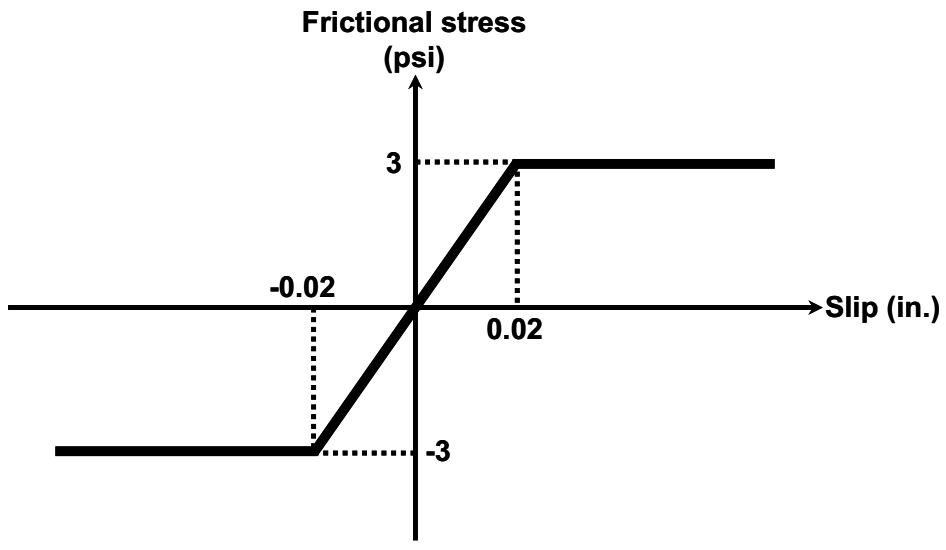

(b)

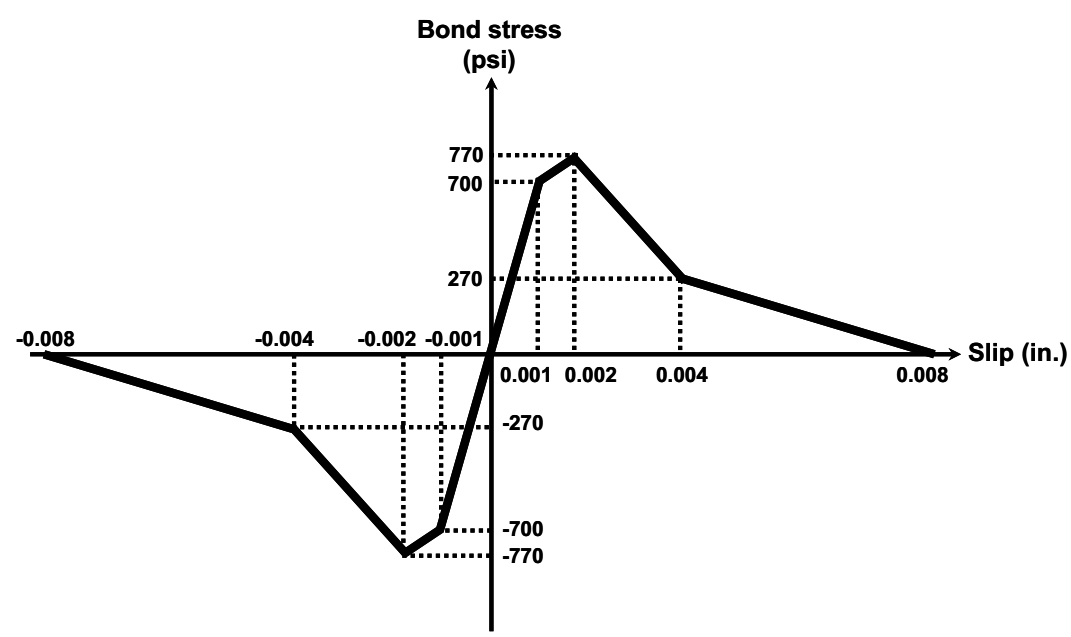

(c)

Figure 3.1: Finite element model for prediction of horizontal cracking in CRCP 
Figure 3.2 shows distribution and directional vectors of principal stress in CRCP between transverse cracks in the numerical analysis. The spacing of the transverse crack was assumed to be $7.0 \mathrm{ft}$ with a pavement thickness of $14 \mathrm{in}$. A single layer of steel, using \#6 bar (0.75-in. diameter), was arranged at the depth of $7.0 \mathrm{in}$. from the surface. A nonlinear temperature gradient with a 3rd degree parabola was assumed [3]. The temperature difference of $21^{\circ} \mathrm{F}$ between the top and bottom of the slab was applied as an environmental loading. The CoTE and elastic modulus of concrete were assumed to be $6 \times 10^{-6} /{ }^{\circ} \mathrm{F}$ and $6 \times 10^{6} \mathrm{psi}$, respectively. The maximum principal stress of 464 psi developed at the depth of steel, and the direction was nearly vertical with a slight upward or downward direction. Therefore, the horizontal cracking can occur near the reinforced steel.

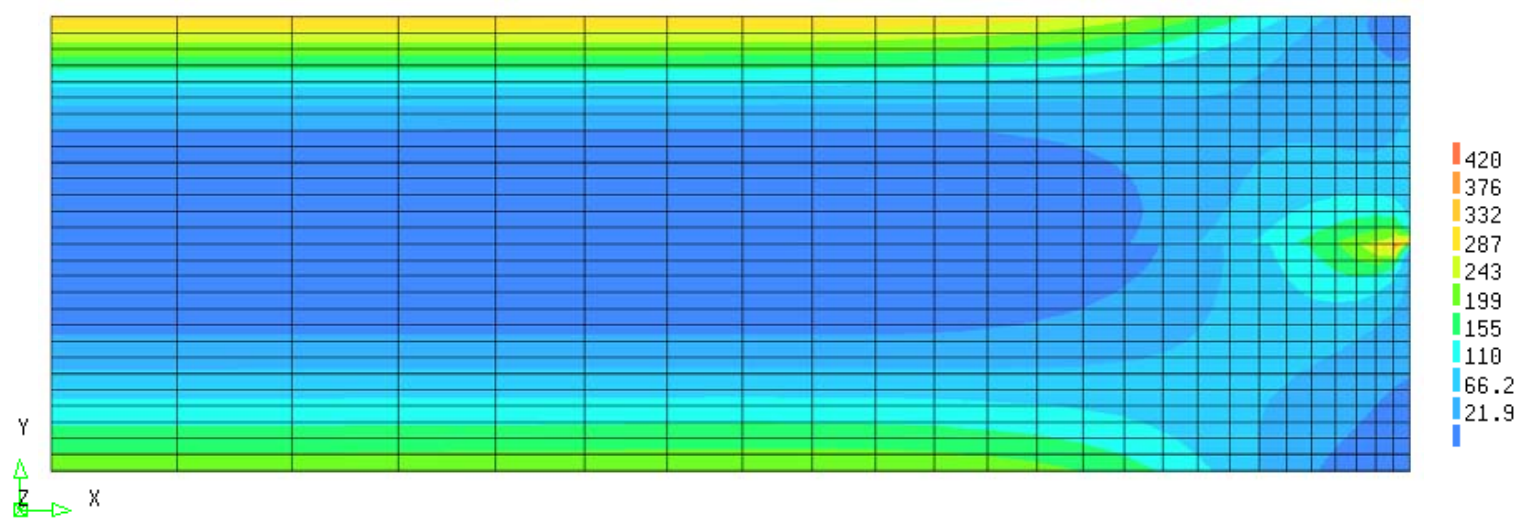

(a) Distribution of principal stress in CRCP

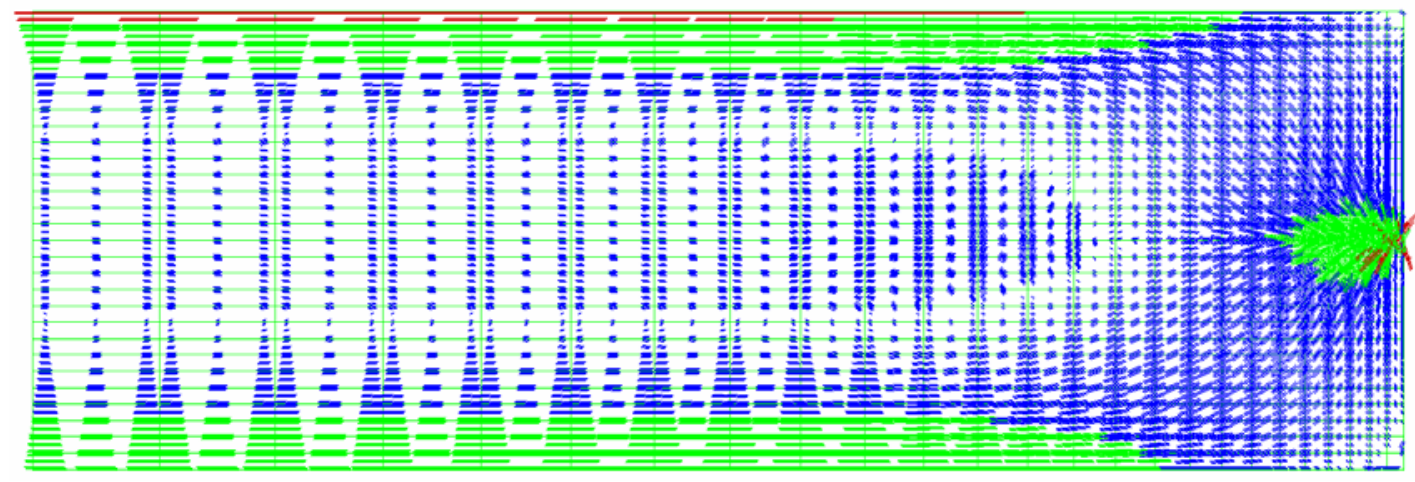

(b) Directional vector of principal stress in CRCP

Figure 3.2: Finite element model for prediction of horizontal cracking in CRCP 


\subsection{MECHANISM OF VERTICAL STRESS IN CONCRETE NEAR STEEL}

When concrete is cast in place, substantial changes in temperature and moisture can occur. The development of temperature and moisture variations in concrete depends not only on material properties but also on environmental conditions. A nonlinear temperature gradient would develop along the depth of concrete slab and result in slab movement. In a cracked or free surface, the slab movement consists of axial and bending components [4]. In CRCP, however, the longitudinal steel restrains the slab movement because the steel is continuous across the transverse crack.

The longitudinal movement of the slab in a cracked surface, which is proportional to uniform temperature drop, will be restrained by the steel because the steel is continuous across the transverse crack, as the two adjacent slabs across the crack create a line of symmetry. Figure 3.3(a) illustrates one slab with steel under uniform temperature drop. The longitudinal restraint of steel due to symmetry creates forces in steel, bond stress, and reaction at the center of the slab. Because the restraining force of steel is applied eccentrically to the upper and lower halves of the slab, local bending moment will be generated. This local moment may cause vertical stress of the concrete element near the steel.

Figure 3.3-(b) explains how the concrete element near steel is restrained by the longitudinal steel when the concrete is subject to a linear temperature gradient. The curling-up of the two adjacent slabs across the transverse crack is rotationally restrained by the flexural rigidity of steel due to the symmetry at the transverse crack. This rotational restraint will give rise to additional force that is vertically exerted to the concrete at steel depth. As a result, a substantial stress in the vertical direction, which is closely related to the horizontal cracking, could develop in concrete at the steel depth. Because slab curling is dependent on the temperature difference between the top and bottom surfaces of a slab [4], it is expected that greater vertical stress would develop in concrete as the temperature difference increases. 


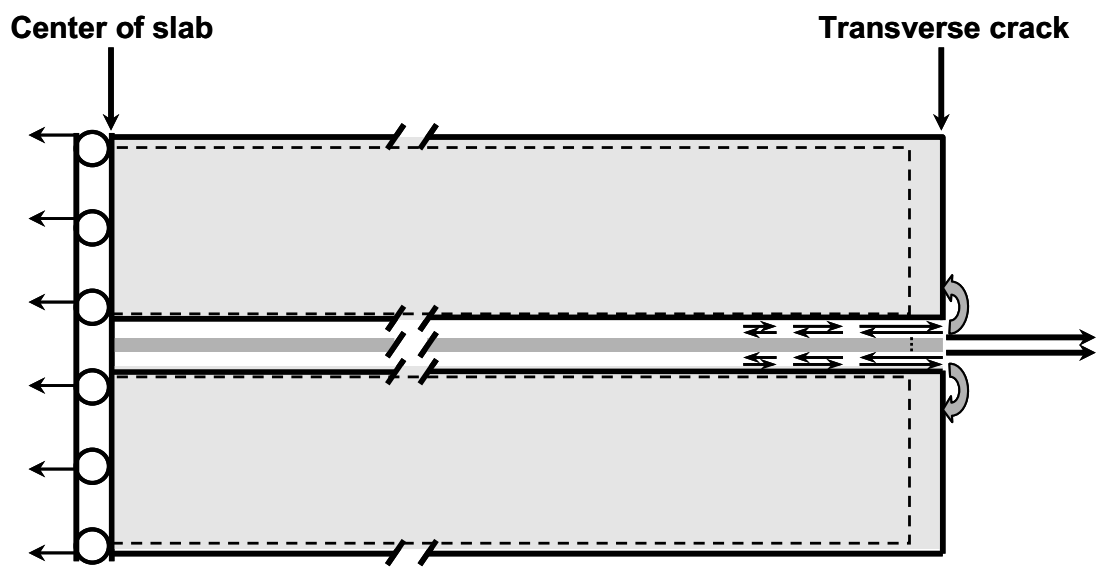

(a) Longitudinal restraint of steel on concrete subject to uniform temperature drop

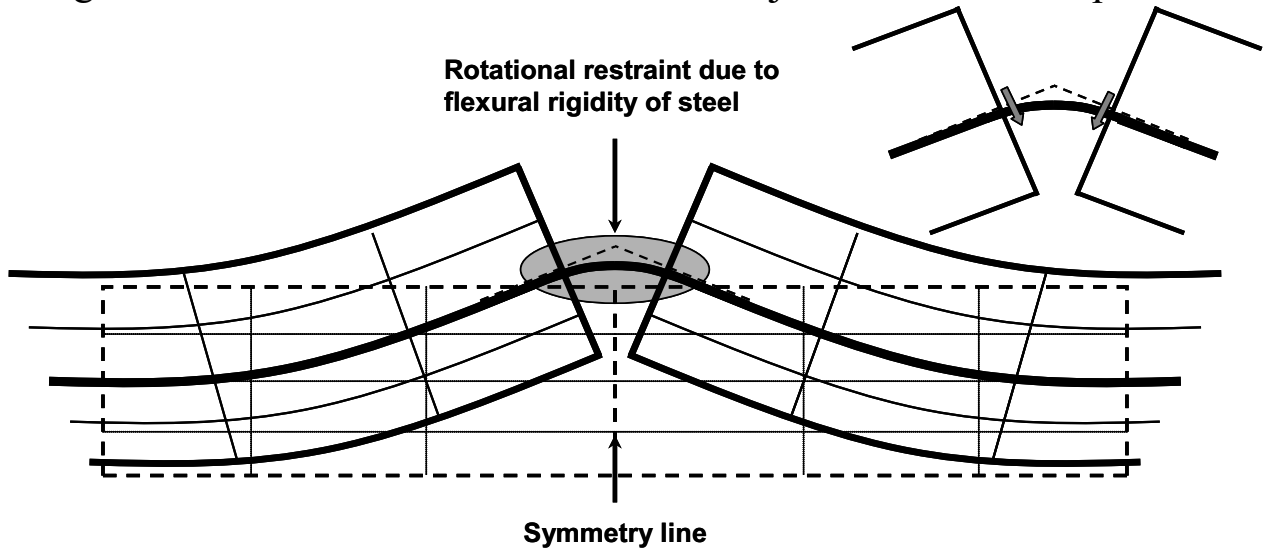

(b) Rotational restraint of steel on concrete subject to linear temperature gradient

Figure 3.3: Restraint of steel on CRCP movement at transverse crack 



\section{LABORATORY TESTING}

\subsection{HORIZONTAL CRACKING FRAME}

In order to identify the horizontal cracking mechanism in $\mathrm{CRCP}$, a cracking frame was slightly modified, deemed the Horizontal Cracking Frame (HCF) [5]. As shown in Figure 4.1, the original cracking frame consists of a frame with two cross heads and two massive steel frame bars. Each steel frame bar, made of invar to minimize displacement due to temperature variations, has a diameter of about 4 in. The water circulated through the pipe in the thermally insulated formwork can be adjusted so that the temperature of the specimen in the frame can match the target concrete temperature.

A primary reason for the modification to the original cracking frame was to include reinforcing steel in the middle of the concrete specimen as shown in Figures 4.2 and 4.3. It is shown that a rebar is inserted in the middle of the concrete specimen, simulating the longitudinal steel of \#6 (0.75-in. diameter) bar in CRCP. The concrete specimen in the HCF is highly restrained by the massive cross head, forcing the specimen to represent the initial behavior of CRCP, which is considerably restrained by the subbase friction and longitudinal steel. HCF can also simulate the behavior of CRCP after a transverse crack occurs because, after a crack in the specimen, each end of a specimen is still restrained by the cross head.

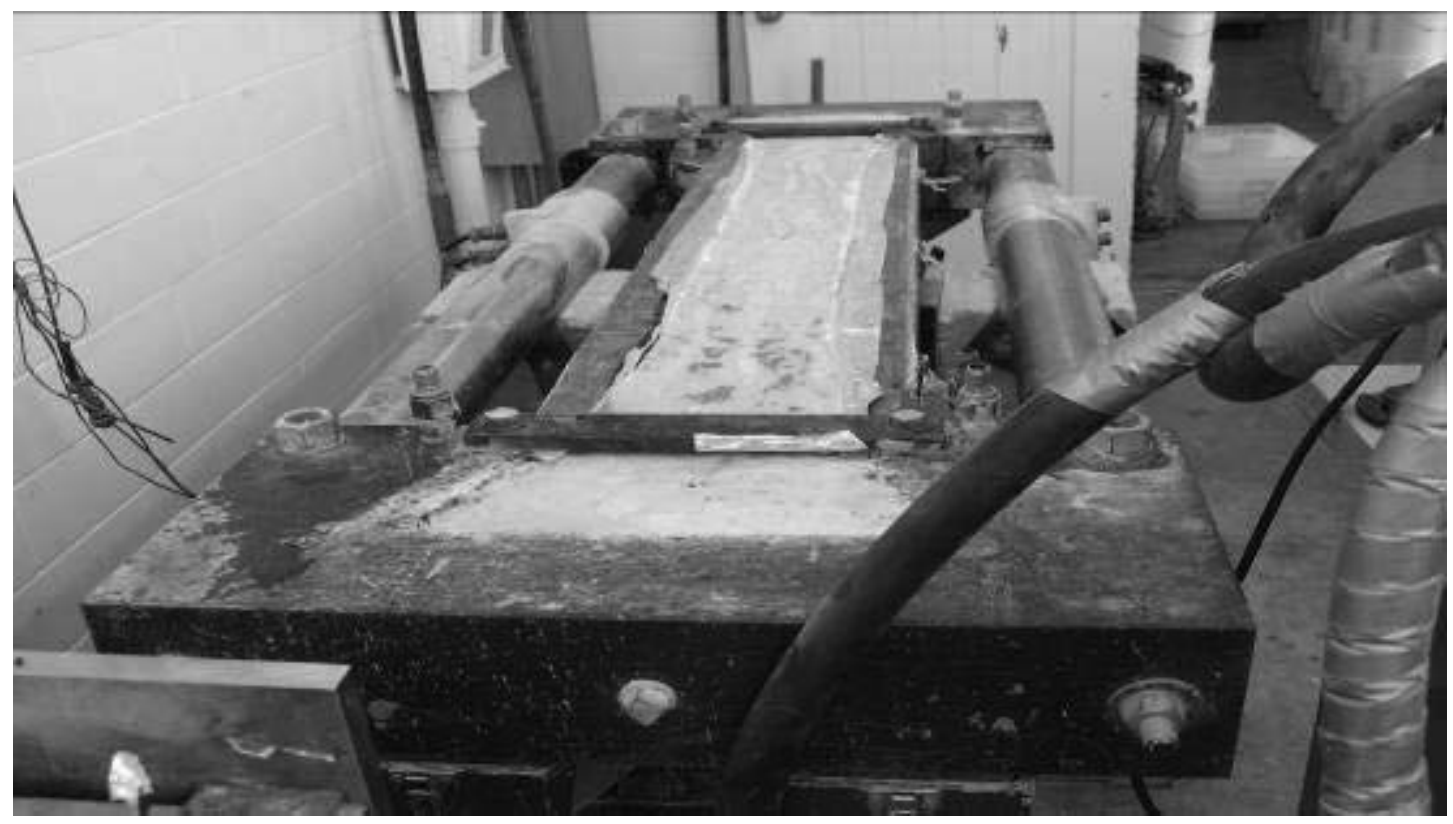

Figure 4.1: Cracking frame 


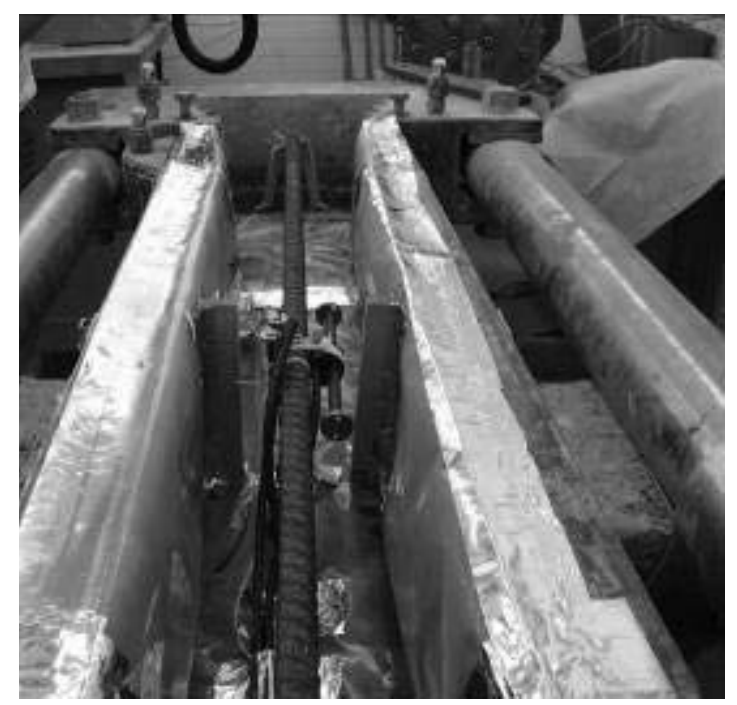

Figure 4.2: Horizontal cracking frame

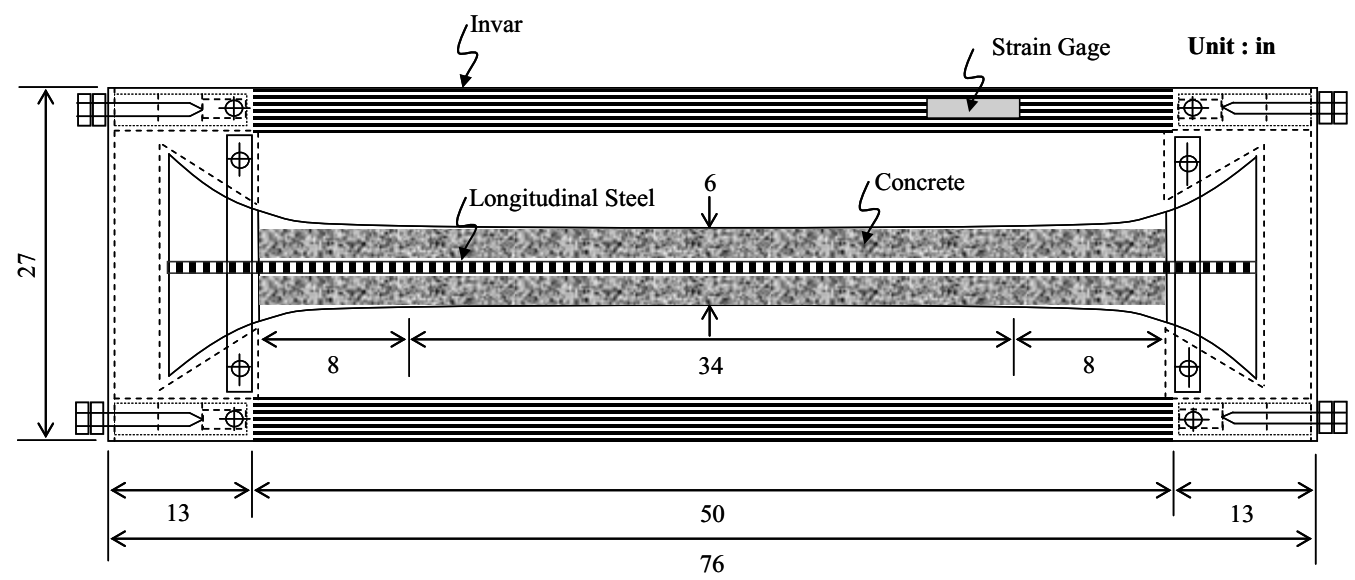

(a) Plan view of $\mathrm{HCF}$

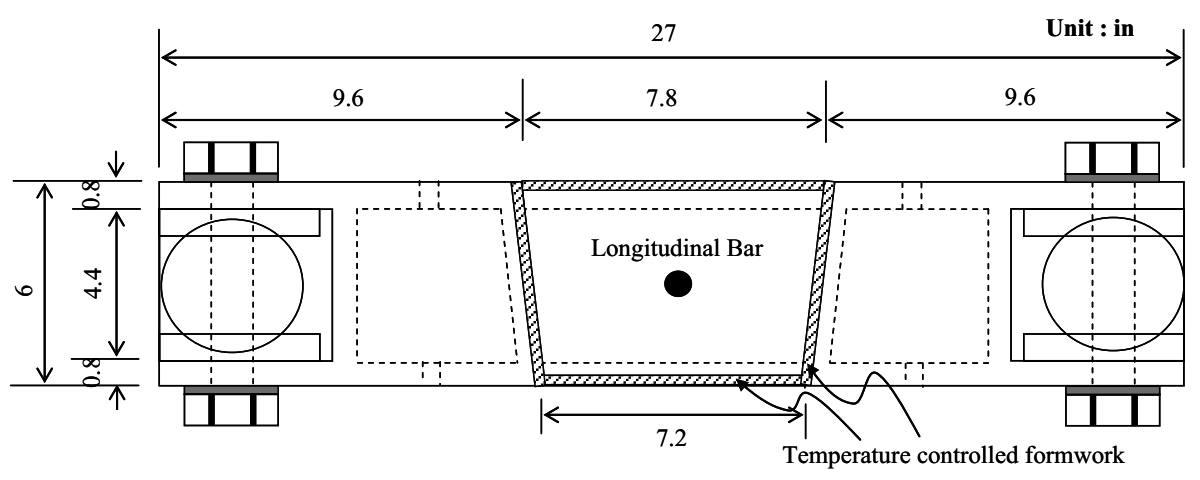

(b) Cross view of $\mathrm{HCF}$

Figure 4.3: Details of HCF 


\subsection{EXPERIMENTAL PROCEDURE}

\subsubsection{Material}

Table 4.1 shows the concrete mix used in the testing with horizontal cracking frame.

Table 4.1: Mixture proportion in testing

\begin{tabular}{lcc}
\hline \hline & Unit & Proportion \\
\hline Cement type I/II & $\mathrm{lb} / \mathrm{yd}^{3}$ & 470 \\
\hline Water & $\mathrm{lb} / \mathrm{yd}^{3}$ & 211.5 \\
\hline Coarse Aggregate & $\mathrm{lb} / \mathrm{yd}^{3}$ & 1942 \\
\hline Fine Aggregate & $\mathrm{lb} / \mathrm{yd}^{3}$ & 1245 \\
\hline Air entraining agent & $\mathrm{fl} \mathrm{oz} / \mathrm{yd}^{3}$ & 1.2 \\
\hline Superplasticizer & $\mathrm{fl} \mathrm{oz} / \mathrm{yd}^{3}$ & 14.1 \\
\hline Water to cementitious ratio & - & 0.45 \\
\hline Air content & $\%$ & 4.5 \\
\hline
\end{tabular}

The concrete with limestone had compressive strength of 5409 psi and elastic modulus of $4.88 \times 10^{6}$ psi at 28 days.

\subsubsection{Concrete strain measurement}

Vibrating wire strain gages (VWSGs) were installed to measure the temperature and strain in concrete specimen. As shown in Figure 4.4., three EM-5 VWSGs were installed in the longitudinal direction at different depths (1-in., 3-in., and 5-in.) from the top surface. These gages measured the longitudinal strain and it is expected that a sudden increase in concrete strain will be observed if a transverse crack occurs in the specimen. In order to induce a crack at the center of the specimen, two acrylic plates (6-in. high, 1-in. wide, and 0.5-in. thick) were placed at the center of the specimen. Two EM-2 VWSGs were also installed vertically at the mid-depth (3-in.) in the center of the specimen. It is expected that these EM-2 gages will exhibit a different trend of strain variation when transverse cracking occurs. 


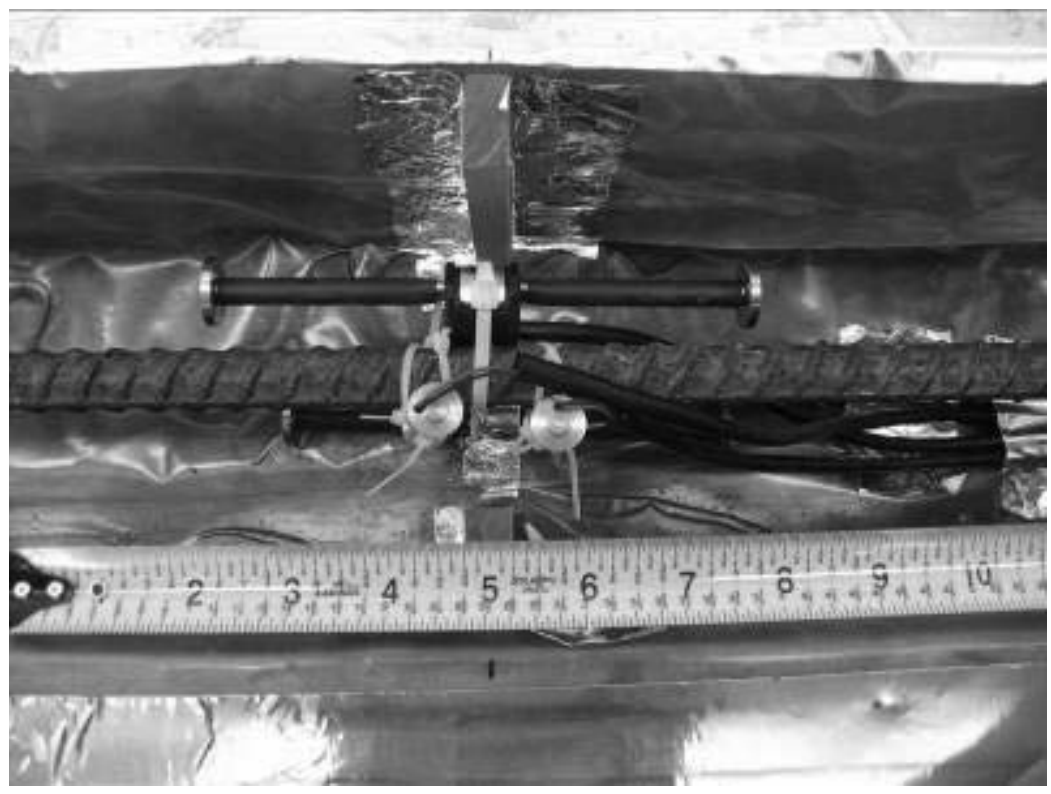

(a) Plan view of installed VWSGs

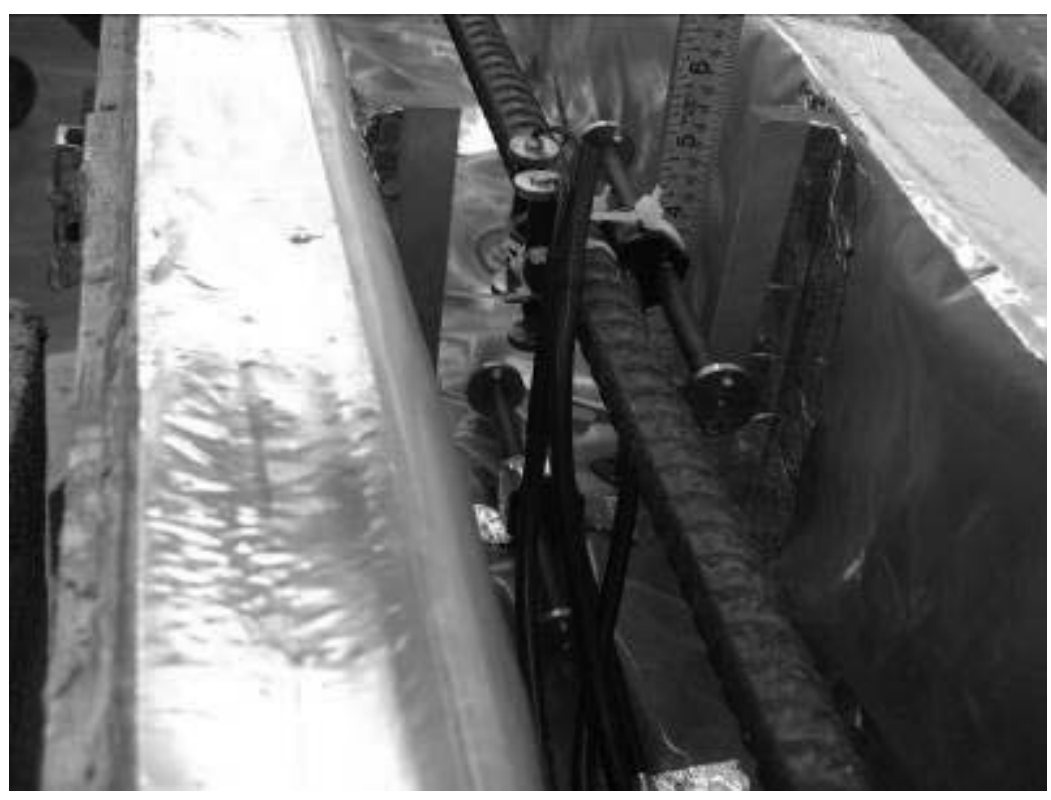

(b) Installed VWSGs

Figure 4.4: Installed VWSGs to measure transverse and horizontal cracks 


\subsection{ANALYSIS OF TEST RESULTS}

Figure 4.5 shows the measured temperature and strain histories in the testing. The concrete temperature was maintained at $105^{\circ} \mathrm{F}$ for three days. During this period, the concrete hardened. In order to simulate the actual temperature condition in CRCP which induces transverse cracking, the specimen was cooled down to $70^{\circ} \mathrm{F}$. Because the volume change of the specimen was restrained by the frame, the tensile stress would build up in the specimen during cooling stages. At the age of 3.4 days, the longitudinal concrete strain at the horizontal VWSGs suddenly increased and the researchers concluded that this sudden increase was due to the crack occurrence. The variation of longitudinal strain showed significant increase when the transverse crack occurred. The vertical strain also suddenly increased. After the transverse crack occurred, the vertical strain was still increasing even though the temperature was decreasing.

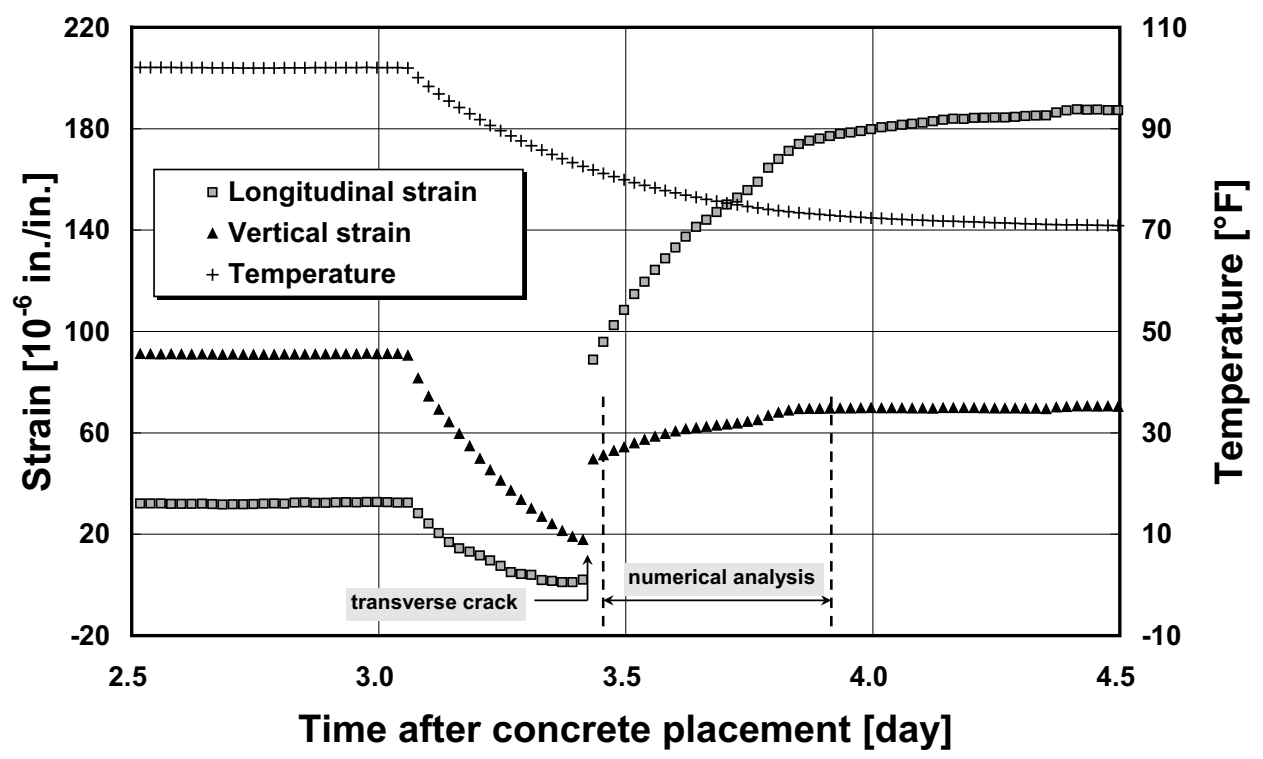

Figure 4.5: Measured strain and temperature histories

HCF testing was analyzed with the numerical model described previously, in which the measured temperature variations along with mechanical and material properties were incorporated. The concrete's behavior from 3.4 days to 3.8 days was analyzed in the numerical analysis. The measured elastic modulus was $3.6 \times 10^{6}$ psi. Figure 4.6 shows measured CoTE of concrete material in testing using stress-free cylinders and it was $4.24 \times 10^{-6} /{ }^{\circ} \mathrm{F}$. Figure 4.7 presents variations of measured and predicted vertical strains during the specified period. The concrete element near steel in the HCF specimen slowly expanded under a uniform temperature drop. This result agreed with the mechanism introduced in the previous section. Figure 4.6 also indicates that the predicted strain varied with different vertical stiffness values of the structural interface between steel and concrete. Among the three interfacial stiffness values evaluated, $8.5 \times 10^{6} \mathrm{psi} / \mathrm{in}$. provided the closest prediction to the measured data. This value can be used in accurately evaluating the horizontal cracking potential. The validity of this value was examined again with a field experiment, which is shown in the next chapter. 


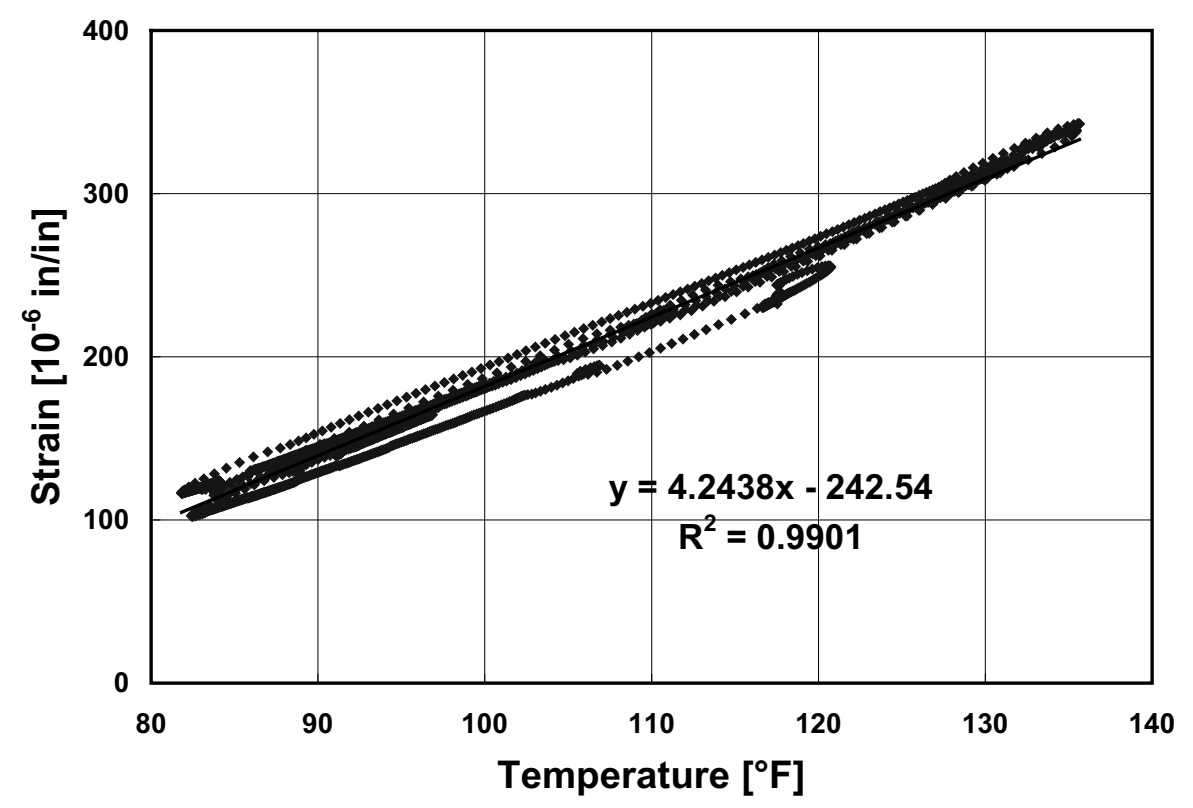

Figure 4.6: Measured coefficient of therma expansion

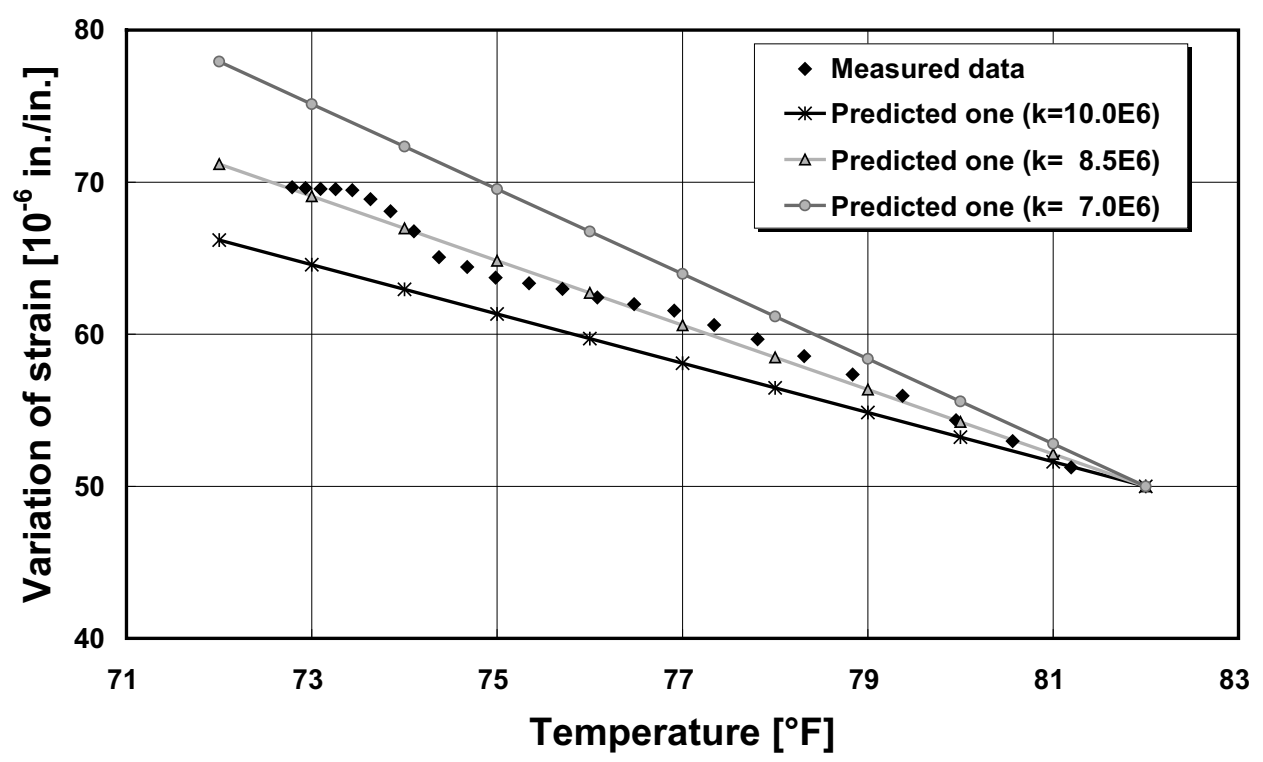

Figure 4.7: Variation of measured and predicted vertical strains 


\section{FIELD VALIDATION OF HORIZONTAL CRACKING MECHANISMS}

\subsection{DESCRIPTION OF TEST SECTION}

In order to investigate realistic behavior of CRCP under environmental loadings, field testing was conducted. The pavement section instrumented for this experiment is located on $\mathrm{IH}-35$ south bound in the Waco District as shown in Figure 5.1. Concrete was poured at 6:30 a.m. on October 28,2009 . The test slab consisted of new 14-in. CRCP over a 4-in. asphalt stabilized base. As shown in Figure 5.2, two layers of longitudinal steel were placed in accordance with TxDOT CRCP Design Standards CRCP(2)-03 at the depth of 4.4 in. and 9.5 in. with 9.5 in. spacing. The new slab was $22 \mathrm{ft}$ wide and tied with the existing lane through two layers of tie bar. The diameter of steel placed in longitudinal and transverse direction was 0.75 in. (\#6 bar).

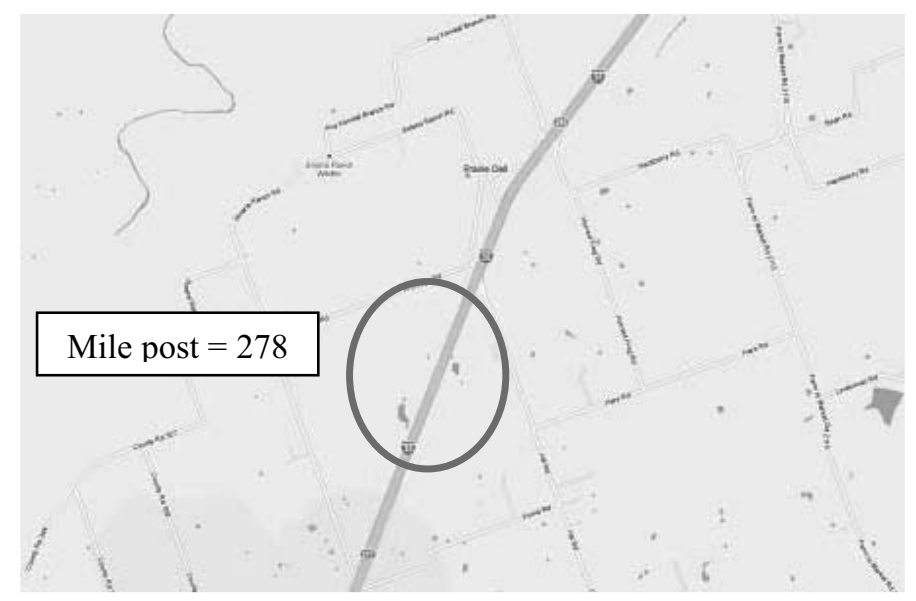

Figure 5.1: Location of test section

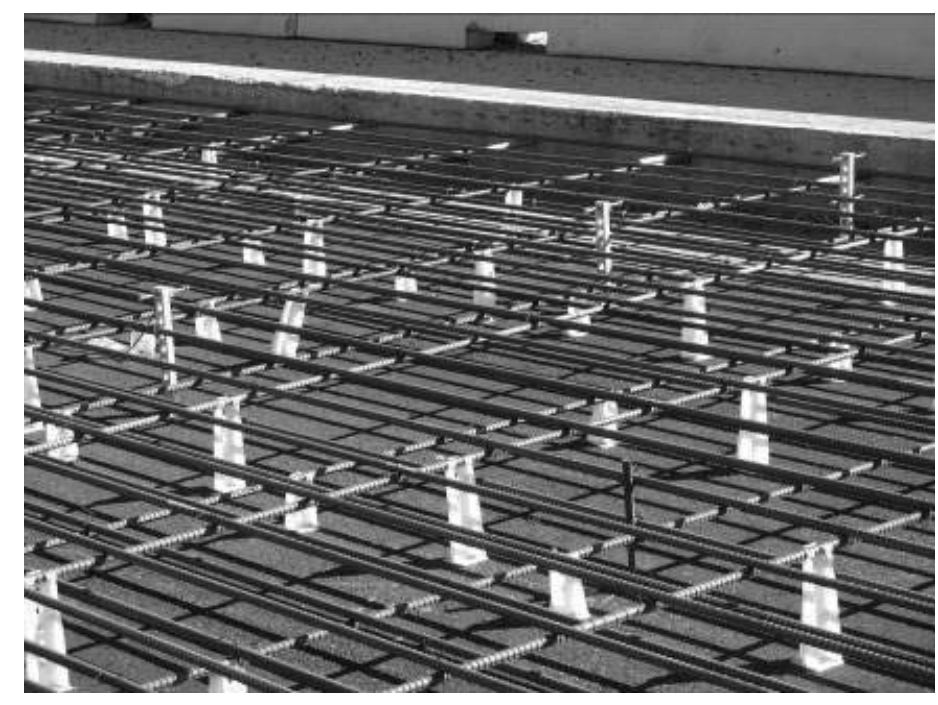

Figure 5.2: Overview of test section 


\subsection{FIELD INSTRUMENTATION}

As shown in Figures 5.3 and 5.4, three VWSGs were installed at different depths in the longitudinal direction to monitor transverse crack occurrence. Two VWSGs were also installed in the vertical direction near two layers of longitudinal steel: one near the top layer of steel and the other near the bottom. Additionally, seven temperature sensors were installed at different depths to evaluate the temperature gradient in the test slab with 14-in. thickness. A transverse crack was induced with a saw cut. The saw cut of 1.5 -in. depth was made 15 hours after concrete placement.

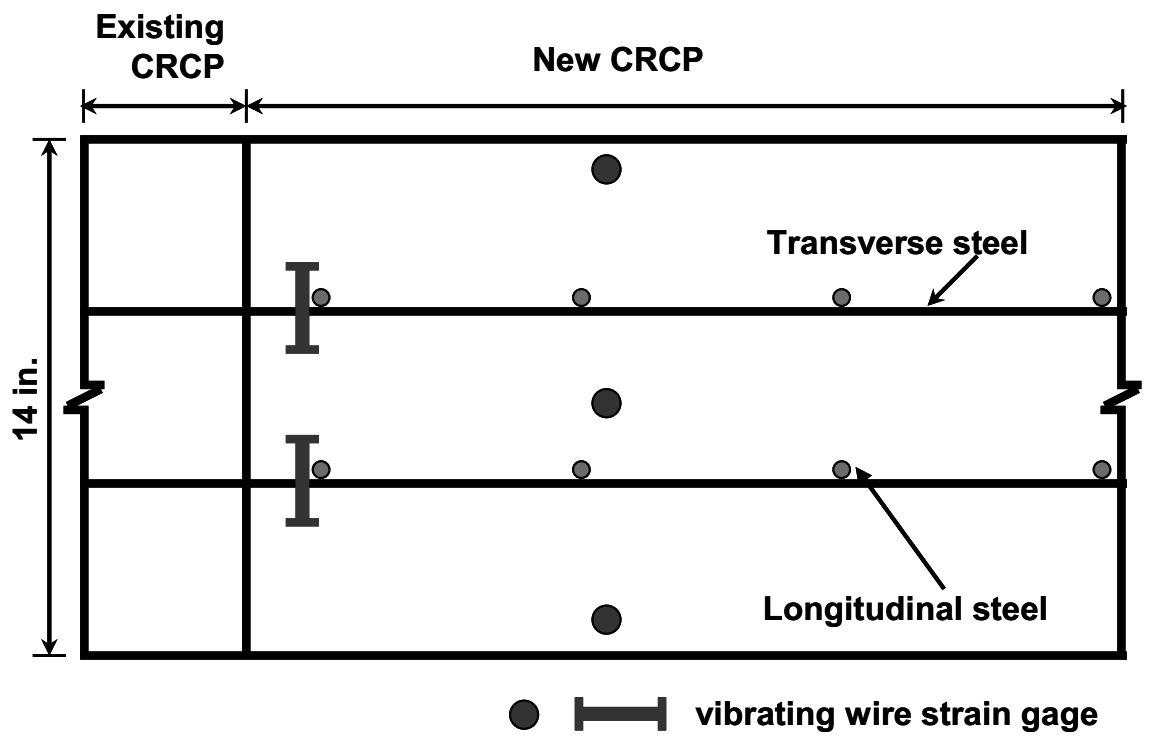

Figure 5.3: Field instrumentation in section view
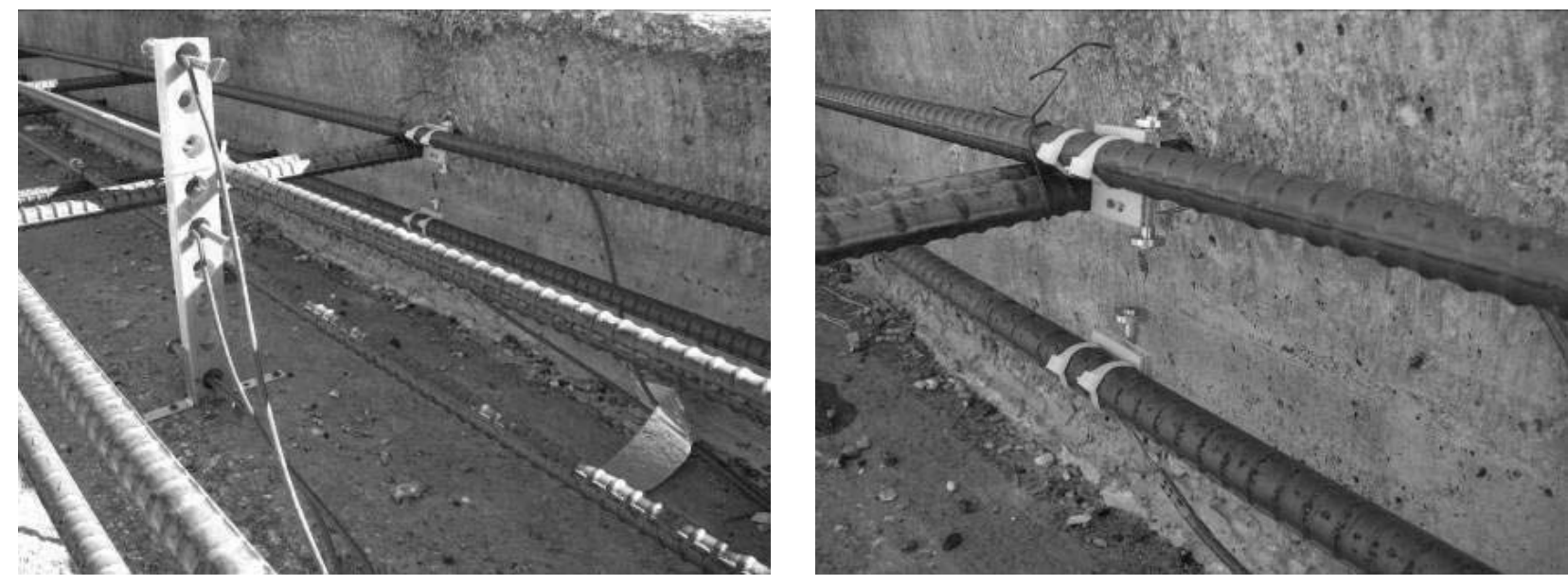

Figure 5.4: Installed strain gages in longitudinal and vertical direction 


\subsection{ANALYSIS OF TEST RESULTS}

Figure 5.5 illustrates strain and temperature histories over time. In the x-axis, the whole number denotes midnight of the day after the concrete placement. For example, 5 means midnight of the 5 th day after concrete placement. There was a sudden increase of longitudinal strain at the 2nd day early morning, caused by the induced transverse crack. Compared to the variation of longitudinal strain at the transverse crack, the vertical strain changed little. Measured vertical strains from 10:00 p.m. on the 5th day to 7:00 a.m. on the 6th day were selected to compare with the results predicted by the numerical analysis.

Figure 5.6 shows the measured temperature profile in the test slab. As expected, the variation of temperature at the surface was greater than that observed at the middle and bottom of the slab. A measured profile was used as an environmental loading input in the numerical analysis. Figure 5.7 shows the variation of measured and predicted strains due to non-linear temperature distribution through the slab depth. For the measured temperature gradient shown in Figure 5.6, the concrete vertical strains near the top layer of steel increased while the ones near the bottom decreased. The variation was greater near the top layer. Unlike the strain variation under uniform temperature changes, the concrete element with the two-mat steel bar was affected not only by the uniform component but also by linear and nonlinear components in temperature gradient. Therefore, the strain varied at different depths. The numerical prediction is also shown in Figure 5.7 using the material property values obtained in the field as discussed next. Figures 5.8 and 5.9 show the measured CoTE and elastic modulus of concrete, respectively. Considering the effect of temperautre on the development of strength and modulus of concrete, the estimated elastic modulus in numerical analysis was $4.7 \times 10^{6} \mathrm{psi}$. The measured CoTE of $4.2 \times 10^{-6} /{ }^{\circ} \mathrm{F}$ were used in the numerical analysis.

In this analysis, the use of $1.8 \times 10^{7} \mathrm{psi} / \mathrm{in}$. as the interfacial stiffness between steel and concrete yielded predicted strain values that were close to the measured values. Even though the stiffness value used in this analysis was almost twice as large as the one used in the analysis for HCF testing described in the previous chapter, this difference is smaller than the one used in a recent study [6]. In the study, the interfacial stiffness was assumed to be sufficiently large without experimental data so that the numerical problem of relative displacement between steel and concrete can be prevented [6]. The stiffness varied from $3.68 \times 10^{6} \mathrm{psi} / \mathrm{in}$. to $3.68 \times 10^{8} \mathrm{psi} / \mathrm{in}$. in a recent study [6]. 


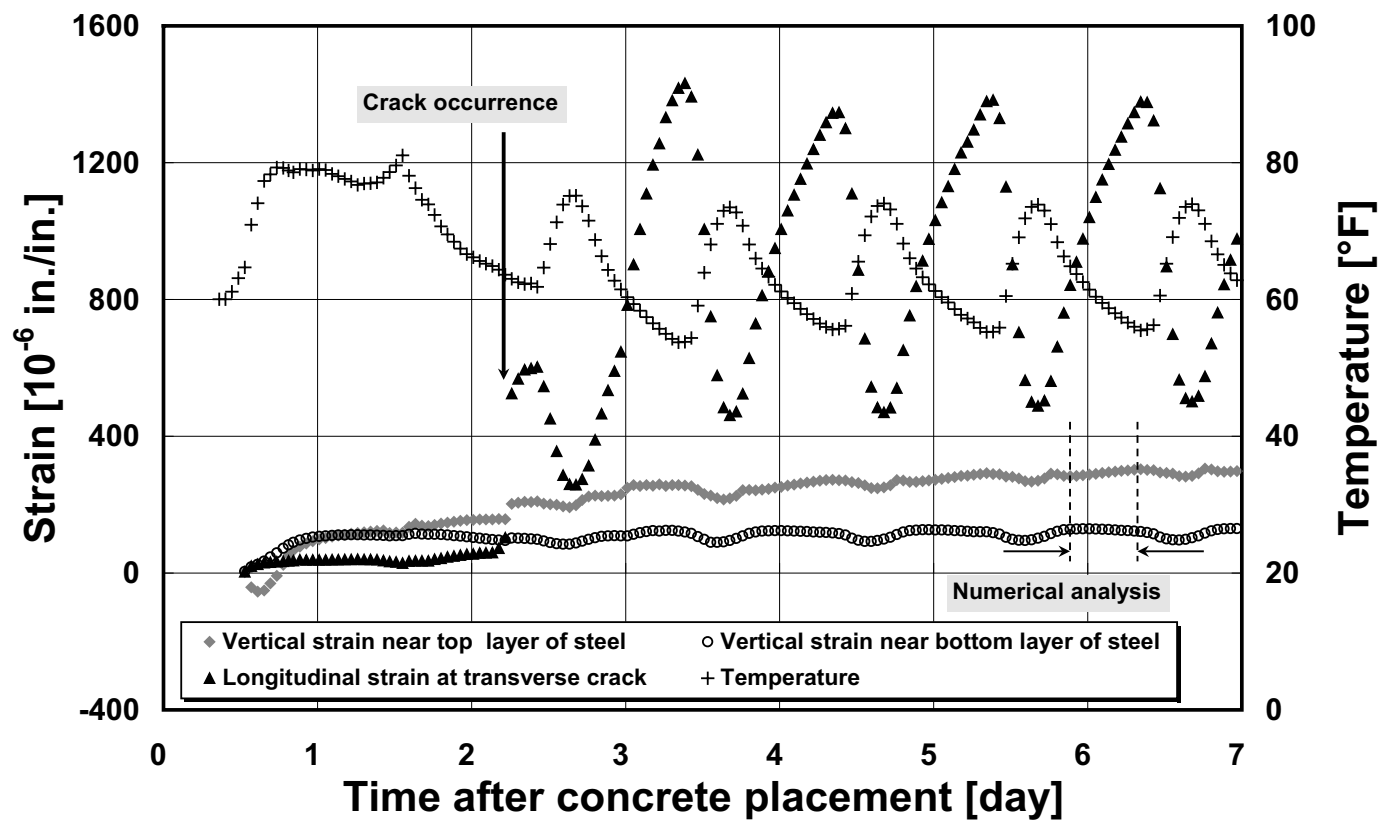

Figure 5.5: Measured strain and temperature histories in field testing

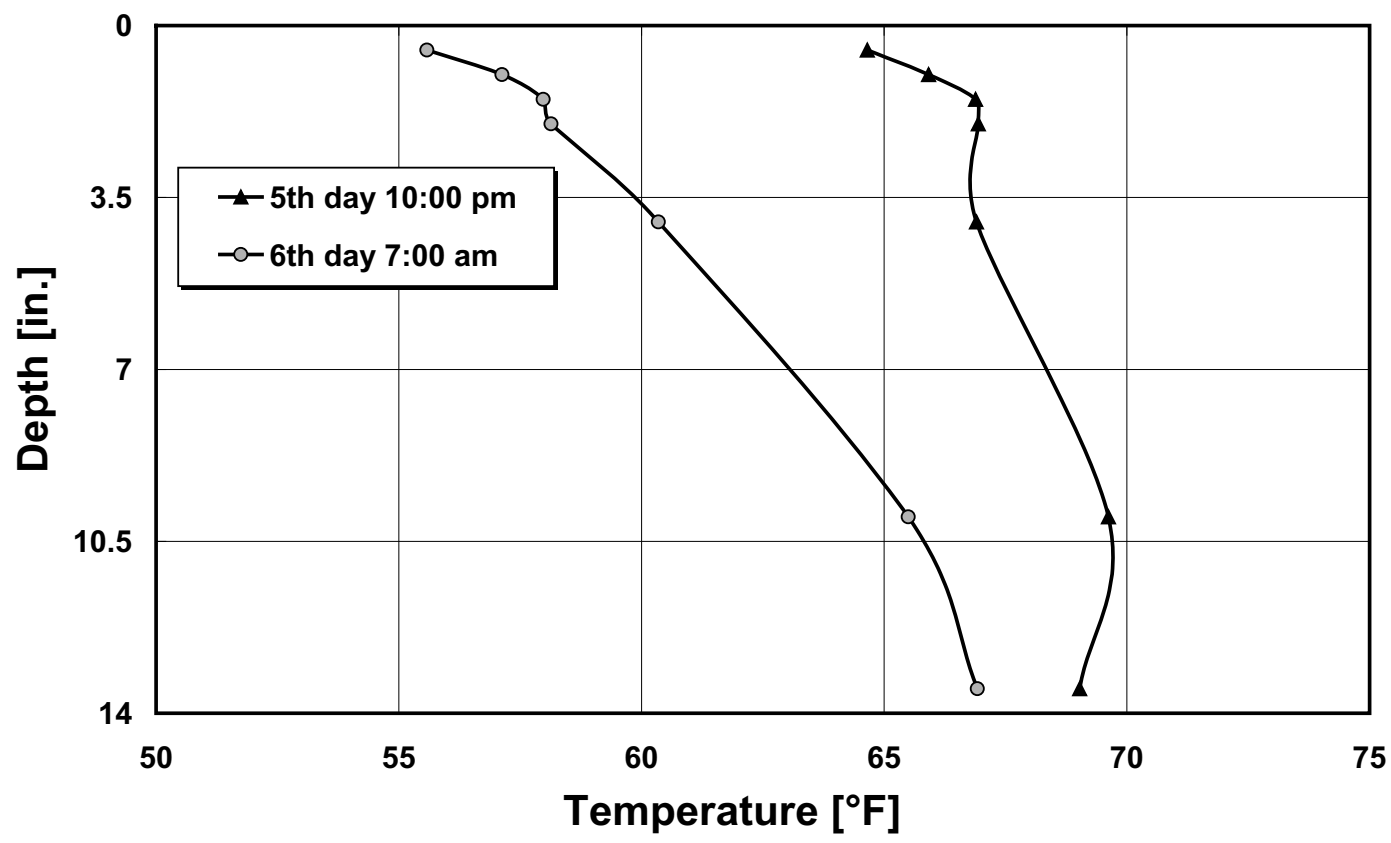

Figure 5.6: Measured temperature profiles 


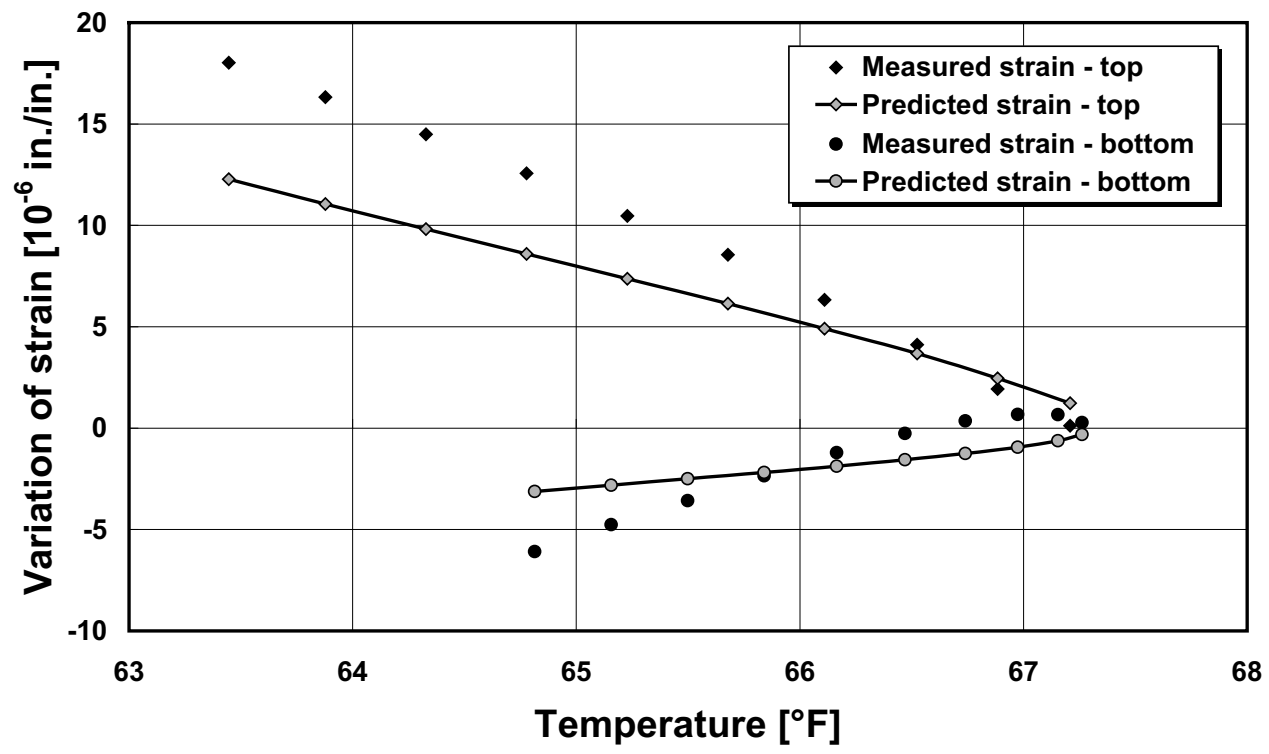

Figure 5.7: Measured vertical strains compared with predicted ones

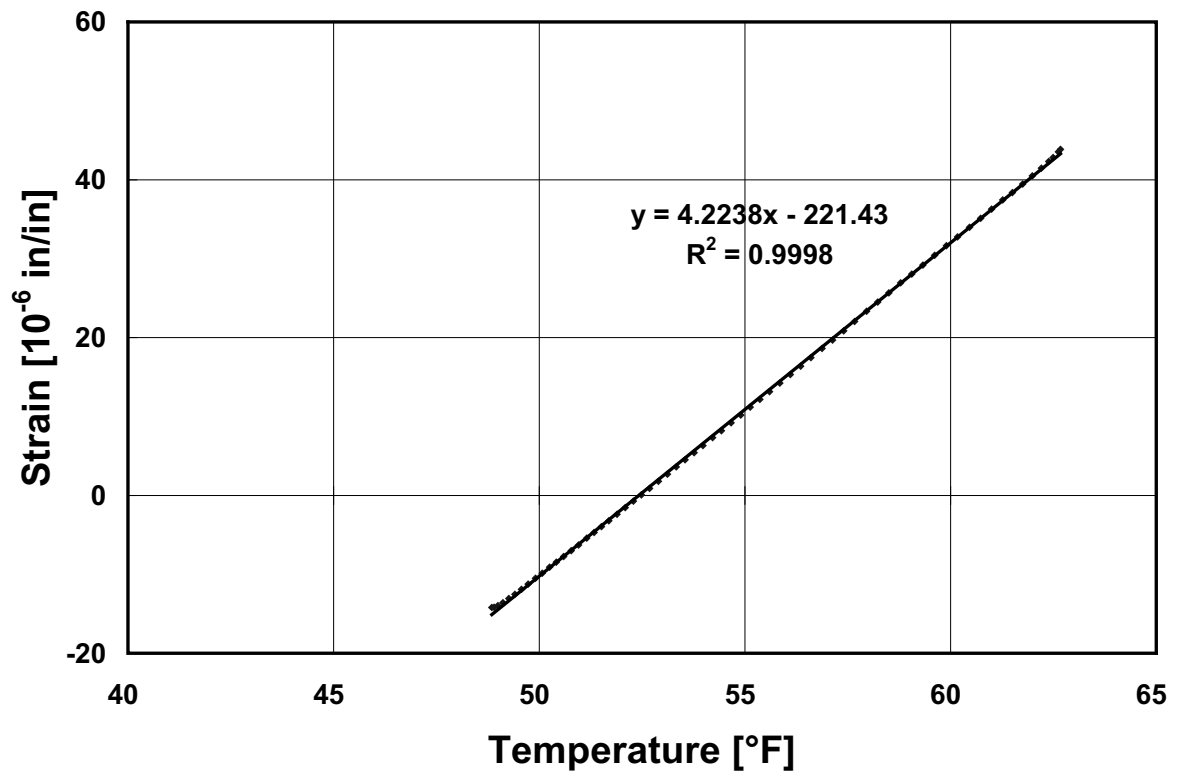

Figure 5.8: Measured coefficient of thermal expansion in the field testing 


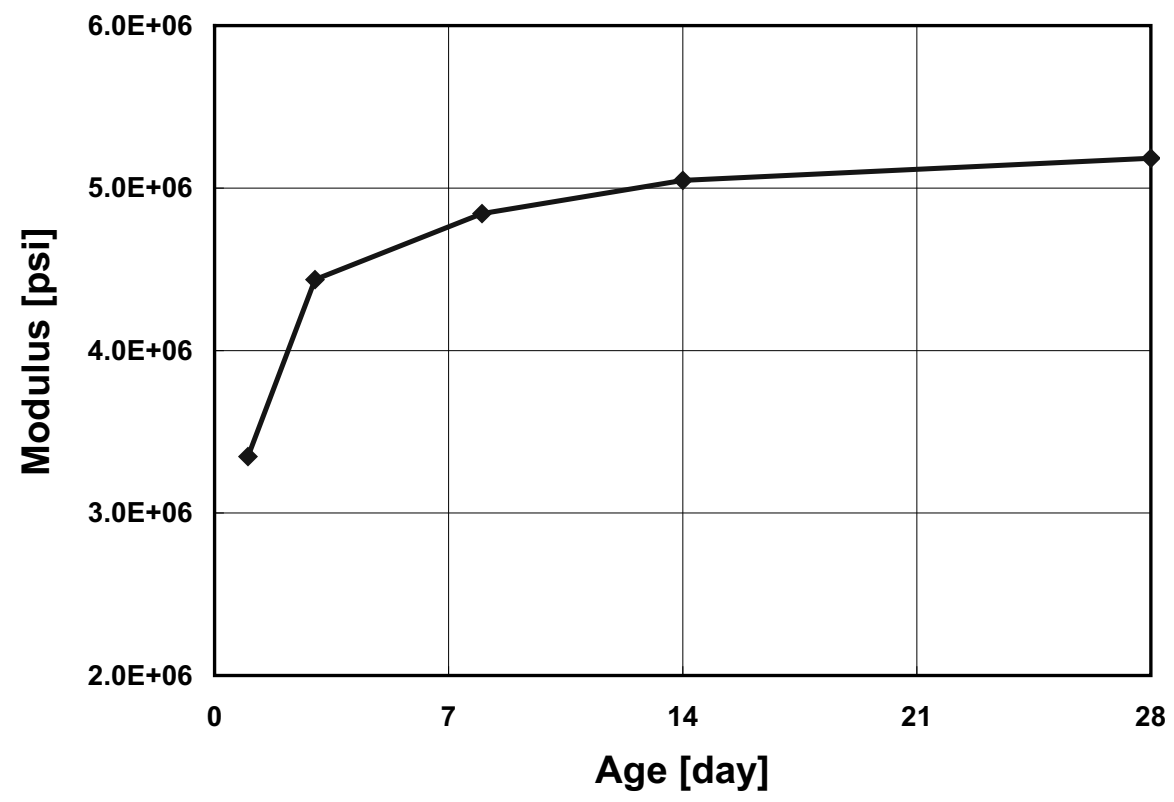

Figure 5.9: Measured elastic modulus of concrete material 


\section{VERTICAL STRESS DEVELOPMENT OF CONCRETE NEAR STEEL UNDER NONLINEAR TEMPERATURE GRADIENT}

\subsection{STRESS DEVELOPMENT DUE TO GENERAL NONLINEAR TEMPERATURE GRADIENT}

HC developed on IH 35 in the Waco District was simulated in the analysis. It was shown that temperature variations could have played a role as discussed in Chapter 2. Figure 6.1 illustrates the decomposition of a general nonlinear temperature gradient into three equivalent components: uniform, linear, and nonlinear [5]. A parabola of 3rd degree was assumed for the temperature profile along the depth of the slab [3]. The temperature difference of $21^{\circ} \mathrm{F}$ was assumed between the top and bottom of the slab. The concrete element near steel at the transverse crack had three stress components, i.e., horizontal, vertical, and shear stresses. Compared to other components, however, the vertical stress, which is closely related to the horizontal cracking potential, was dominant in stress development as shown in Figure 3-2(b). Therefore, the vertical stress was mainly presented in this study. One steel mat was placed at a depth of $7.0 \mathrm{in}$. and \#6 bar was used in the analysis. CoTE and elastic modulus at 28 days were assumed to be $6 \times 10^{-6} /{ }^{\circ} \mathrm{F}$ and $6 \times 10^{6}$ psi, respectively.

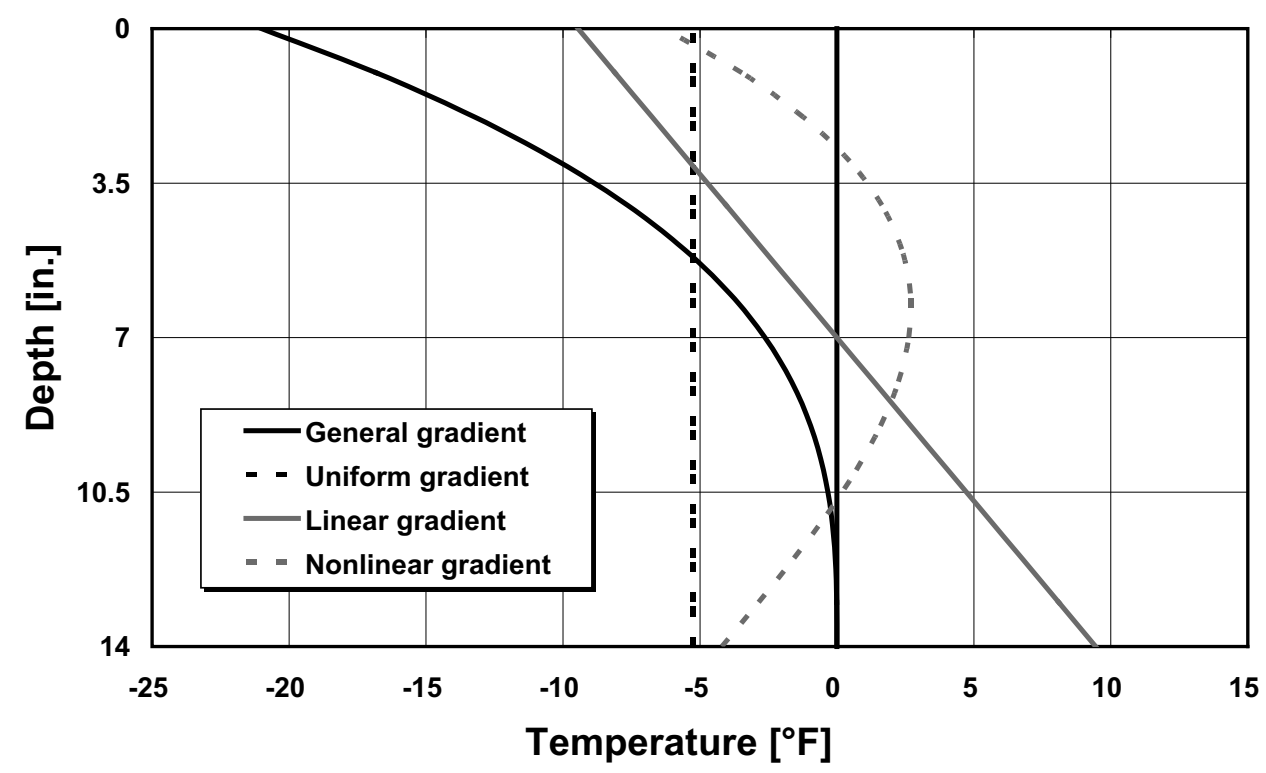

Figure 6.1: Decomposition of general nonlinear temperature gradient

Figure 6.2 indicates the distribution of vertical stress in concrete under a general temperature gradient. While vertical stress was negligible at the top and bottom slab surfaces, significant tensile stress developed at the concrete element near longitudinal steel when the slab was subject to a general temperature gradient. The uniform gradient generated symmetric vertical stress along the slab depth because the same amount of bending moment, as shown in Figure 3.3-(a), would be applied to two split slabs through the longitudinal steel. A linear gradient, which causes curling movement in the slab, also led to vertical stress in the concrete near steel. The vertical 
force created by the steel's flexural rigidity restrained the curling-up of slab, as shown in Figure 3.3-(b), and thus higher stress developed in the concrete near steel. Unlike stress development due to uniform gradient, tensile and compressive stresses existed at concrete elements above and below steel, respectively. This is because the vertical force was acting downward to the concrete through the steel.

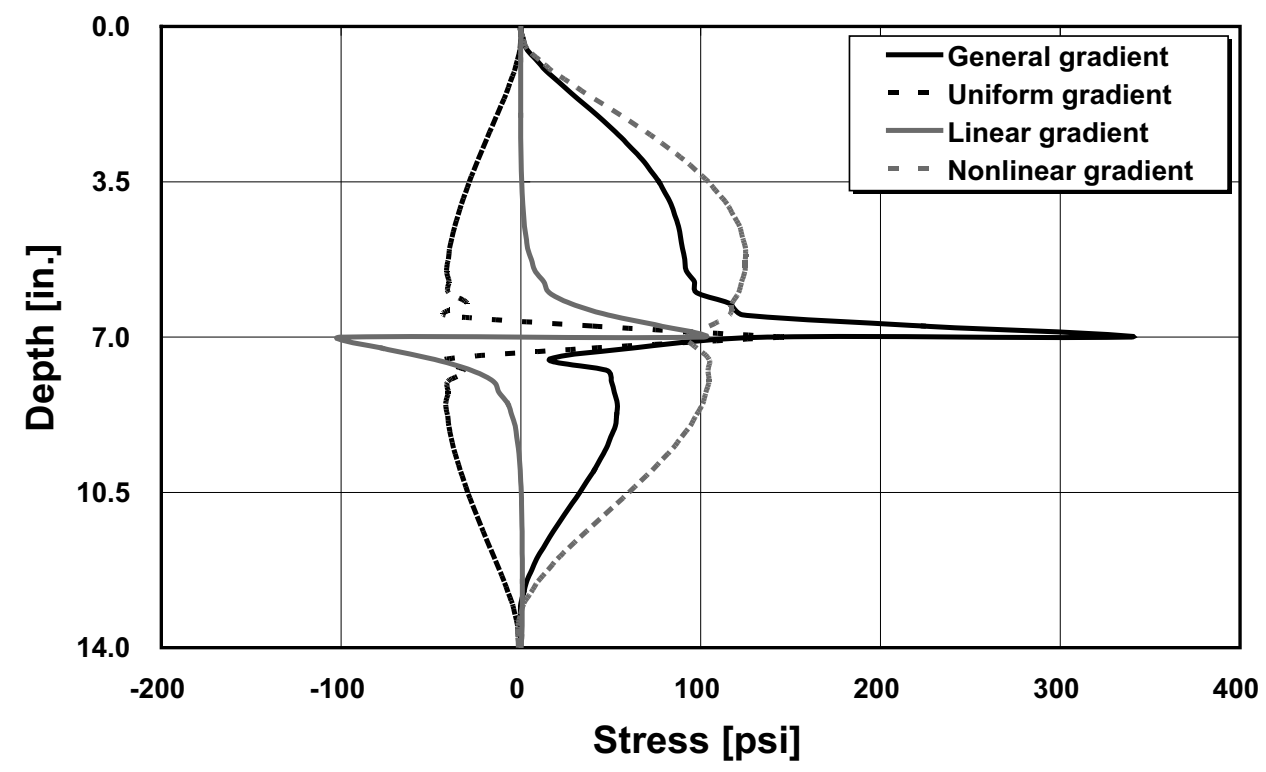

Figure 6.2: Distribution of vertical stress in CRCP at transverse crack subject to general nonlinear temperature gradient

\subsection{STRESS DEVELOPMENT DUE TO UNIFORM TEMPERATURE DROP AND LINEAR TEMPERATURE GRADIENT}

Figure 6.3 shows the effects of uniform temperature drop on the vertical stress development of concrete at transverse crack. As expected, a higher vertical stress developed as the uniform temperature decreased. The effect of CoTE is shown in Figure 6.4, where CoTE varied from $4 \times 10^{-6} /{ }^{\circ} \mathrm{F}$ to $6 \times 10^{-6} /{ }^{\circ} \mathrm{F}$. It shows dominant effect of CoTE on vertical stress development. The effect of crack spacing and the number of steel layers was investigated. Because the vertical stress was caused by a uniform temperature gradient, which is related to the slab's length change, it is expected that crack spacing may also affect vertical stress development in concrete near steel. Figure 6.5 indicates that the vertical stress changed over the transverse crack spacing in CRCP. The longer slab would accompany more slab movement under a uniform gradient and thus the steel's restraining force would be increased. Because the bending moment is proportional to the restraining force in steel, the developed vertical stress would be greater. Figure 6.5 also explains that $\mathrm{HC}$ may occur frequently at relatively early ages. As CRCP ages, more transverse cracks develop and the cracks become closer to each other. The reduced crack spacing reduces the restraining force in steel and thus vertical stress will be decreased in concrete near steel.

Figure 6.5 implies the advantage of a two-mat steel bar in preventing horizontal cracking in CRCP. Even though the steel ratio of a slab with two-mat steel placement was the same as one- 
mat, vertical stress was significantly reduced. This is because the distance between the steel's restraining force and the resultant reaction at the slab's center was reduced. As shown in Figure 3.3-(a), the bending moment, which caused the vertical stress in concrete, would decrease due to the reduction in lever arm length. The stress of concrete near the bottom layer of steel developed less than near the top because not only was the lever arm reduced but also the subbase friction lessened bending moment near the bottom layer of steel. The slab's curling-up is directly proportional to the temperature difference of the linear gradient at the top and the bottom surfaces of slab [4]. This analysis results are in consistent with the HC development on IH 35 in the Waco District where HC was in one-mat steel section and non-existent in two-mat section.

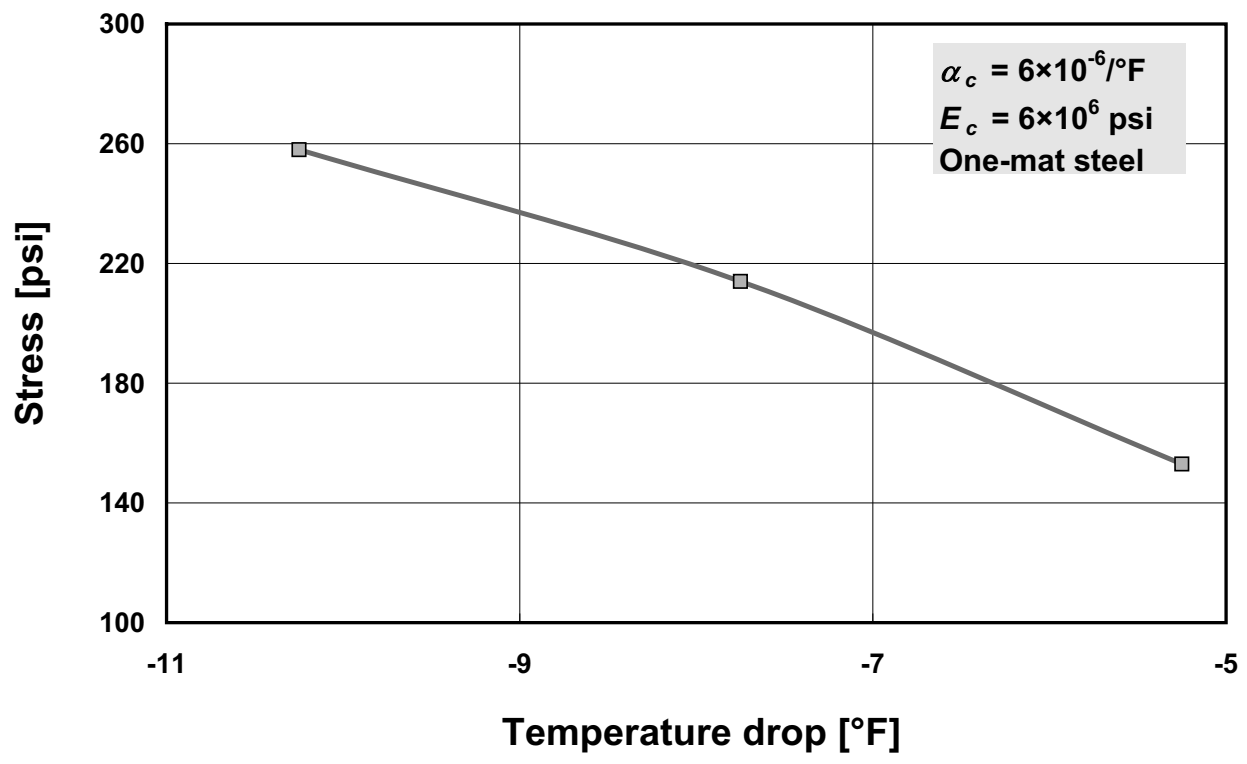

Figure 6.3: Effect of uniform temperature drop on vertical stress development

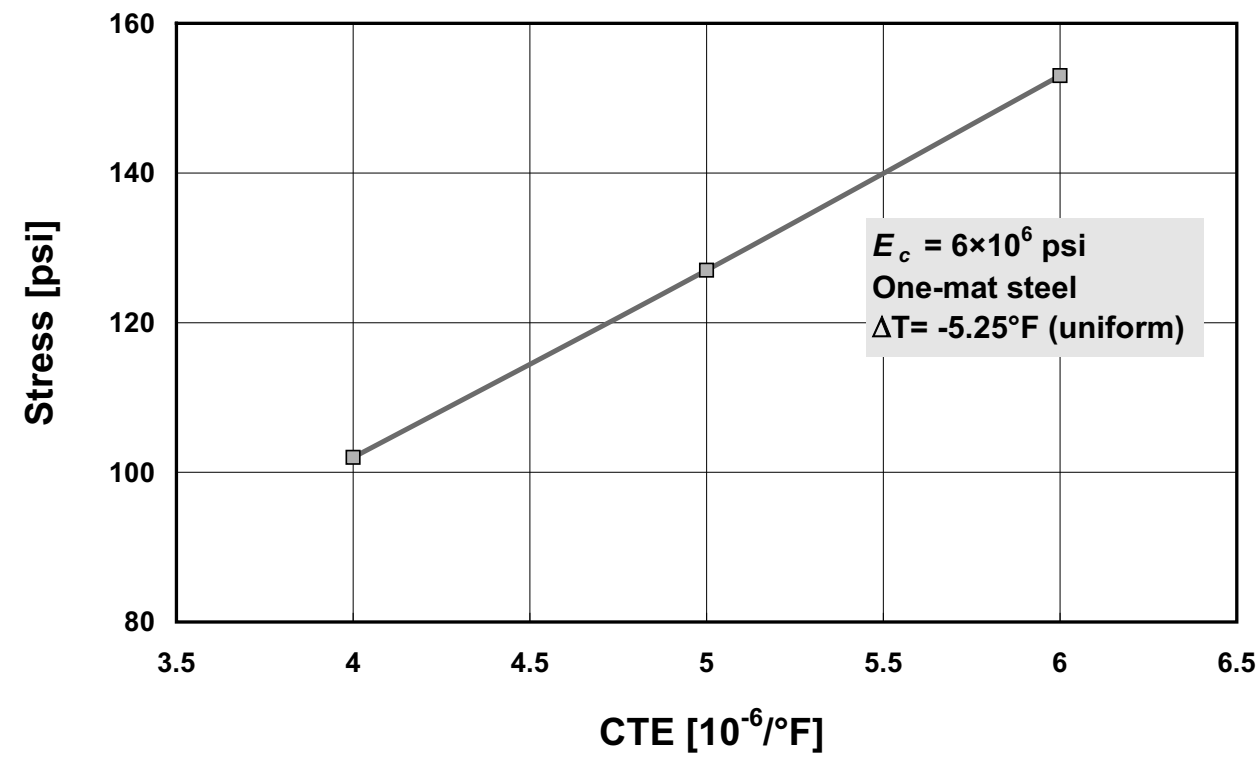

Figure 6.4: Effect of CoTE on vertical stress development 


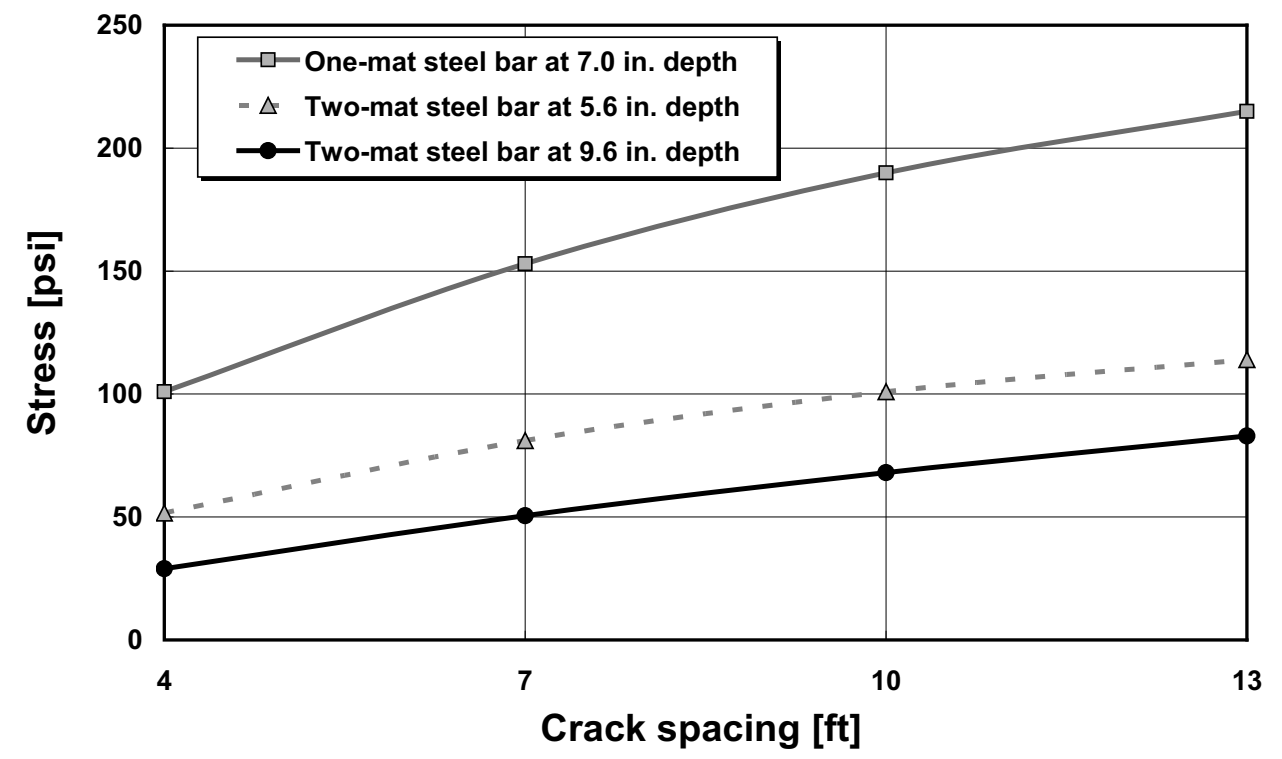

Figure 6.5: Effects of transverse crack spacing and number of steel layers on vertical stress development

Figure 6.6 illustrates the changes of vertical stress in concrete over temperature differences in linear gradient. As temperature difference increased, the vertical force to restrain the slab's movement increased and consequently higher vertical stress developed. Two-mat steel bar also reduced vertical stress in concrete subject to linear temperature gradient.

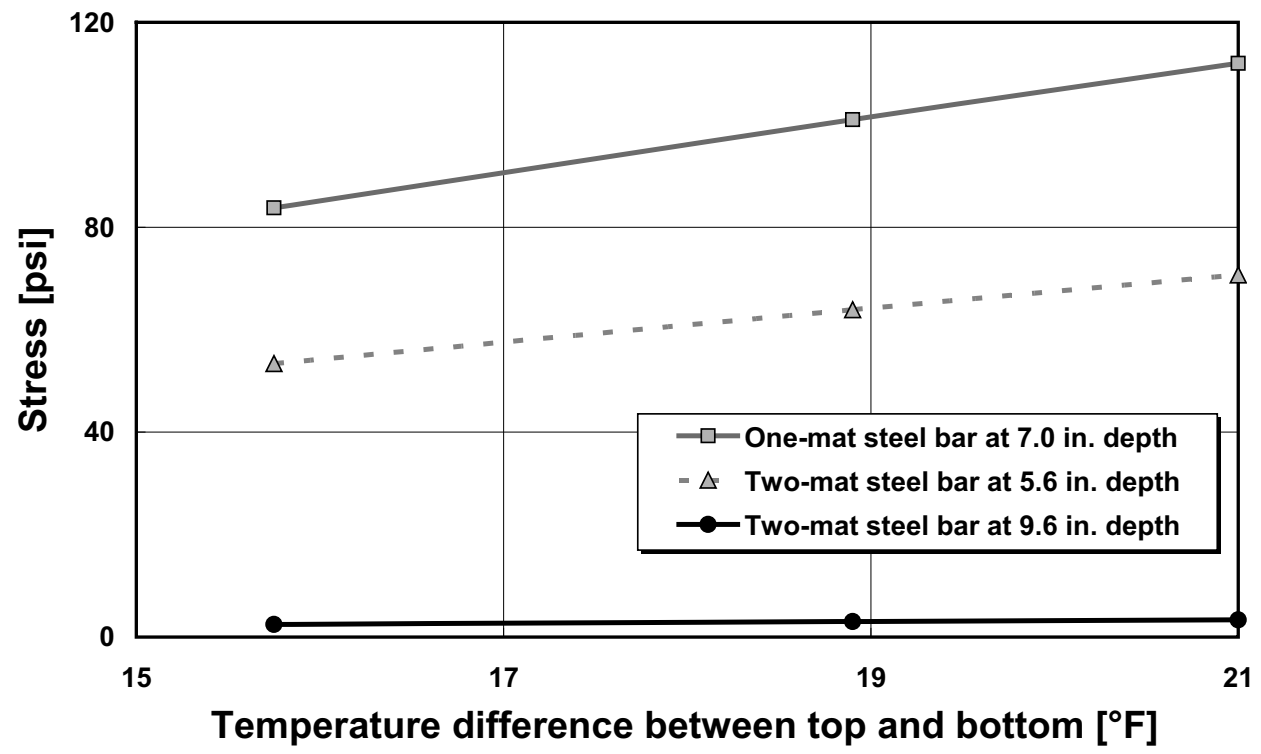

Figure 6.6: Effect of temperature difference on vertical stress developmen 


\section{NUMERICAL PARAMETRIC STUDY ON HORIZONTAL CRACKING POTENTIAL IN CRCP}

\subsection{NUMERICAL STUDY ON HORIZONTAL CRACKING POTENTIAL IN CRCP}

HC potential in CRCP was numerically evaluated in accordance with a factorial experiment. Factors related to material, construction and design were considered in the numerical analysis. Based on the results, appropriate design standards and materials and construction specifications can be developed to prevent HC in CRCP. Table 7.1 represents the standard input values used for numerical analysis.

As described earlier, coarse aggregate type has substantial effects on CoTE and the modulus of elasticity of concrete. Figure 7.1 shows the maximum vertical stress of concrete with different CoTEs and elastic modulus. The variation of maximum vertical stress was proportional to CoTE's changes because higher CoTE generated more volume changes. The larger elastic modulus, which would increase the restraining force in steel, resulted in a vertical stress increase. This is consistent with the field observations where the frequency of horizontal cracking increased in CRCP with concrete with higher CoTE and modulus of elasticity. It is also shown that the effect of CoTE is more dominant in developing stress than elastic modulus.

Figure 7.2 shows general nonlinear temperature gradient with different degree of nonlinearity. Even though three different gradients had the same average temperature of $5.25^{\circ} \mathrm{F}$, the temperature difference between the top and bottom of slab surfaces increased as the nonlinearity became higher. The higher temperature gradient could be caused by the effect of drying shrinkage due to surface drying. Figure 7.3 shows that the vertical stress increased with a higher degree of nonlinearity in the temperature gradient. Even though the average temperature change was the same in each gradient, the parabola gradient of 4th degree showed the largest vertical stress development. This is because more restraining force in steel was generated in response to the slab's curling-up and thus vertical stress development was increased. Figure 7.3 indicates the importance of such construction operations as curing. Temperature and moisture gradients, which cause slab volume changes, are closely related to the curing operation. Therefore, it is important to control the quality of field curing operations in order to reduce HC potential in CRCP.

Figure 7.4 shows the benefit of two-mat steel bar in reducing HC potential in CRCP. For the given temperature gradient, two-mat steel placement significantly reduced the stress in concrete. It indicates that the bending moment was reduced due to the decrease of the lever arm length between the restraint force in steel and the resulting reaction force at the slab's center. Therefore, the risk of $\mathrm{HC}$ would be reduced through placement of two-mat longitudinal steel.

The results shown in Figures 7.3 and 7.4 are consistent with the findings on IH 35 in the Waco District as described in Chapter 2, where the section with one-mat steel and larger ambient temperature variations experienced $\mathrm{HC}$ while no $\mathrm{HC}$ was observed in the section with two-mat steel and smaller ambient temperature variations. The results from this numerical study proved to 
be the reasonableness of the analysis method. In the next section, a full experimental analysis was conducted to develop design standards and materials and construction specifications to minimize $\mathrm{HC}$ in Texas.

Table 7.1: Default input in numerical analysis

\begin{tabular}{ll}
\hline Transverse crack spacing & 7 -ft \\
\hline Pavement thickness & 14 -in. \\
\hline Amount of steel & $0.66 \%$ with \#6 bar \\
\hline Temperature gradient & $3^{\text {rd }}$ degree parabola \\
\hline Coefficient of thermal expansion & $6 \times 10^{-6} /{ }^{\circ} \mathrm{F}$ \\
\hline Elastic modulus of concrete & $6 \times 10^{6} \mathrm{psi}$ \\
\hline Elastic modulus of steel & $29 \times 10^{6} \mathrm{psi}$ \\
\hline Steel depth & 7 -in. $(4.4 \text {-in. and } 9.5 \text {-in. })^{*}$ \\
\hline two-mat steel bars
\end{tabular}

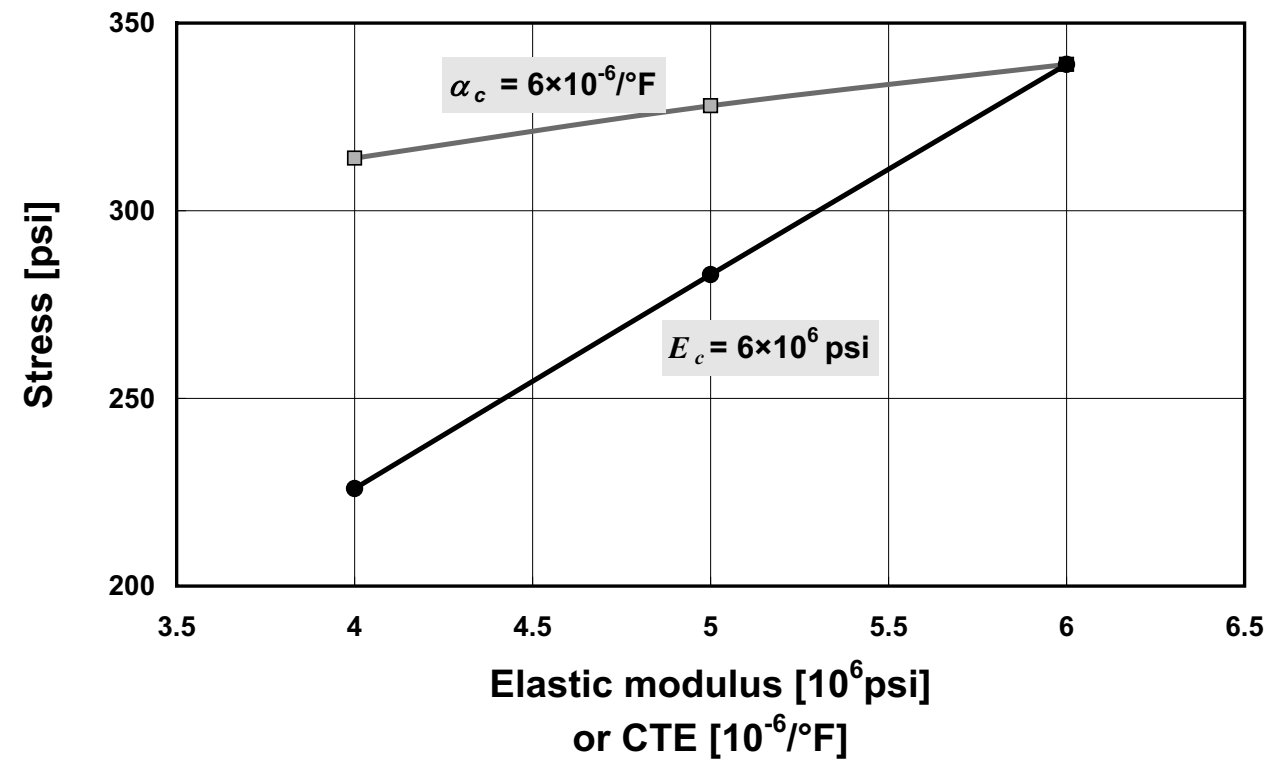

Figure 7.1: Effect of elastic modulus and CoTE on vertical stress development 


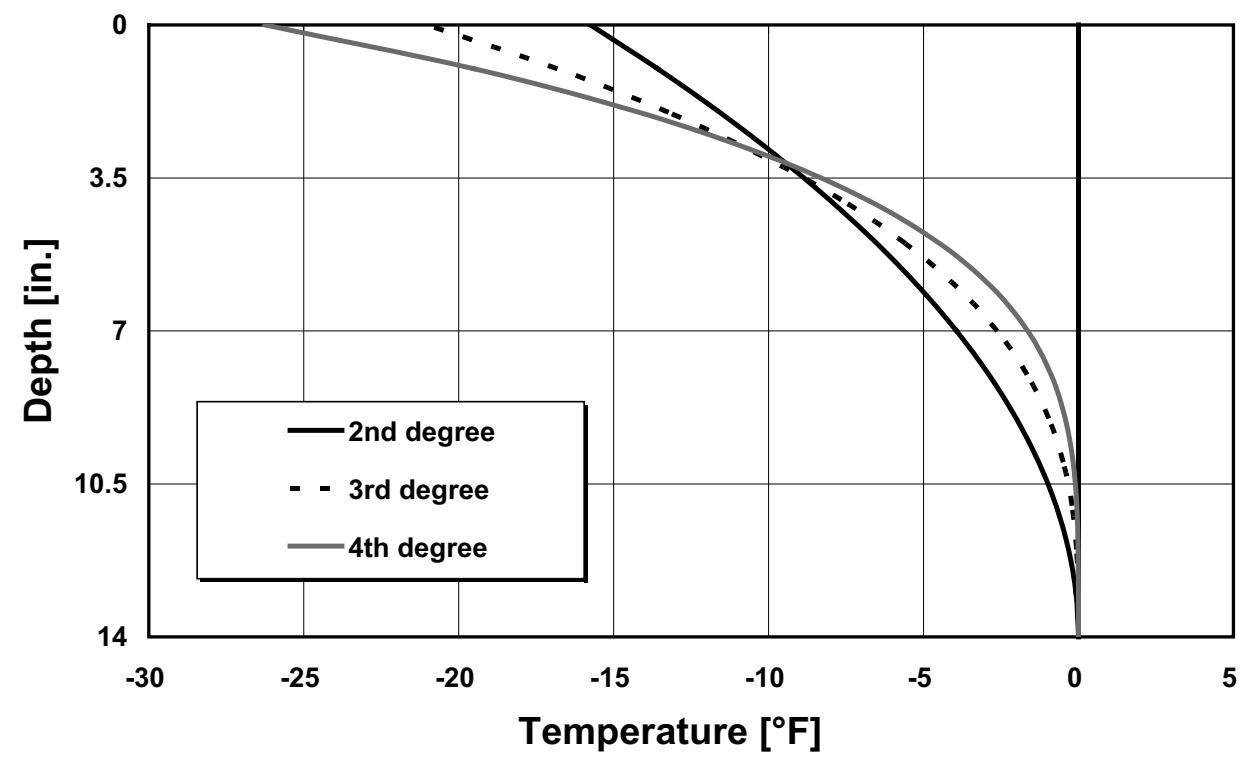

Figure 7.2: Nonlinear temperature gradient with different degree of nonlinearity

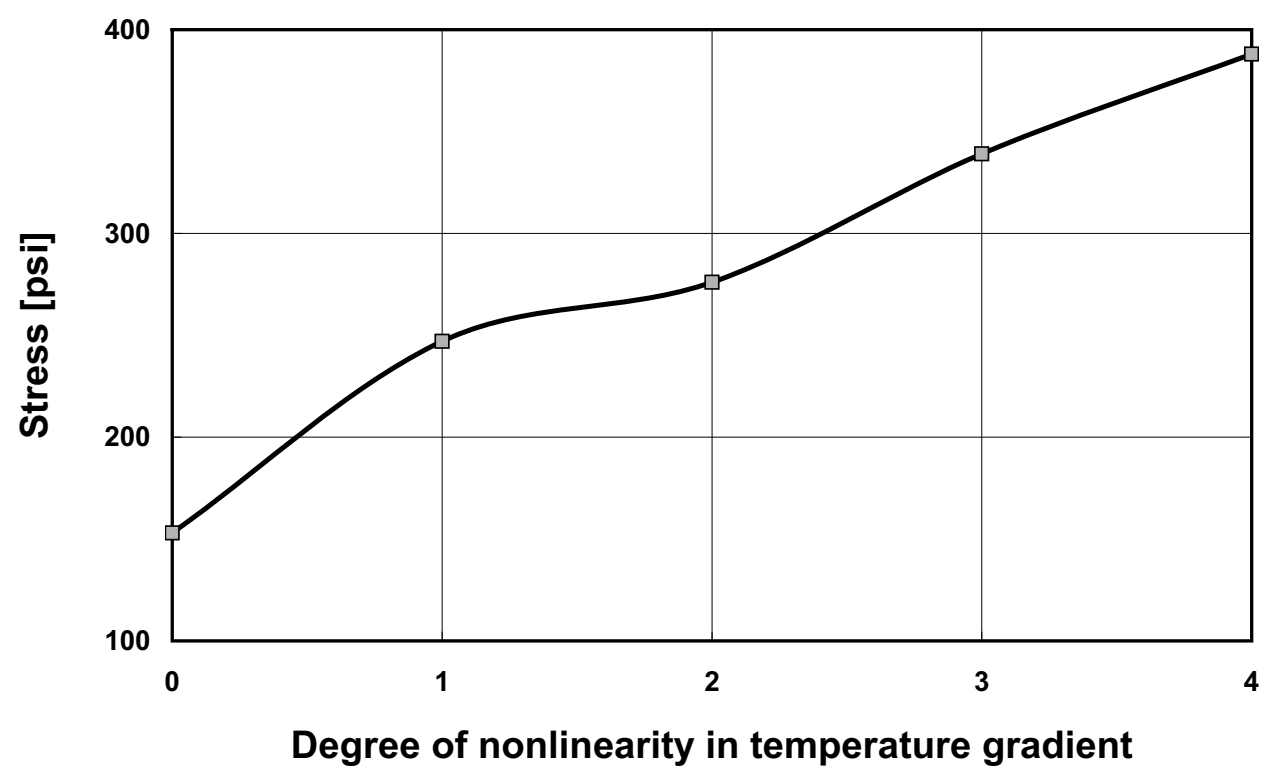

Figure 7.3: Effect of degree of nonlinearity in temperature gradient on vertical stress development 


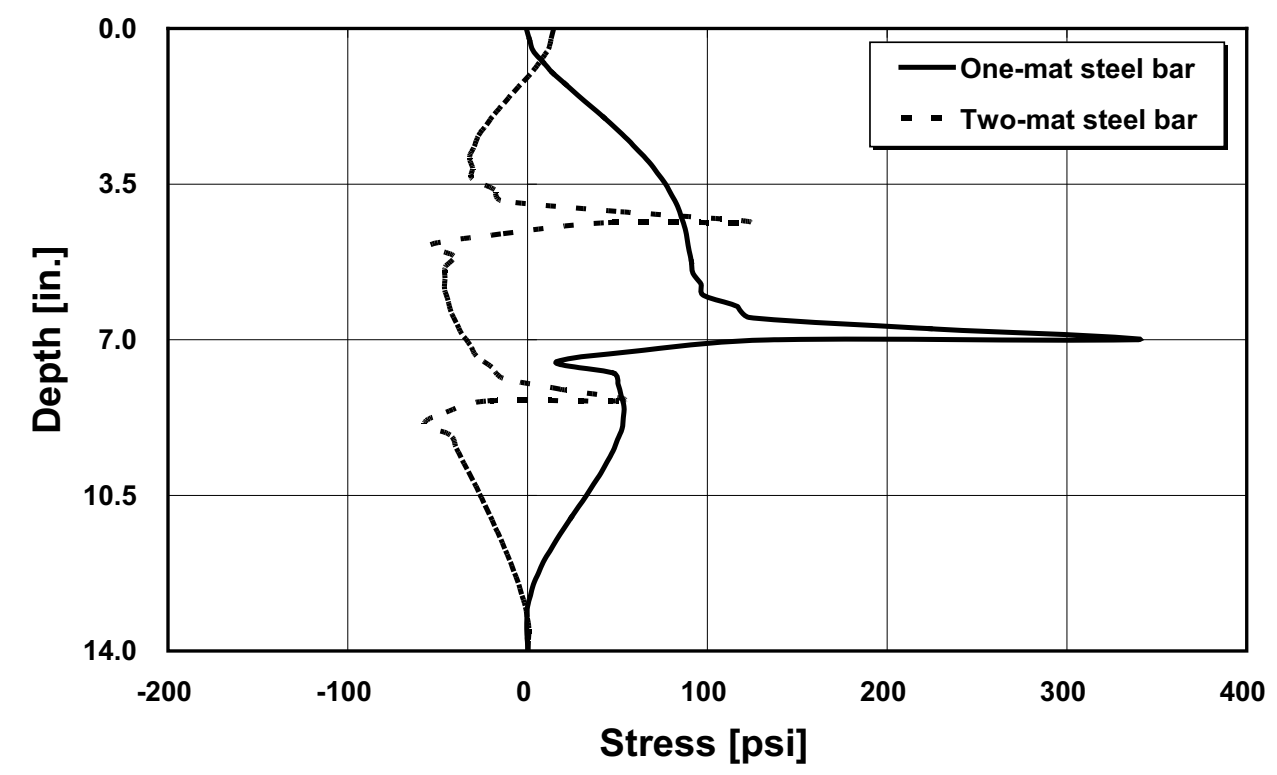

Figure 7.4: Distribution of vertical stress in CRCP at transverse crack

\subsection{FACTORIAL EXPERIMENT FOR ANALYSIS OF HC POTENTIAL}

Based on the observations of $\mathrm{HC}$ in Texas, it appears that design, materials and construction all have effects on the occurrence of HC. Design issues include the number of steel layers. CoTE and modulus of elasticity of concrete are material properties that appear to have an impact on horizontal cracking. Environmental conditions during construction, especially air or concrete temperatures, also appear to be related to $\mathrm{HC}$. In other words, effective means to prevent $\mathrm{HC}$ in CRCP may have to be a combination of prudent design, the use of appropriate materials and construction practices. HC could be avoided if proper combinations of design, materials and construction are implemented. Even though the interactions among design, materials and construction variables could be quite complicated, it may be possible to develop CRCP design, materials selection and construction practices that will prevent horizontal cracking.

In this section, a comprehensive factorial experiment was developed for the analysis of $\mathrm{HC}$ potential in CRCP in Texas. Table 7.2 shows a factorial experiment developed for this purpose. Based on the results, appropriate design standards and materials and construction specifications could be developed to prevent horizontal cracking in CRCP.

There are 48 cells in the factorial experiment in Table 7.2. The full discussion of main effects and interactions among variables could be quite complicated. Accordingly, the discussion is provided on only the main effects of the 5 variables as shown in the next page. The results of the 48 analysis are shown in the Appendix A in terms of contour. 
Table 7.2: Factorial experiment

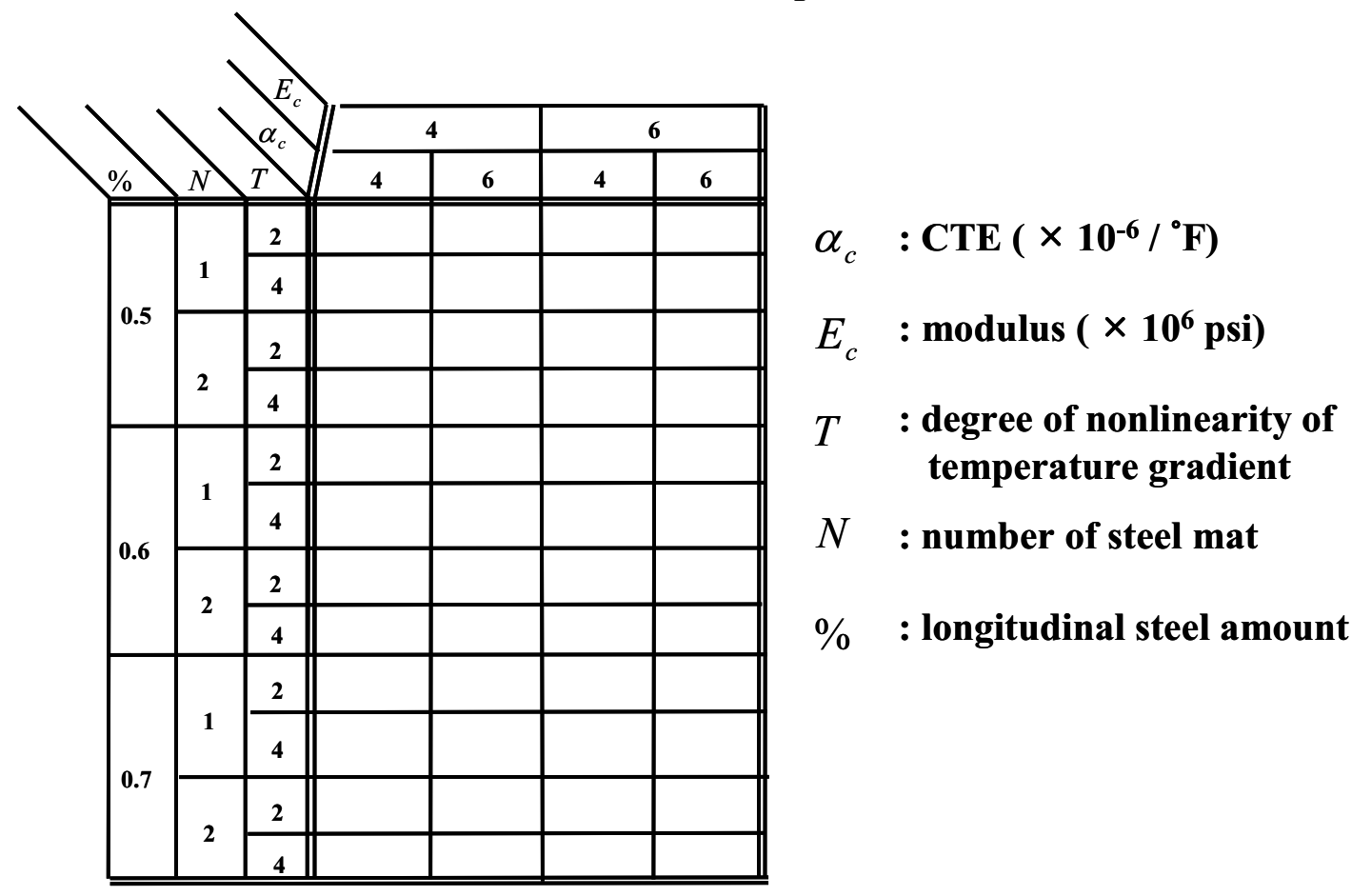

1. Effect of concrete modulus of elasticity: Figures 7.5 - 7.16 show the effect of concrete modulus of elasticity on concrete vertical stress for various input combinations. The effect depends on the level of other input variables. However, in general, higher modulus concrete results in larger vertical stress in concrete and potential for $\mathrm{HC}$.

2. Concrete CoTE: Figures 7.5 - 7.16 illustrate that CoTE has consistent effects on HC potential; the larger the CoTE, the greater the potential for $\mathrm{HC}$, even though the effects are dependent on the level of other input variables.

3. Degree of nonlinearity of temperature gradient: In general, larger degree of nonlinearity of temperature gradient results in higher concrete vertical stress and potential for HC.

4. Longitudinal steel amount: Three steel amounts were compared $-0.5 \%$ (Figures 7.5 thru 7.8), $0.6 \%$ (Figures 7.9 thru 7.12) and $0.7 \%$ (Figures 7.13 thru 7.16). Pair-wise comparisons indicate larger concrete vertical stress as steel amount increases. This could mislead in that, as longitudinal steel amount is increased, crack spacing decreases and concrete vertical stress will be reduced. It should be kept in mind that in this analysis, constant crack spacing was used and caution is required for the interpretation of the analysis results.

5. Number of steel layers: Currently, TxDOT requires the use of two-mat steel when the slab thickness is greater than 13 inches. In all combinations of inputs shown in Figures 7.5 thru 7.16, two-mat steel results in lower concrete vertical stress and $\mathrm{HC}$ potential. This result agrees with the field finding on IH 35 in the Waco District discussed in Chapter 2. 


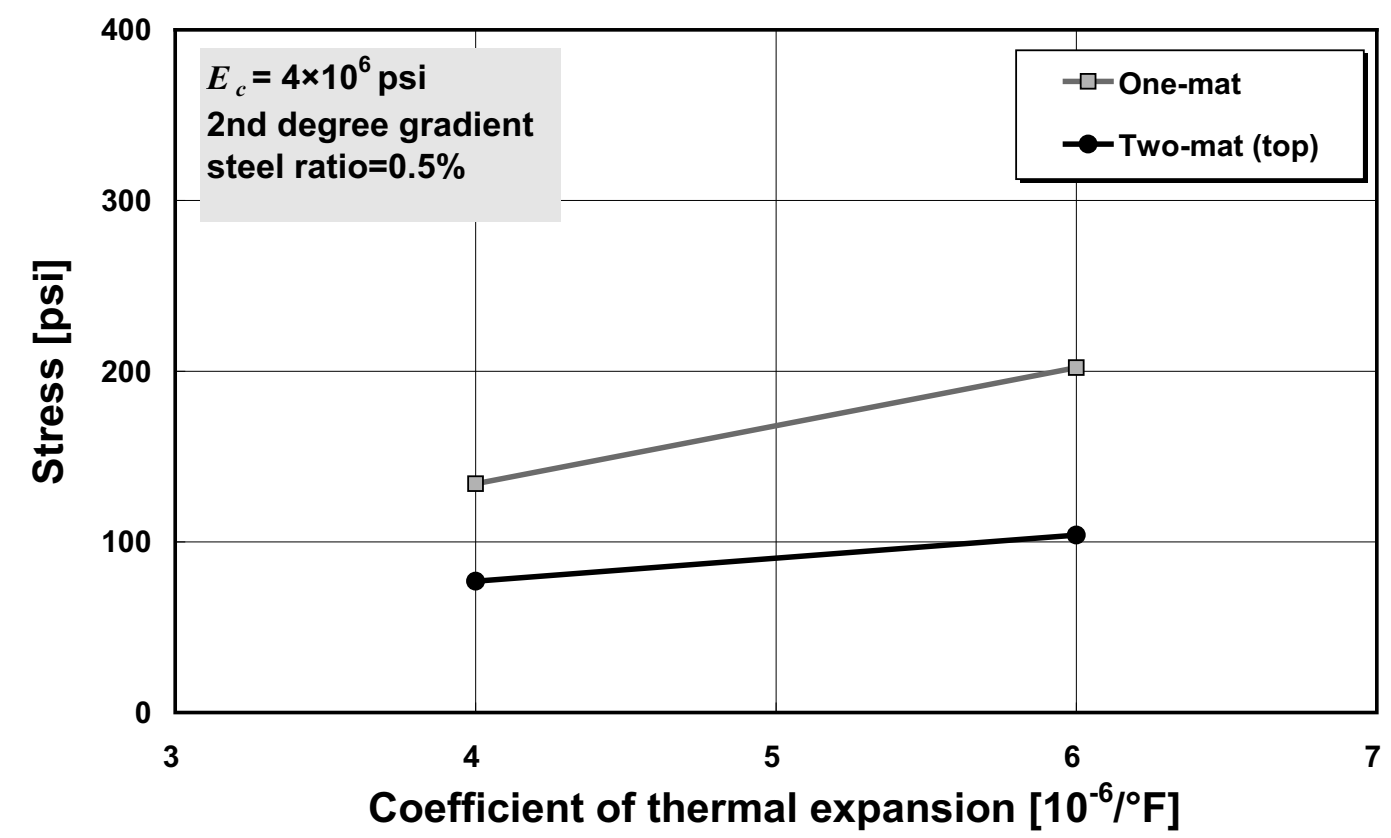

Figure 7.5: Analysis results in factorial experiment $\left(E_{c}=4 \times 10^{6} \mathrm{psi}, 2^{\text {nd }}\right.$ degree gradient, $0.5 \%$ ratio $)$

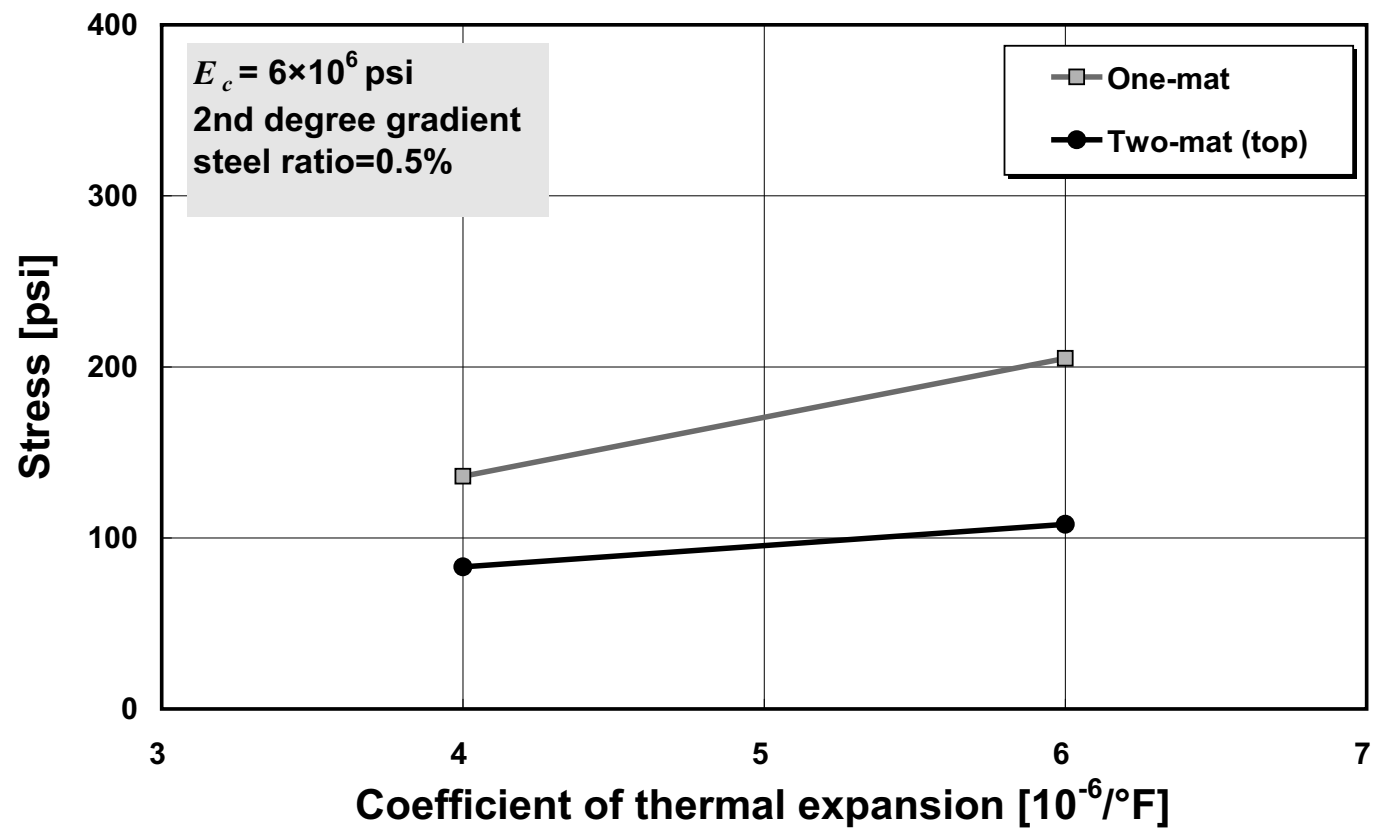

Figure 7.6: Analysis results in factorial experiment $\left(E_{c}=6 \times 10^{6} \mathrm{psi}, 2^{\text {nd }}\right.$ degree gradient, $0.5 \%$ ratio $)$ 


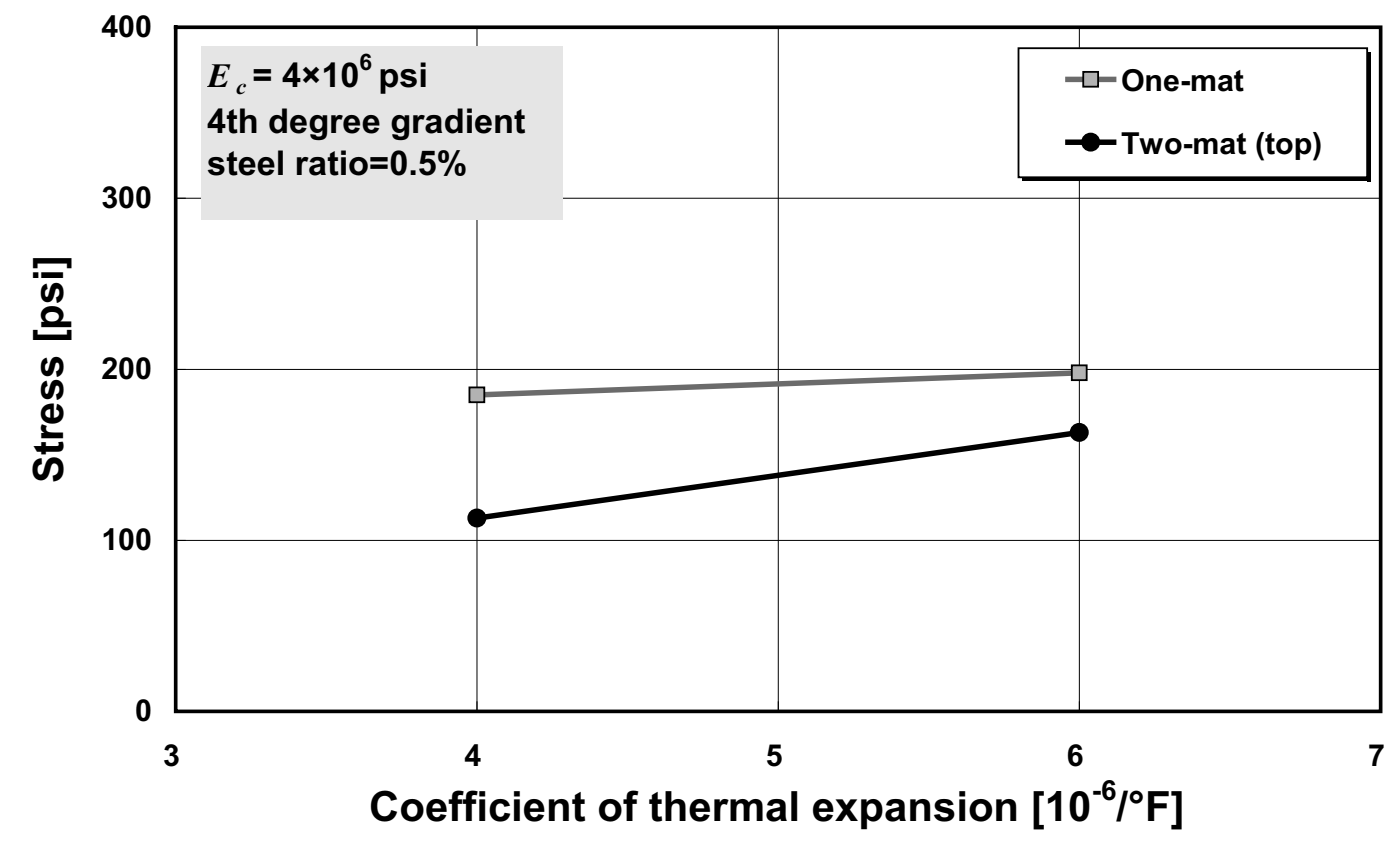

Figure 7.7: Analysis results in factorial experiment $\left(E_{c}=4 \times 10^{6} \mathrm{psi}, 4^{\text {th }}\right.$ degree gradient, $0.5 \%$ ratio $)$

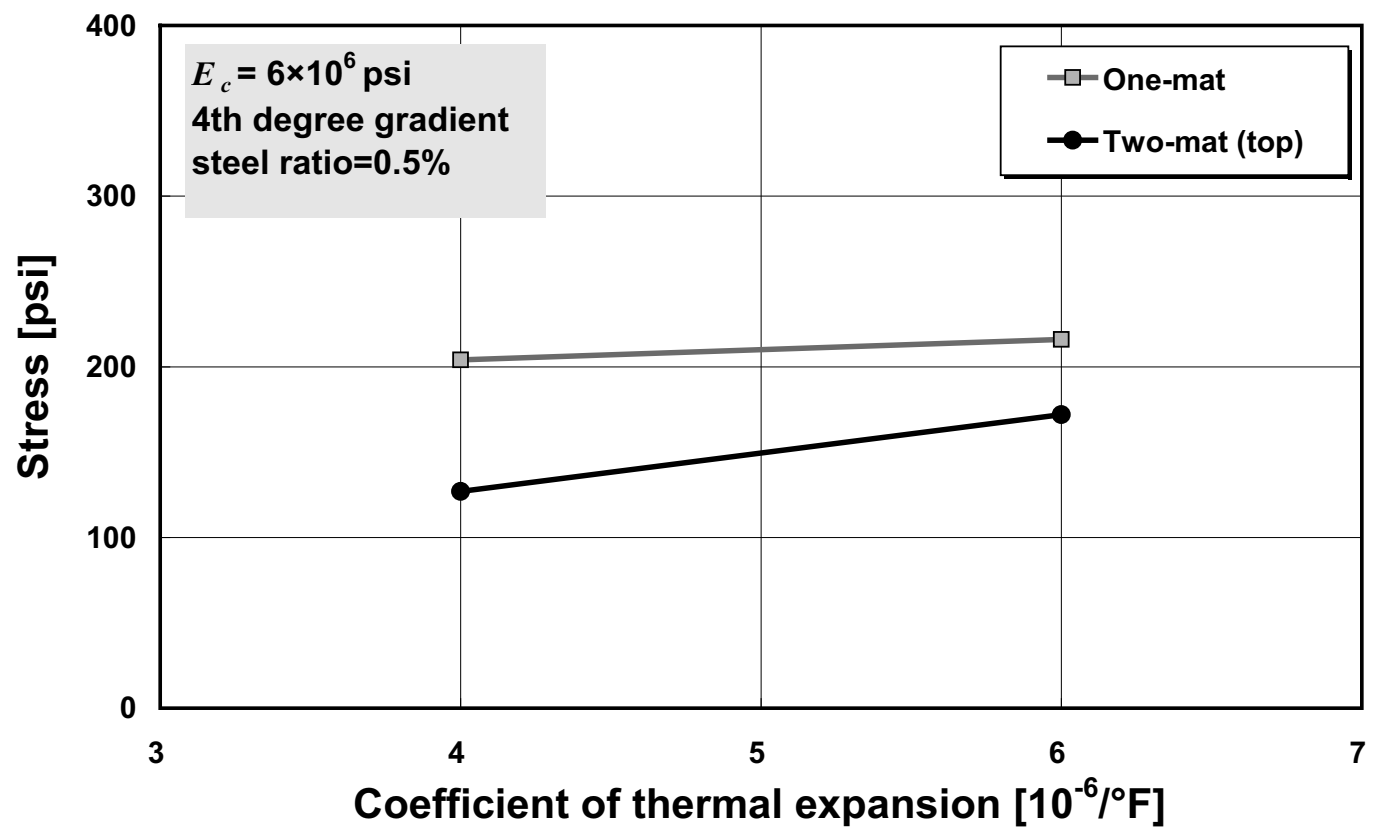

Figure 7.8: Analysis results in factorial experiment $\left(E_{c}=6 \times 10^{6} \mathrm{psi}, 4^{\text {th }}\right.$ degree gradient, $0.5 \%$ ratio $)$ 


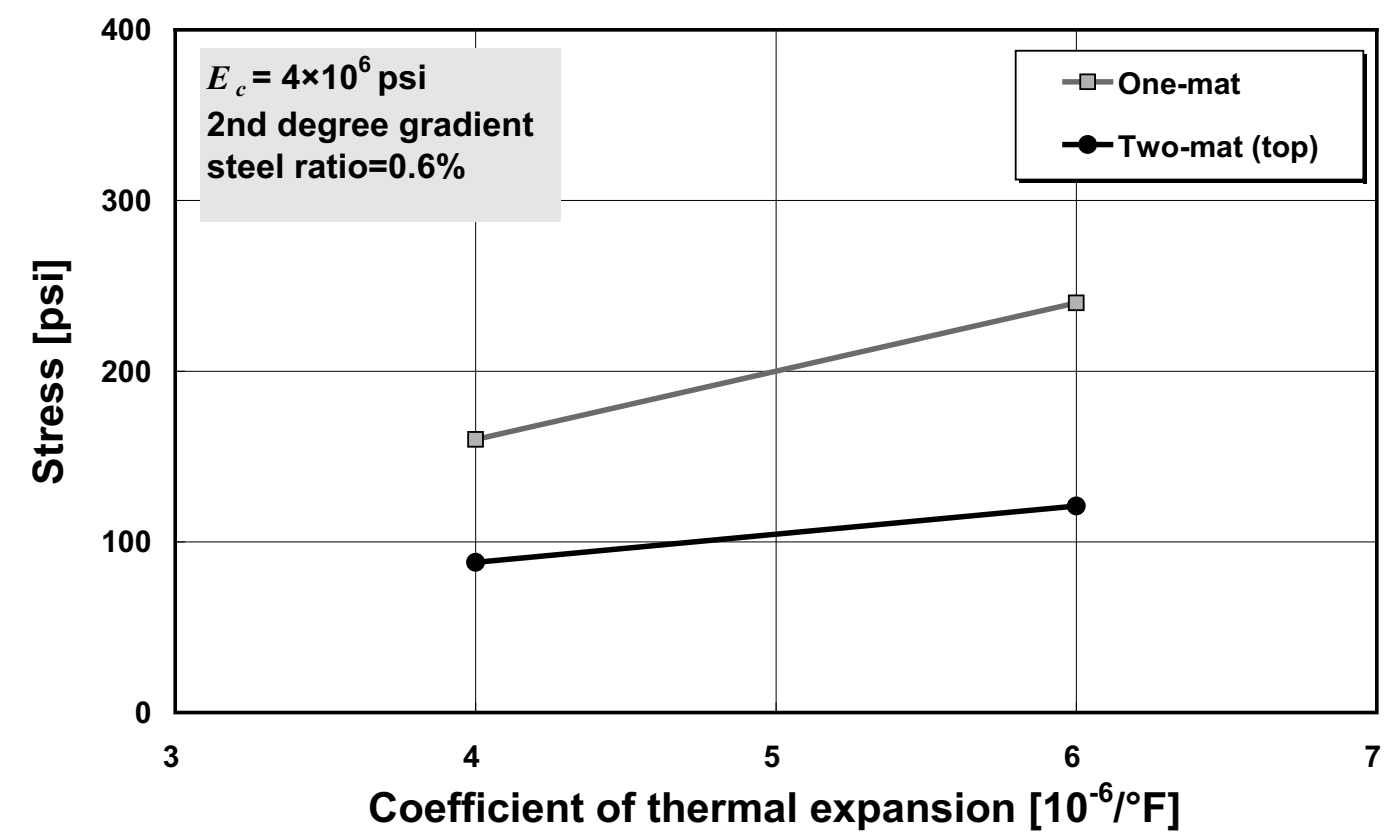

Figure 7.9: Analysis results in factorial experiment $\left(E_{c}=4 \times 10^{6} \mathrm{psi}, 2^{\text {nd }}\right.$ degree gradient, $0.6 \%$ ratio $)$

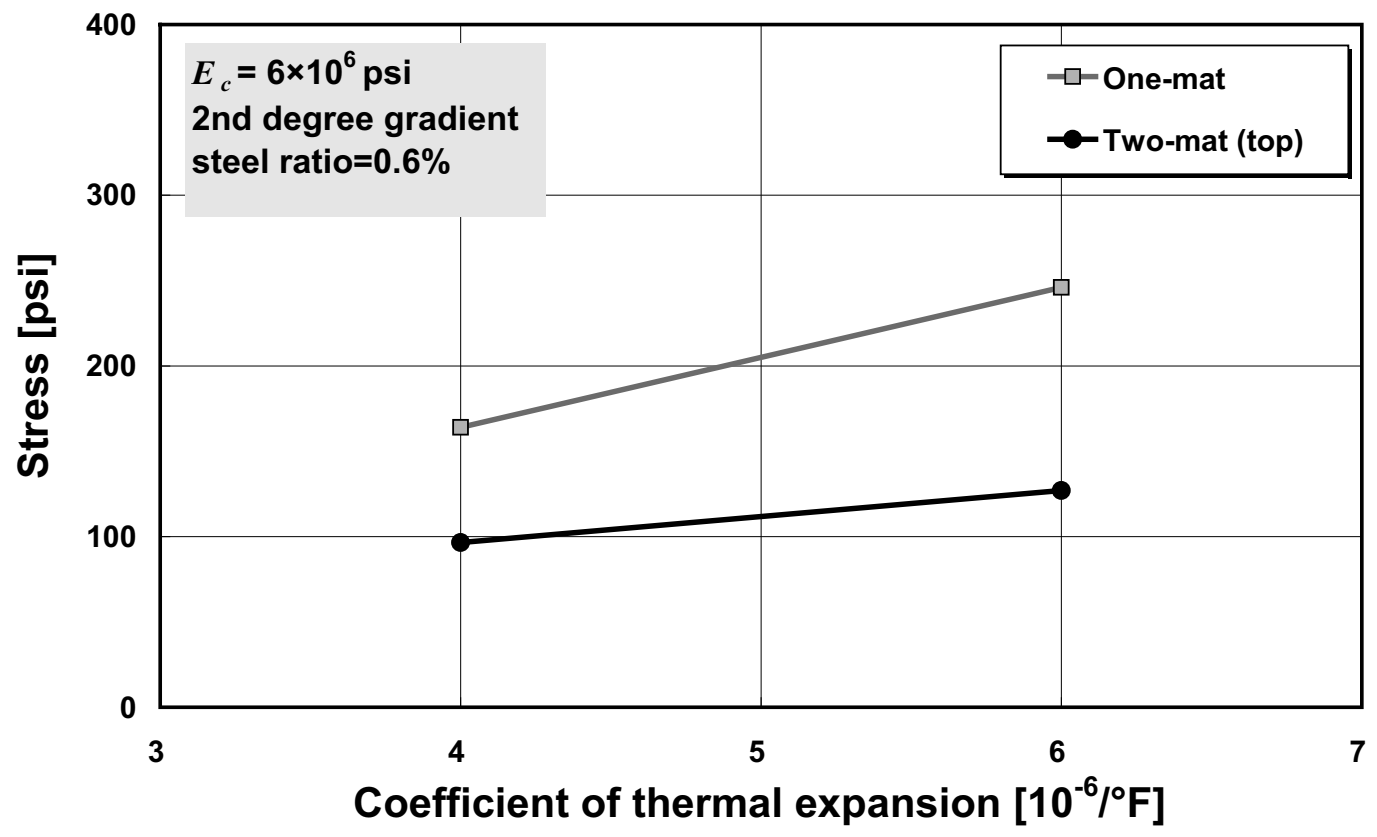

Figure 7.10: Analysis results in factorial experiment $\left(E_{c}=6 \times 10^{6} \mathrm{psi}, 2^{\text {nd }}\right.$ degree gradient, $0.6 \%$ ratio $)$ 


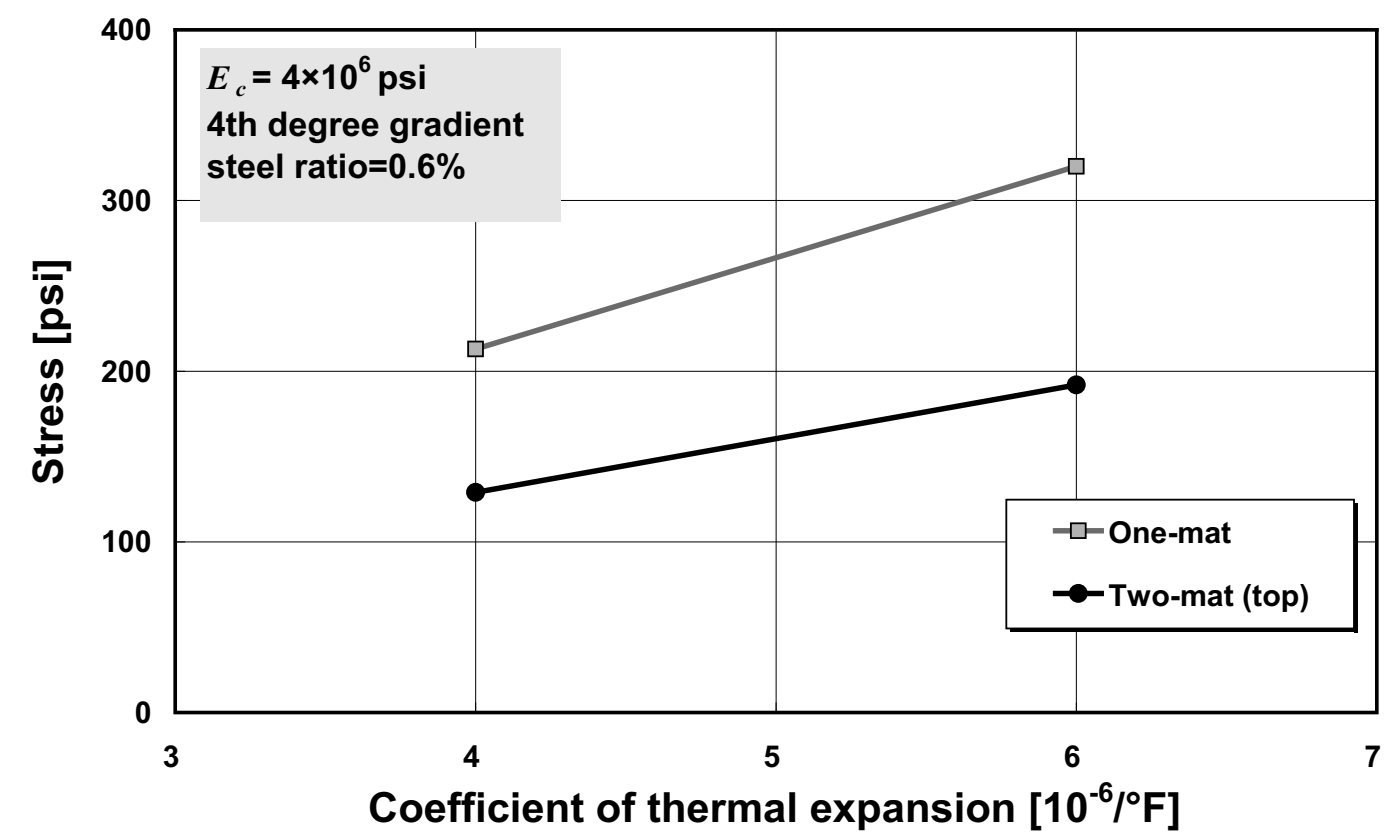

Figure 7.11: Analysis results in factorial experiment $\left(E_{c}=4 \times 10^{6} \mathrm{psi}, 4^{\text {th }}\right.$ degree gradient, $0.6 \%$ ratio $)$

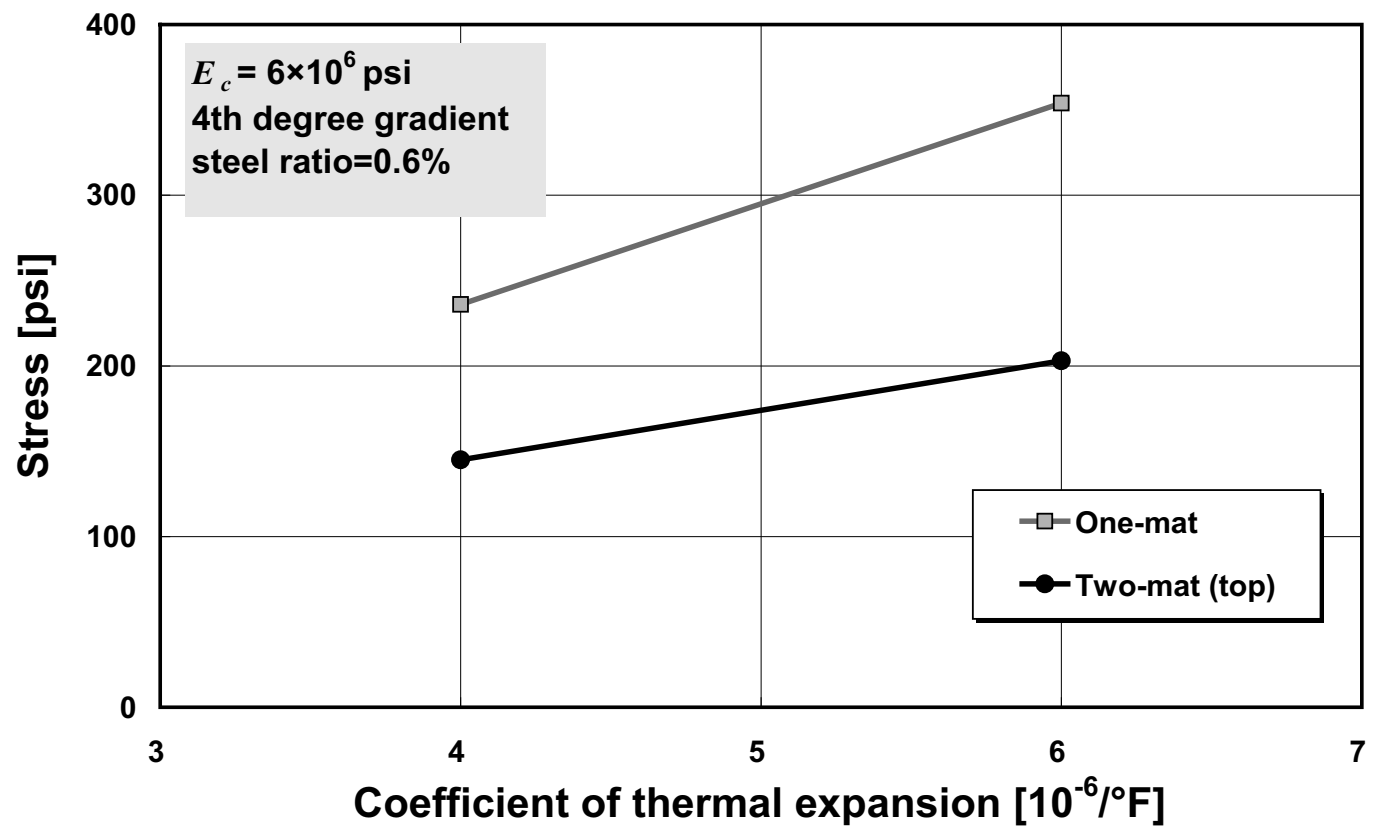

Figure 7.12: Analysis results in factorial experiment $\left(E_{c}=6 \times 10^{6} \mathrm{psi}, 4^{\text {th }}\right.$ degree gradient, $0.6 \%$ ratio $)$ 


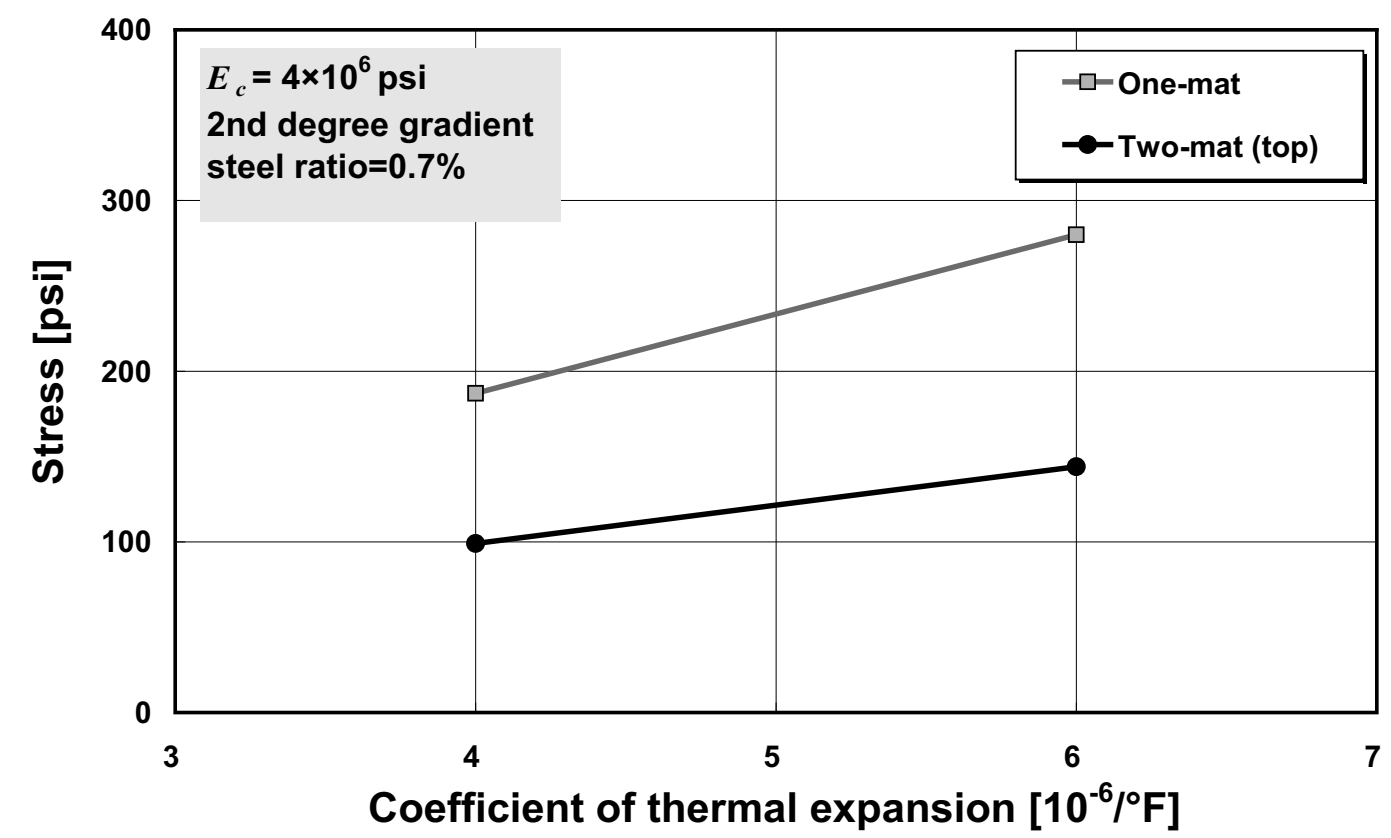

Figure 7.13: Analysis results in factorial experiment $\left(E_{c}=4 \times 10^{6} \mathrm{psi}, 2^{\text {nd }}\right.$ degree gradient, $0.7 \%$ ratio $)$

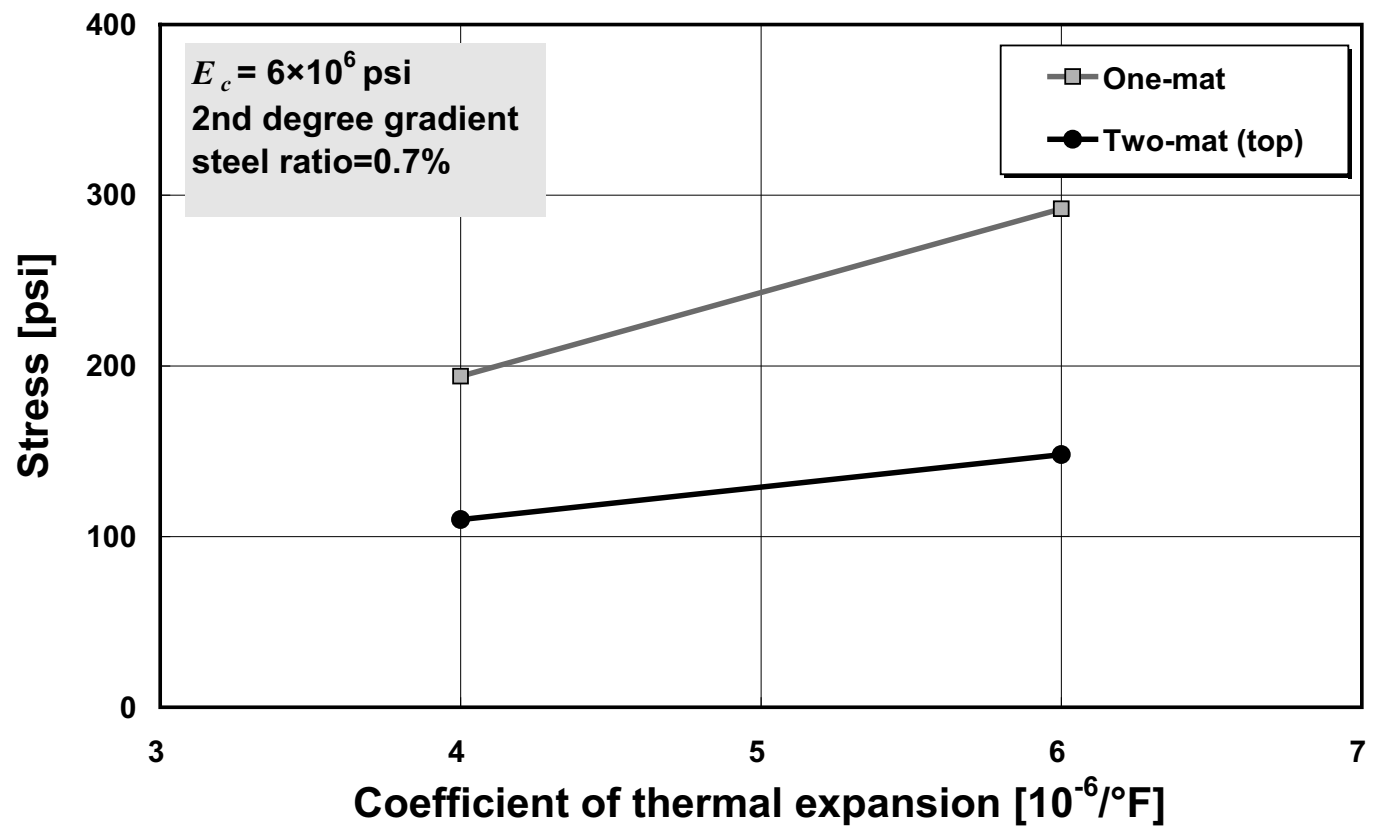

Figure 7.14: Analysis results in factorial experiment $\left(E_{c}=6 \times 10^{6} \mathrm{psi}, 2^{\text {nd }}\right.$ degree gradient, $0.7 \%$ ratio $)$ 


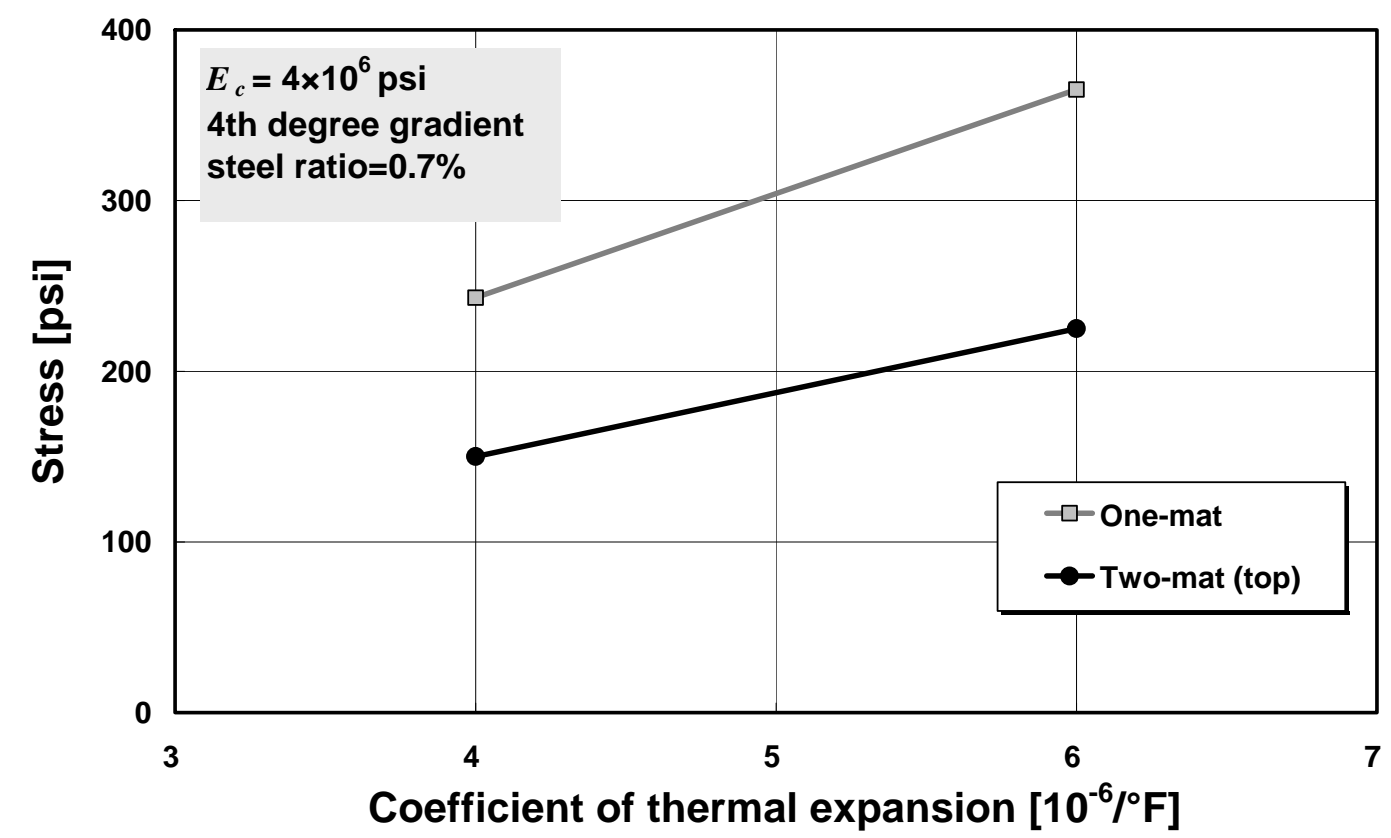

Figure 7.15: Analysis results in factorial experiment $\left(E_{c}=4 \times 10^{6} \mathrm{psi}, 4^{\text {th }}\right.$ degree gradient, $0.7 \%$ ratio)

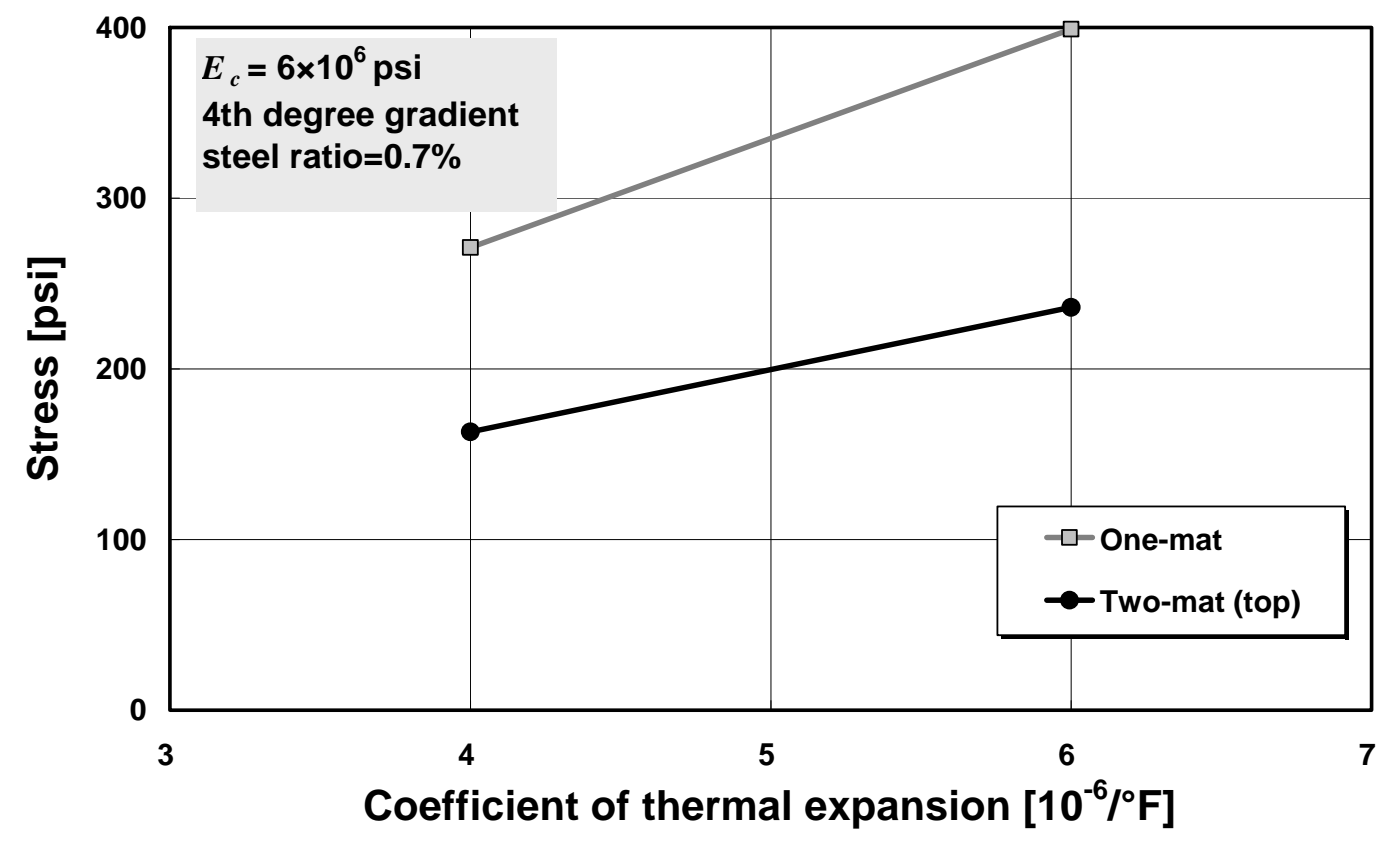

Figure 7.16: Analysis results in factorial experiment $\left(E_{c}=6 \times 10^{6} \mathrm{psi}, 4^{\text {th }}\right.$ degree gradient, $0.7 \%$ ratio $)$

\subsection{GUIDELINES TO MINIMIZE HORIZONTAL CRACKING}

The analysis results presented in the previous section provide the relative importance of each design, materials and construction variable. However, it is difficult to quantify the effects of 
some of the variables, such as the nonlinearity of the temperature variations through the slab depth. As for the temperature variations, the field environmental condition will vary on a daily basis as well as on an hourly basis. Accordingly, from a practical standpoint, it is not desirable to develop rigid guidelines on design, materials and construction variables. Rather, more general guidelines are suitable. Based on this, the following general guidelines were developed.

\section{A. DESIGN}

1. Use two-mat steel where applicable.

2. Larger amount of longitudinal steel induces more transverse cracks and thus reduces vertical concrete stress, resulting in lower potential for HC. Consider the use of increased longitudinal steel, if the materials and other conditions make $\mathrm{HC}$ potential high. From a practical standpoint, this option is less desirable.

3. When concrete with low CoTE and modulus is used, the amount of longitudinal steel could be reduced without risking $\mathrm{HC}$ development.

4. In the past, one-mat of steel with larger size bar was used for 14-in and 15-in slabs. This practice should be discouraged.

B. MATERIALS

1. If possible, coarse aggregate type that provides lower CoTE and elastic modulus values should be used in CRCP. If the only aggregate type available locally will make concrete with high CoTE and modulus, consider the use of other pavement type, such as concrete pavement, contraction design (CPCD).

2. Since HC potential increases with low concrete strength at early ages and larger CoTE and drying shrinkage, develop and utilize concrete mix designs that will provide adequate concrete strength with lower drying shrinkage. This can be achieved by lowering water-cement ratio and increasing coarse aggregate content.

\section{CONSTRUCTION}

1. Make sure that the curing operations are in accordance with the requirements in the Item 360 in the standard specifications.

2. During the steel placement, make sure that the vertical location of the longitudinal steel is within the tolerance limits. 


\section{PARTIAL DEPTH REPAIR}

\subsection{INTRODUCTION}

A large number of distresses in CRCP in Texas are caused by horizontal cracks at the depth of longitudinal steel. However, TxDOT does not have specifications or design standards for the repair of distresses caused by horizontal cracking. Accordingly, full-depth repairs (FDR) are done, when in fact, all that's needed is partial-depth repair (PDR). FDR necessarily requires cutting of longitudinal steel, and restoring the continuity of longitudinal steel is quite a challenge, resulting in further distresses in the FDR areas and repeated repairs. FDR is also expensive. The efficiency of TxDOT operations will be improved if proper guidelines, specifications, and design standards become available on PDR, along with proper training of TxDOT staff involved in the decision making for PCC pavement repairs. As a part of this study, special specifications were developed for PDR, which is included in Appendix B.

In order to investigate the field applicability and effectiveness of special specifications developed in this study for PDR of distresses caused by horizontal cracking in CRCP, a partial depth repair was conducted by the research team. The PDR section is located on US 290 eastbound in Hempstead in the Houston District. Figure 8.1-(a) shows the distress caused by HC. It is noted that a tied concrete shoulder was provided and the distress is not at the edge of the pavement. The repair was conducted in accordance with the special specifications. The distressed concrete was removed manually after breaking the concrete by a jackhammer. Figure 8.1-(b) confirms that the distress was confined to the depth of longitudinal steel. Vertical steel was inserted between old and new concrete at the horizontal crack plane and steel strain gages were installed. The objective was to estimate the vertical stress at the interface. It also shows the vertical bars installed along with steel strain gages. The extent of the repair area was 26-in. wide, 44-in. long and 5-in. deep. Figure 8.2 illustrates the plan view of steel and gage installations.

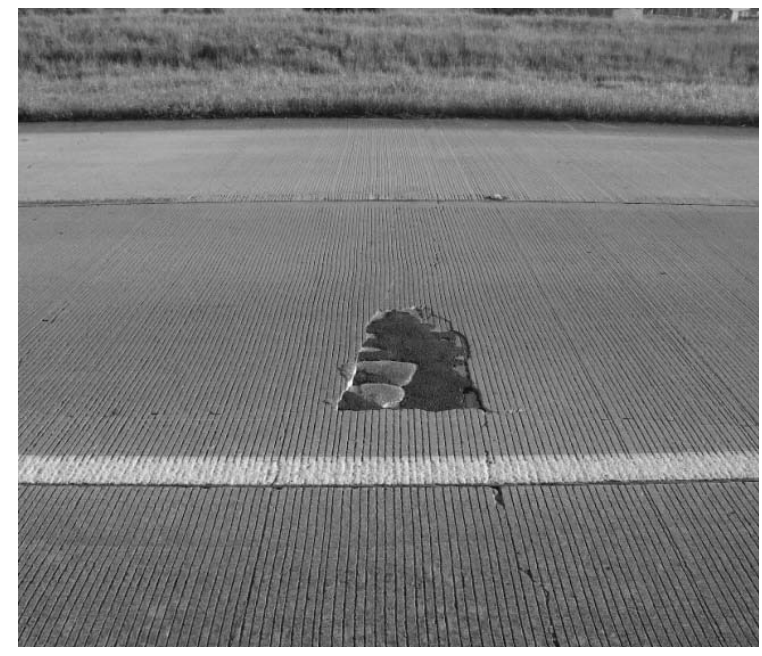

(a)

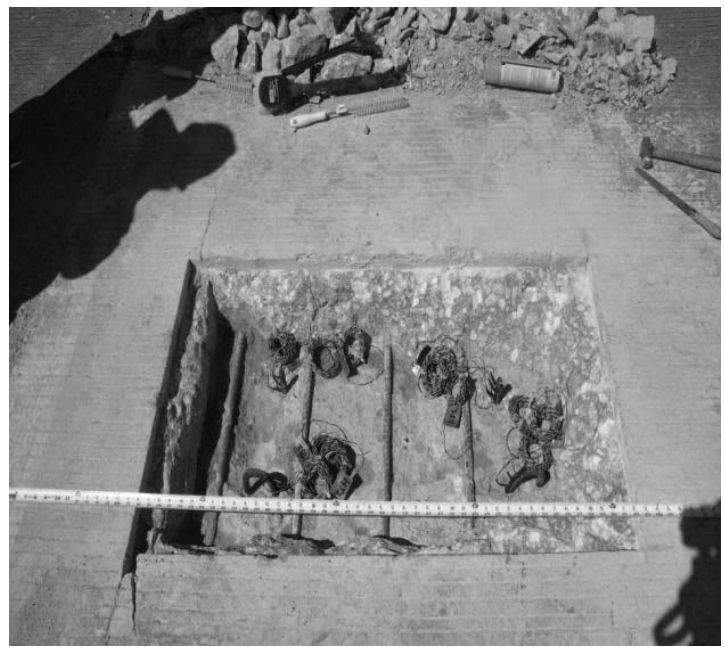

(b)

Figure 8.1: Distressed concrete slab with horizontal cracking 


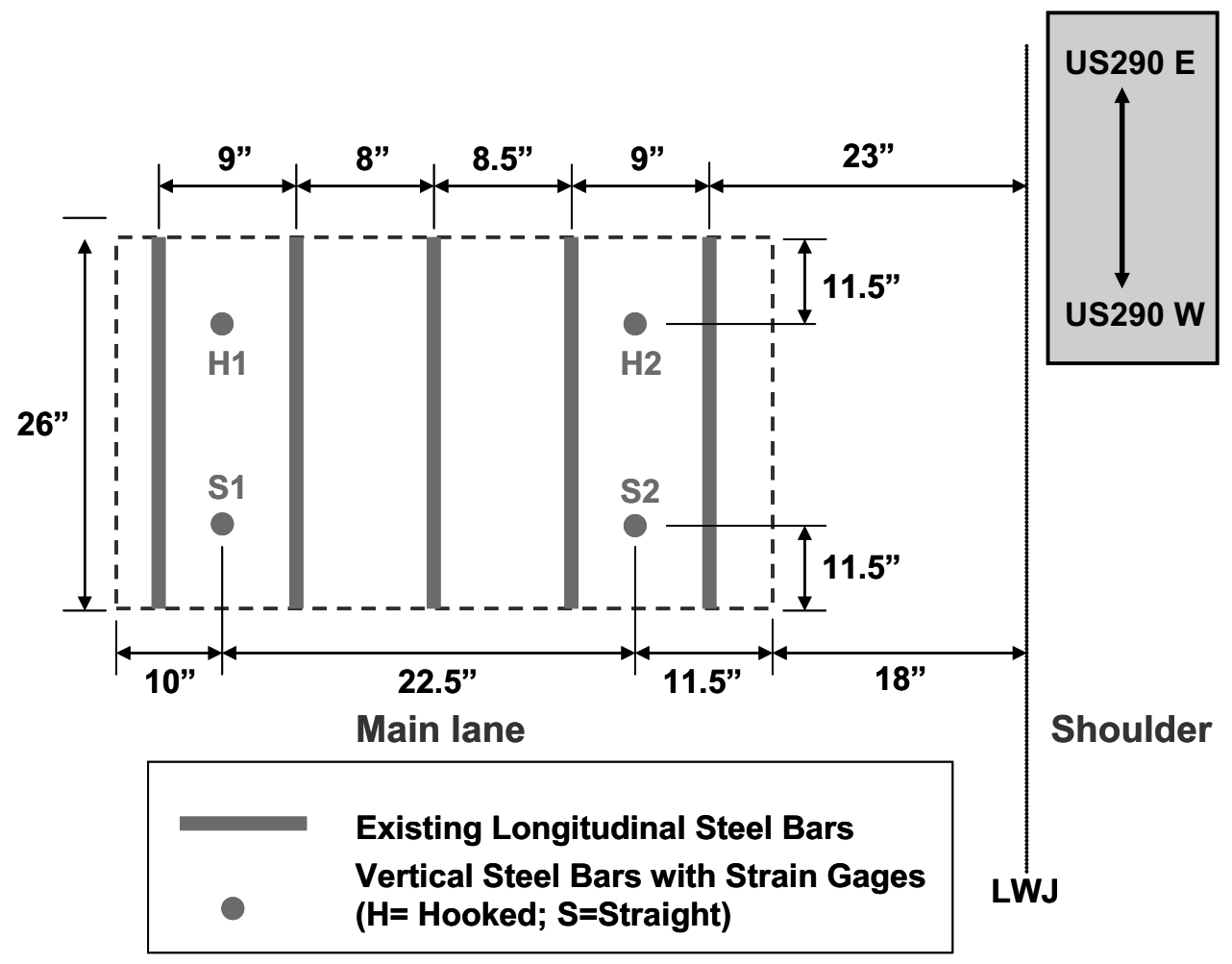

Figure 8.2: Plan view of test section

\subsection{INSTRUMENTATION AND TEST RESULTS}

As shown in Figure 8.3, two different shapes of \#5 bars were installed vertically; one is straight and the other hooked. It was expected that the four bars installed vertically would restrain the vertical relative movement between existing slab and new concrete patch and consequently would help prevent new concrete patch from debonding from existing slab. On each bar, three steel strain gages were attached at different distances from the interface to measure steel stress and corresponding debonding potential of new concrete patch from existing slab. Additionally, three temperature sensors at different depths were installed so that the environmental loadings were quantitatively evaluated.

Figure 8.4 shows measured temperature histories from temperature sensors. As expected, the top region of the slab had a larger variation of temperature than the bottom. Figures 8.4 to 8.7 display the variation of measured stresses of four bars vertically installed. It indicates that the tensile stress occurred in the bars when temperature dropped and the variations increased as the measured steel element became close to the interface between existing slab and new concrete patch. However, the magnitude and variations of steel stress were quite small. Also, there was little difference in steel stress between hooked and straight bars. This implies that the bond strength between old and new concrete was good and debonding didn't occur during the monitoring period. Even though long-term monitoring is needed before a positive conclusion can 
be made regarding bond condition at the interface, it appears that the construction practice during the repair was adequate for the development of required bond strength.

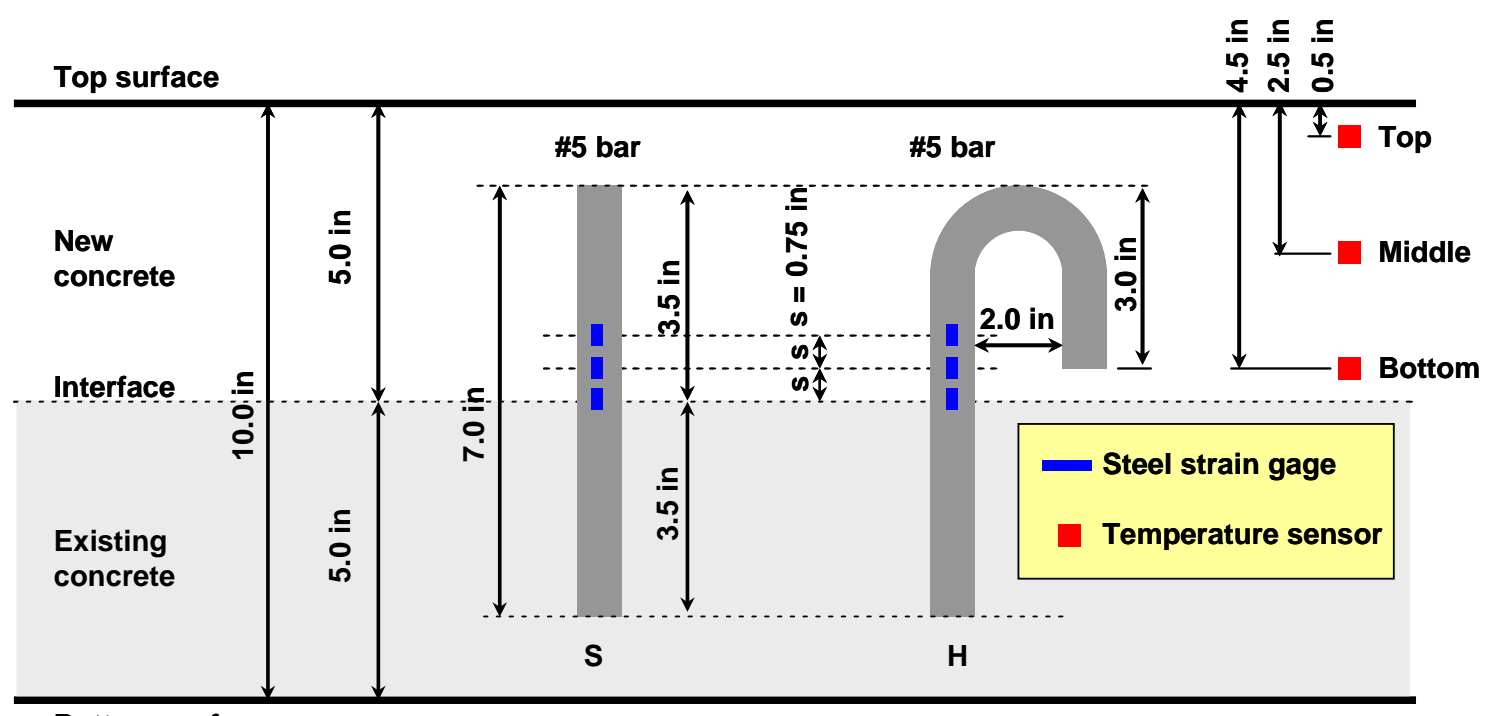

Bottom surface

Figure 8.3: Instrumentation in the field

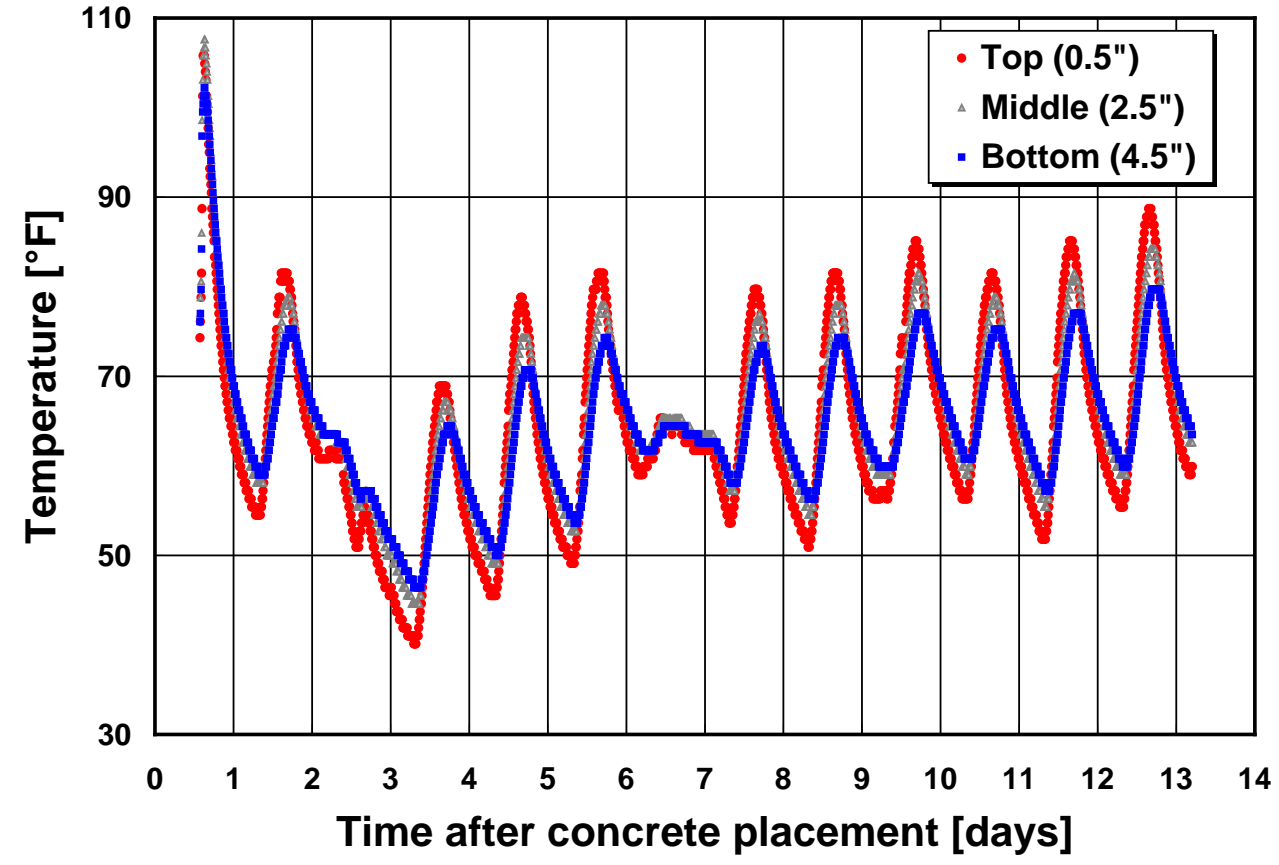

Figure 8.4: Measured temperature histories 


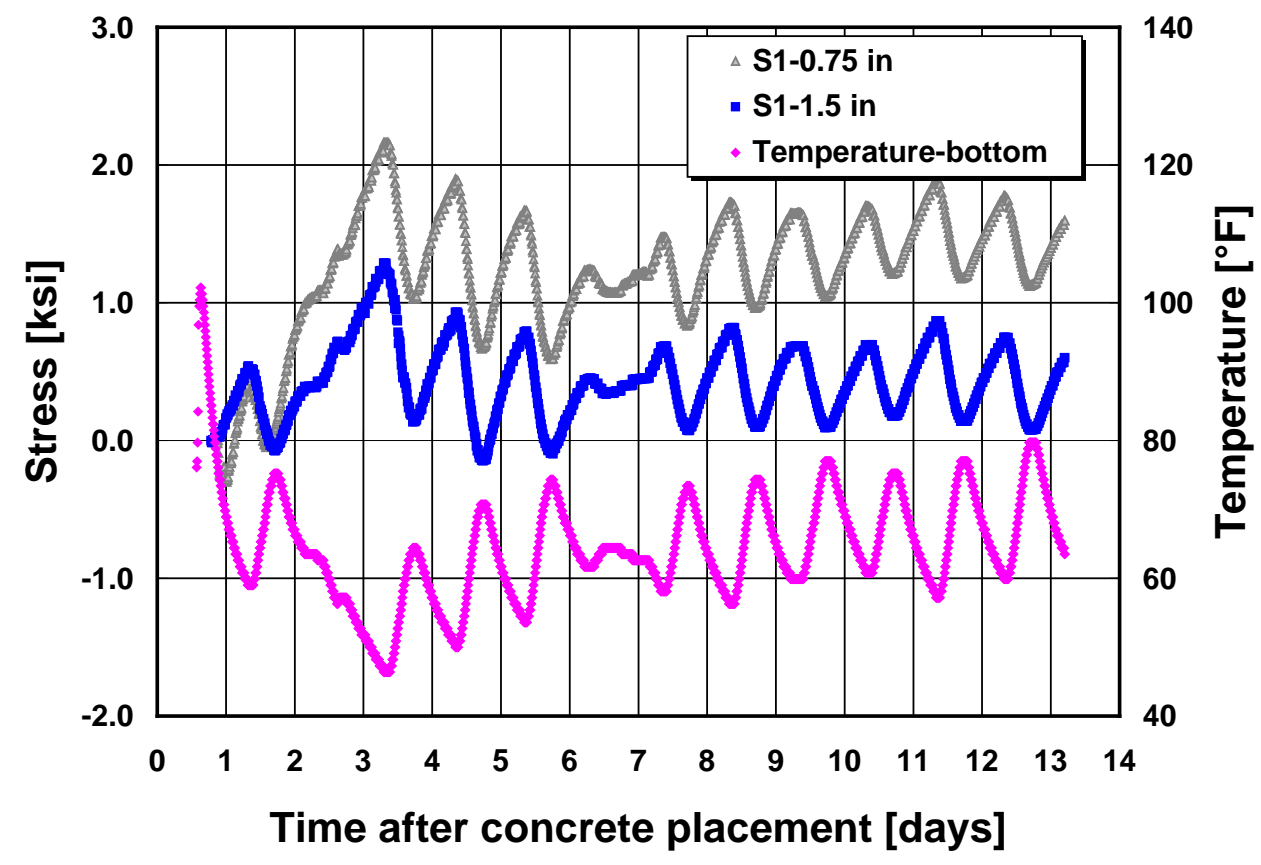

Figure 8.5: Variation of steel stress in S1 bar

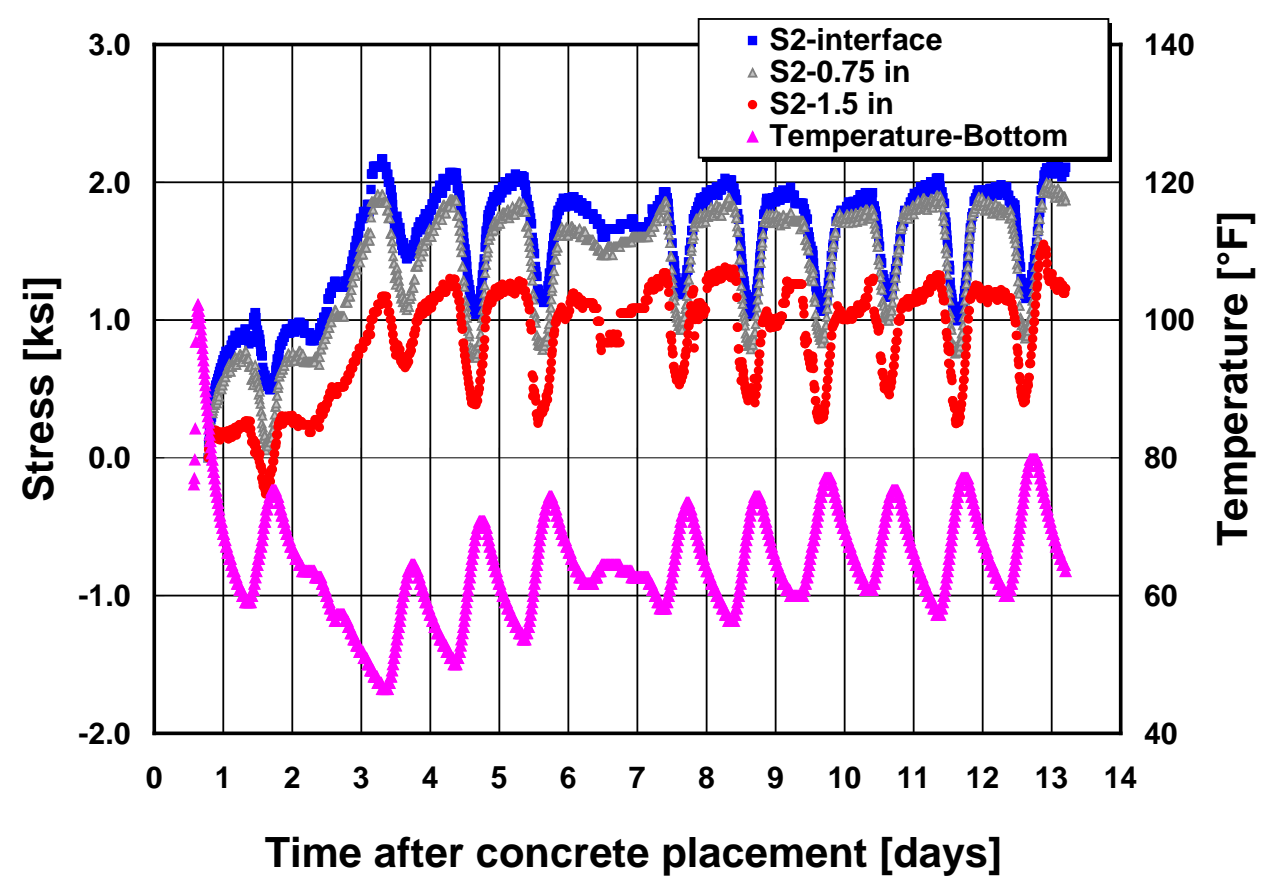

Figure 8.6: Variation of steel stress in S2 bar 


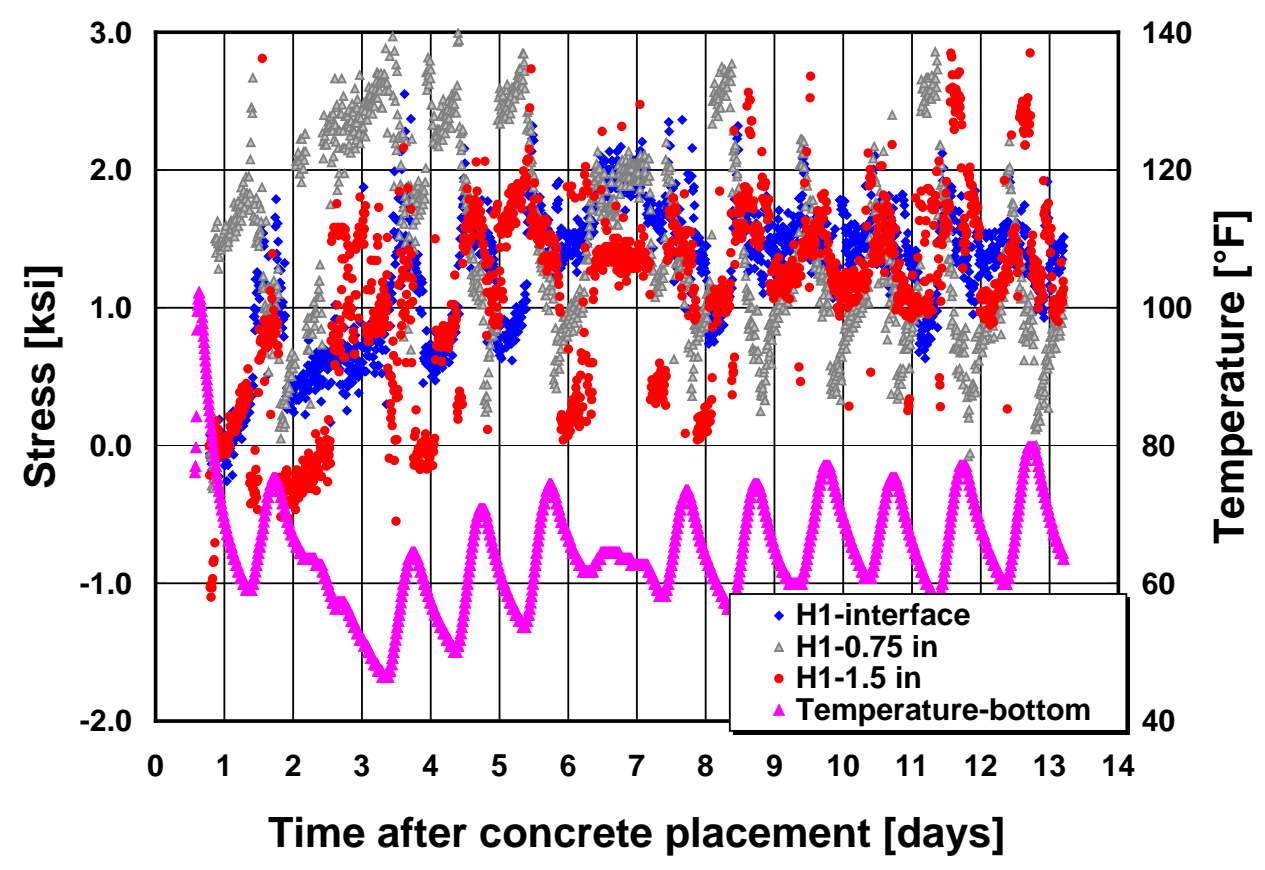

Figure 8.7: Variation of steel stress in H1 bar

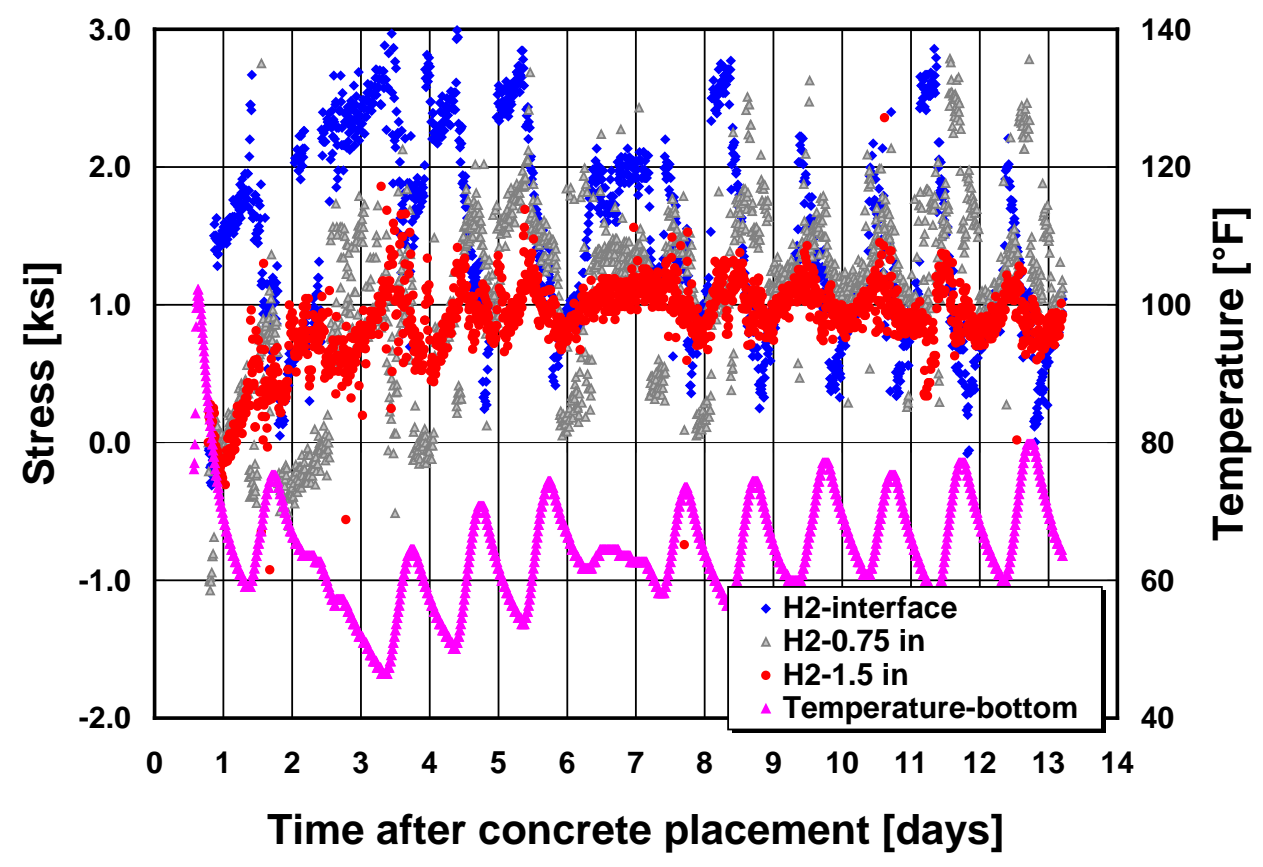

Figure 8.8: Variation of steel stress in $\mathrm{H} 2 \mathrm{bar}$ 


\section{CONCLUSIONS}

The primary objective of this study was to identify the mechanism of horizontal cracking in CRCP due to environmental loading (temperature and moisture variations). To this end, a numerical model was developed to predict the risk of horizontal cracking in CRCP. Laboratory and field testing was also conducted to evaluate the actual behavior of concrete near longitudinal steel. The measured data was used to develop and validate a numerical model for the prediction of horizontal cracking potential in CRCP. The mechanism of vertical stress development in concrete near longitudinal steel was investigated with a comprehensive numerical analysis. Based on the findings in this research, the following conclusions are made.

1. Longitudinal steel plays a significant role in the development of horizontal cracking in CRCP. Longitudinal steel restrains concrete volume changes due to temperature and moisture variations, and this restraint results in vertical stress in concrete. Tensile stresses develop at concrete near longitudinal steel because of steel restraint. The direction of principal stress is close to the vertical line. It indicates that horizontal cracking can occur in concrete near the steel. The cracks initiate from the transverse crack and propagate along the longitudinal steel.

2. Because horizontal cracks result from concrete volume changes near steel being restrained, concrete with a higher CoTE will have a greater potential for horizontal cracks in CRCP. The risk of horizontal cracking also increases with a larger concrete elastic modulus and nonlinear temperature gradient with higher degree. This is consistent with the field observations where the frequency of horizontal cracking increased in CRCP with concrete of higher CoTE and modulus of elasticity.

3. Two-mat placement of longitudinal steel reduces the potential for horizontal cracking in CRCP compared with one-mat steel placement.

4. Horizontal cracking potential will be reduced with enhanced quality control during construction such as quality curing and compliance with tolerance in vertical steel placement.

The findings above indicate that horizontal cracking potential depends on pavement design, concrete material properties and the quality of construction practices including temperature and moisture control. On the other hand, considering the significant effect of CoTE on HC development, it is more appropriate to use a different pavement type, such as jointed plain concrete pavement (JPCP or CPCD) when the only coarse aggregate type available locally has a high CoTE value. 


\section{REFERENCES}

1. Kim S., Won M., and McCullough B. F., Three-Dimensional Nonlinear Finite Element A nalysis of Continuously Reinforced Concrete Pavements, Research Report 1831-1, Cente $r$ for Transportation Research, The University of Texas at Austin, 2000

2. DIANA, release 9.1., Division of Engineering Mechanics and Information Technology, TNO Building and Construction Research, Delft, The Netherlands, 2007

3. Mohamed A. R. and Hansen W., Effect of Nonlinear Temperature Gradient on Curling S tress in Concrete Pavements, Transportation Research Record 1568, TRB, National Rese arch Council, Washington D.C., 1997, pp. 65-71

4. Ghali A. and Favre R., Concrete Structures: Stresses and Deformations, 2nd edition, E\& FN SPON, London, 1994

5. Springenschmid R (ed.), Prevention of thermal cracking in concrete at early ages, state of the art report by RILEM TC 119. E\&FN Spon, New York, 1998

6. Rots J., Computational Modeling of Concrete Fracture, Ph.D. Dissertation, Delft Univers ity, The Netherlands, 1988 



\section{APPENDIX A}

Vertical Stress Contour of Analysis Results per Factorial Experiment

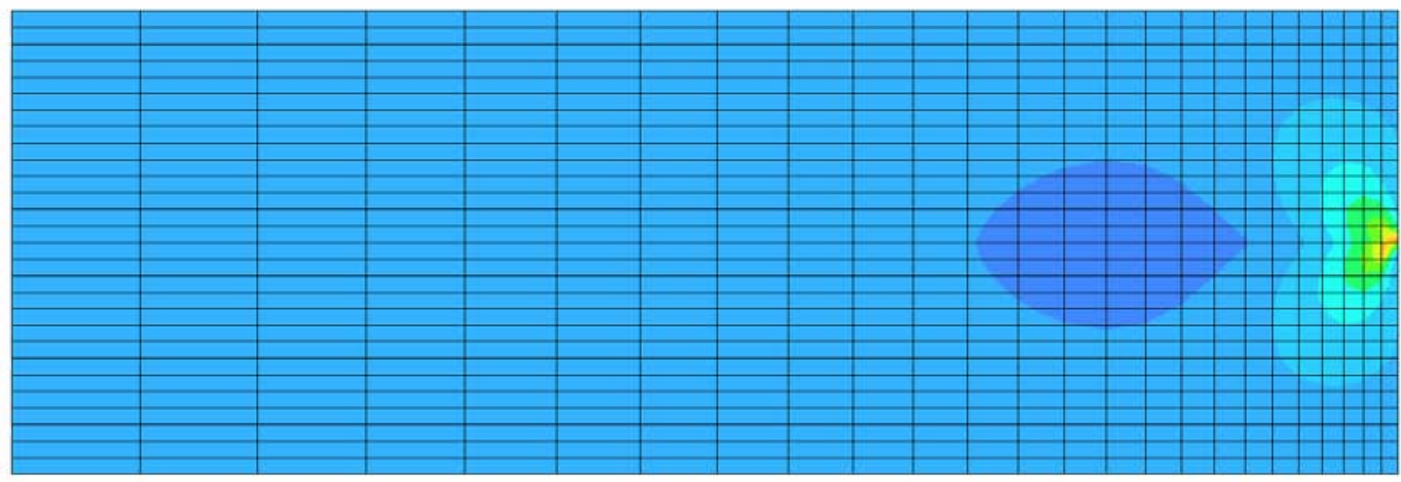

$E_{c}=4 \times 10^{6} \mathrm{psi} ; \alpha_{\mathrm{C}}=4 \times 10^{-6} /{ }^{\circ} \mathrm{F} ; 2^{\text {nd }}$ degree gradient; one-mat; steel ratio $=0.5 \%$

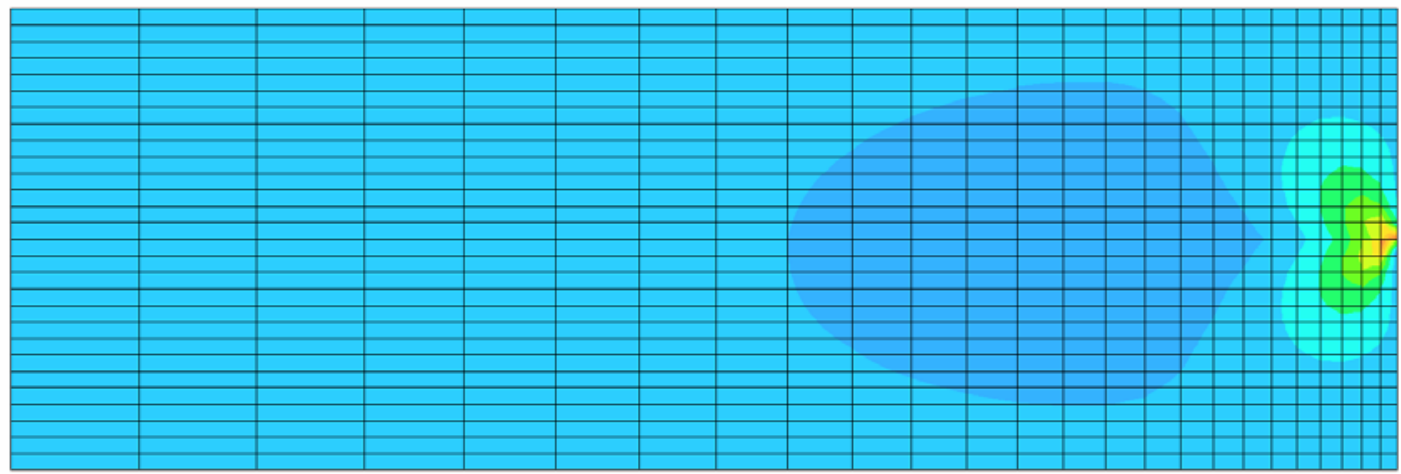

$E_{c}=6 \times 10^{6} \mathrm{psi} ; \alpha_{C}=4 \times 10^{-6} /{ }^{\circ} \mathrm{F} ; 2^{\text {nd }}$ degree gradient; one-mat; steel ratio $=0.5 \%$ 


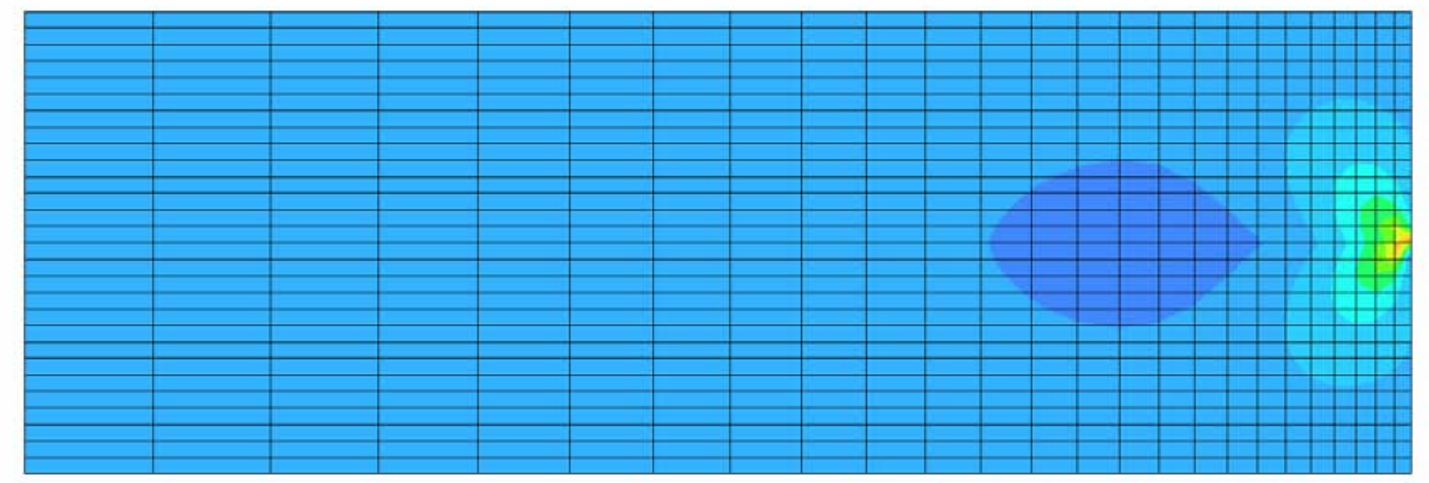

$E_{c}=4 \times 10^{6} \mathrm{psi} ; \alpha_{\mathrm{c}}=6 \times 10^{-6} /{ }^{\circ} \mathrm{F} ; 2^{\text {nd }}$ degree gradient; one-mat; steel ratio $=0.5 \%$

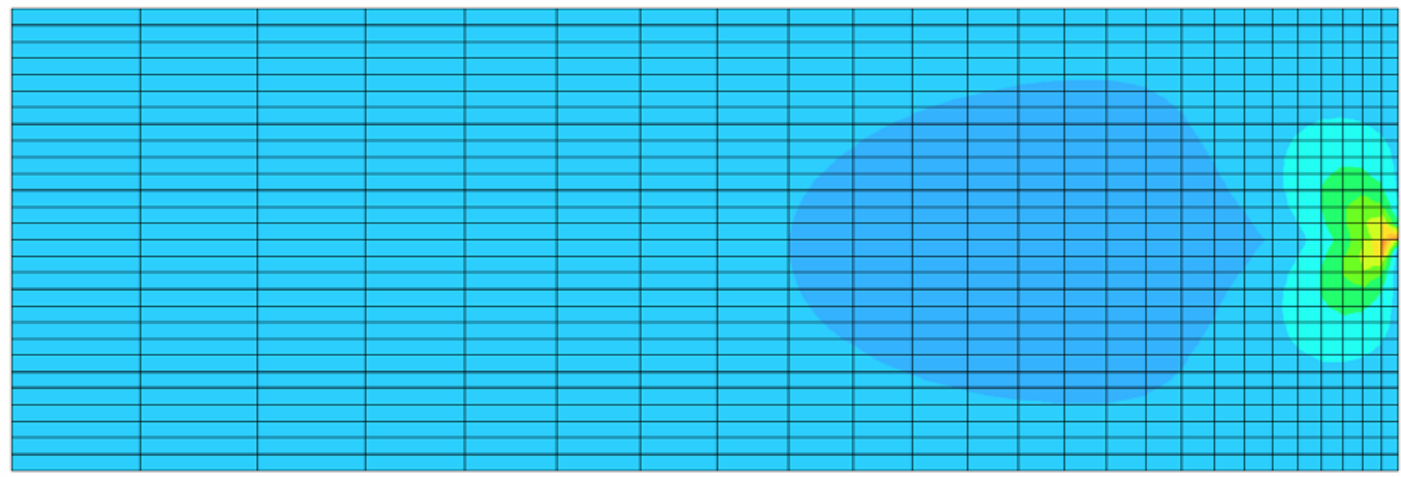

$E_{c}=6 \times 10^{6} \mathrm{psi} ; \alpha_{\mathrm{c}}=6 \times 10^{-6} /{ }^{\circ} \mathrm{F} ; 2^{\text {nd }}$ degree gradient; one-mat; steel ratio $=0.5 \%$ 


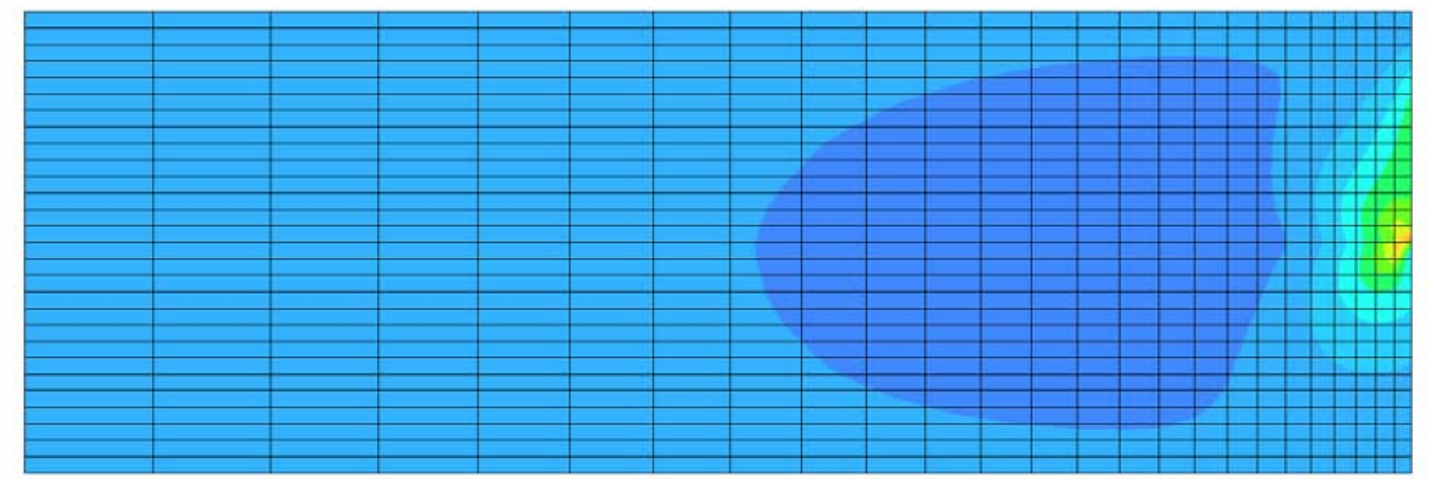

$E_{c}=4 \times 10^{6} \mathrm{psi} ; \alpha_{c}=4 \times 10^{-6} /{ }^{\circ} \mathrm{F} ; 4^{\text {th }}$ degree gradient; one-mat; steel ratio $=0.5 \%$

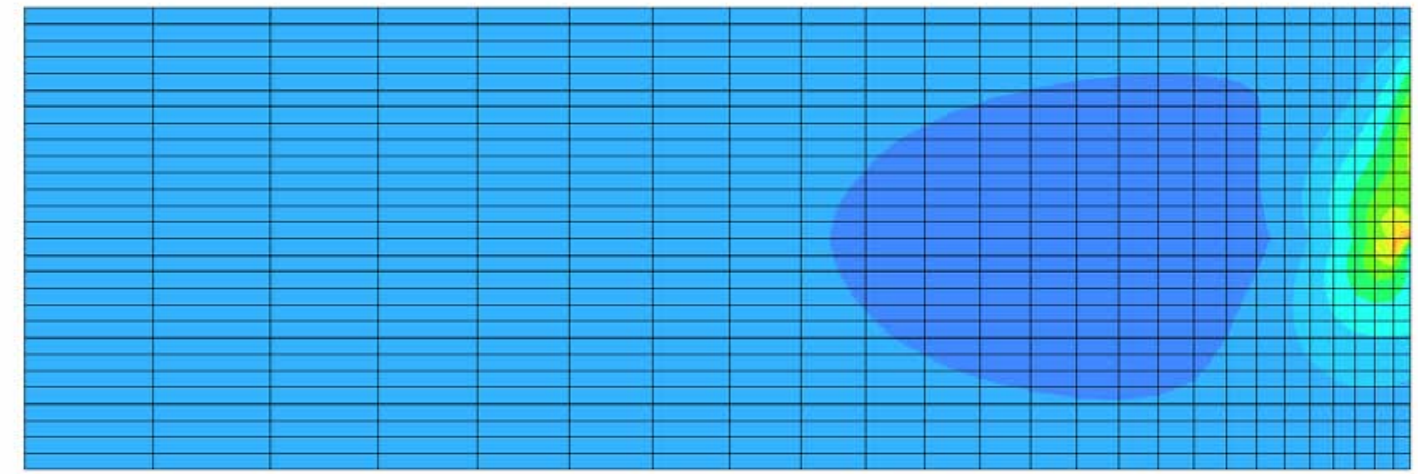

$E_{c}=6 \times 10^{6} \mathrm{psi} ; \alpha_{\mathrm{C}}=4 \times 10^{-6} /{ }^{\circ} \mathrm{F} ; 4^{\text {th }}$ degree gradient; one-mat; steel ratio $=0.5 \%$ 


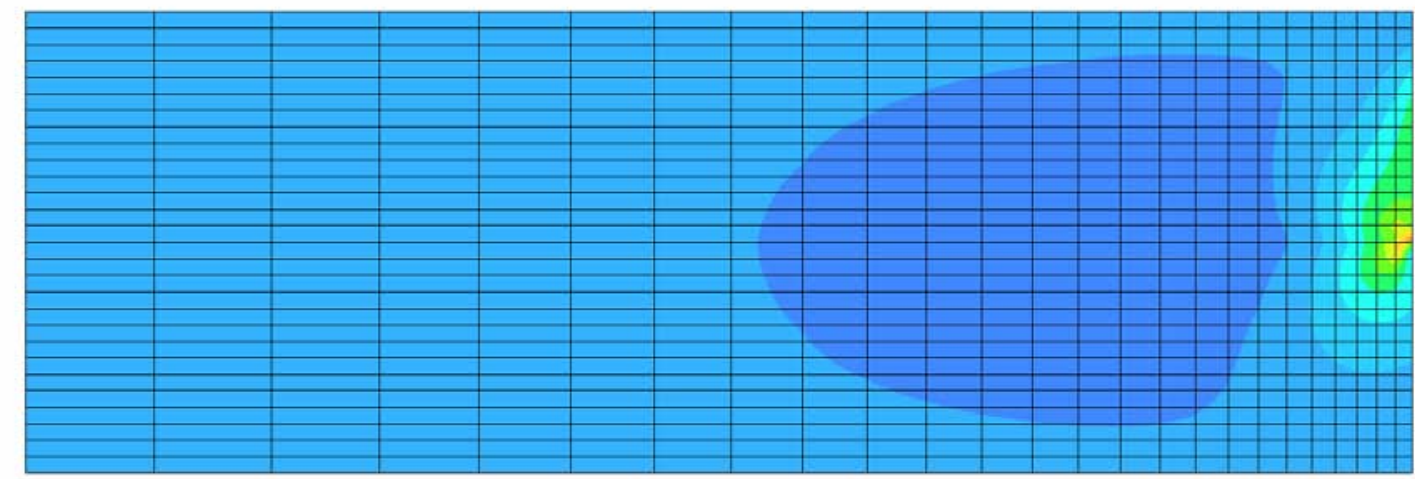

$E_{c}=4 \times 10^{6} \mathrm{psi} ; \alpha_{\mathrm{c}}=6 \times 10^{-6} /{ }^{\circ} \mathrm{F} ; 4^{\text {th }}$ degree gradient; one-mat; steel ratio $=0.5 \%$

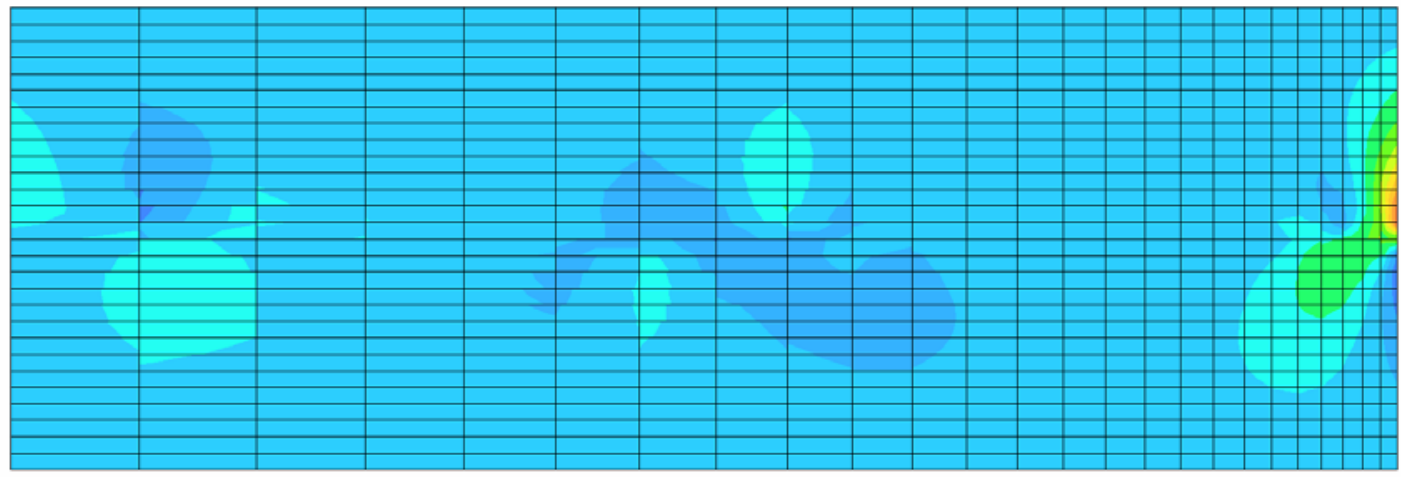

$E_{c}=6 \times 10^{6} \mathrm{psi} ; \alpha_{\mathrm{c}}=6 \times 10^{-6} /{ }^{\circ} \mathrm{F} ; 4^{\text {th }}$ degree gradient; one-mat; steel ratio $=0.5 \%$ 


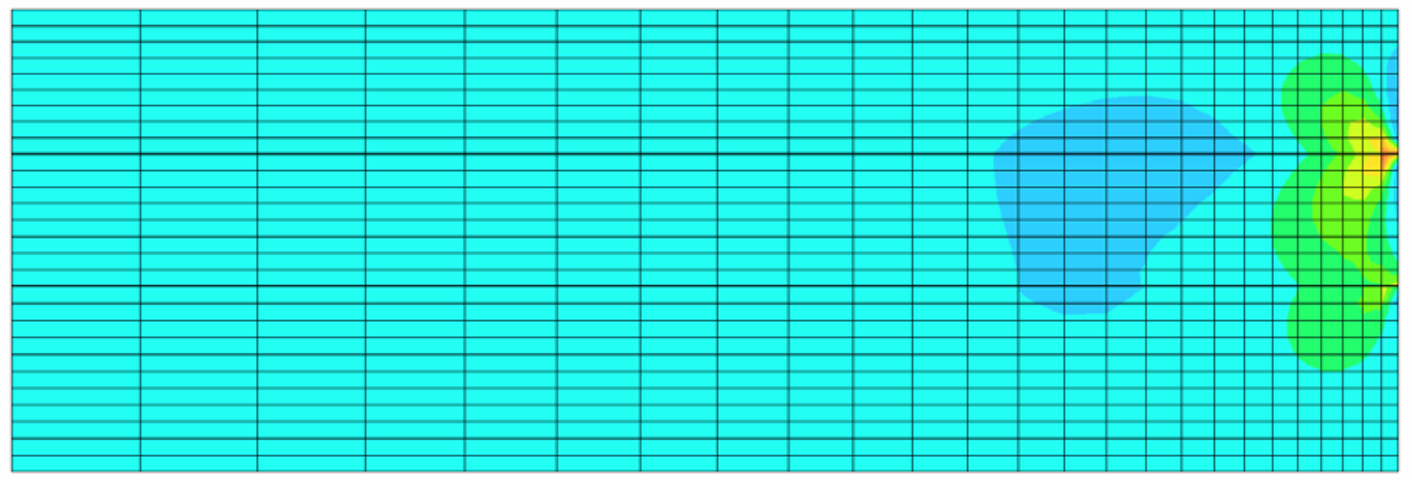

$\stackrel{i}{i=x}$

$$
E_{c}=4 \times 10^{6} \mathrm{psi} ; \alpha_{\mathrm{c}}=4 \times 10^{-6} /{ }^{\circ} \mathrm{F} ; 2^{\text {nd }} \text { degree gradient; two-mat; steel ratio }=0.5 \%
$$

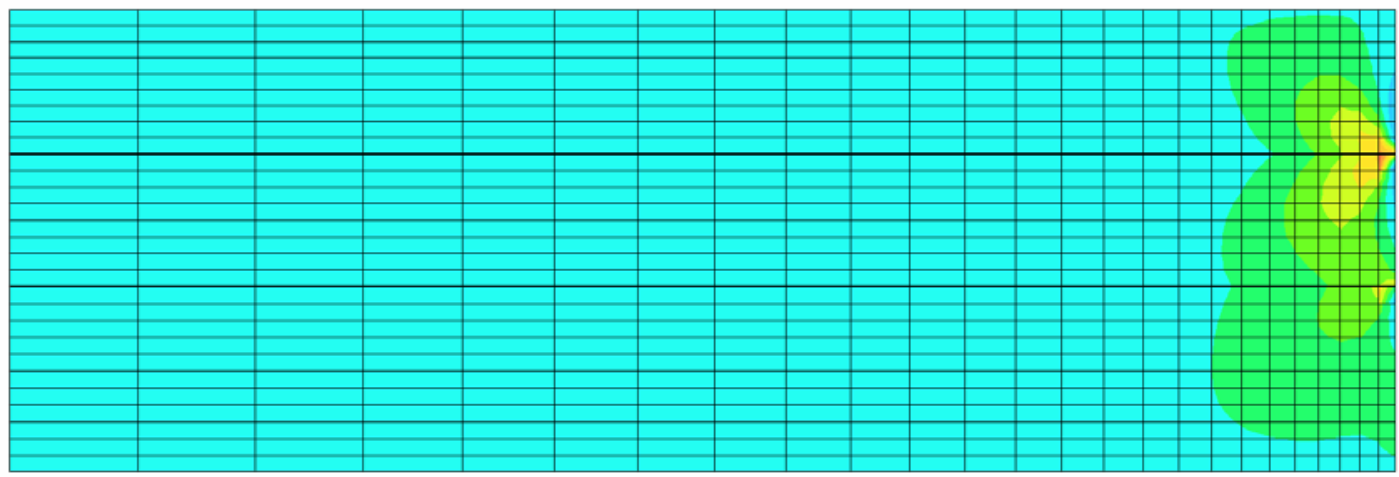

$E_{c}=6 \times 10^{6} \mathrm{psi} ; \alpha_{c}=4 \times 10^{-6} /{ }^{\circ} \mathrm{F} ; 2^{\text {nd }}$ degree gradient; two-mat; steel ratio $=0.5 \%$ 


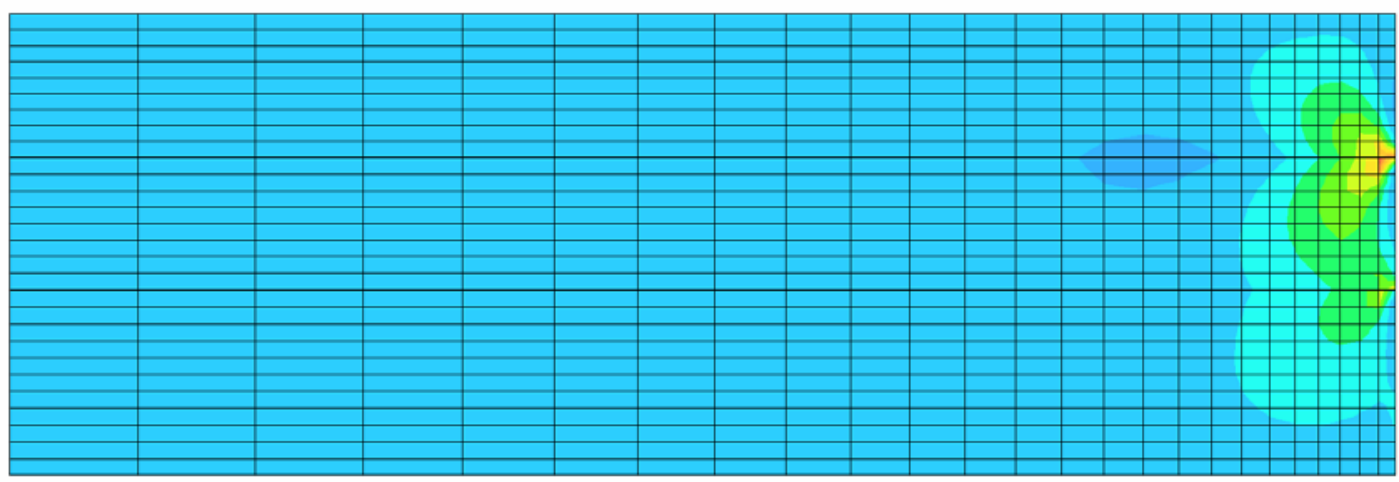

$E_{c}=4 \times 10^{6} \mathrm{psi} ; \alpha_{\mathrm{c}}=6 \times 10^{-6} /{ }^{\circ} \mathrm{F} ; 2^{\text {nd }}$ degree gradient; two-mat; steel ratio $=0.5 \%$

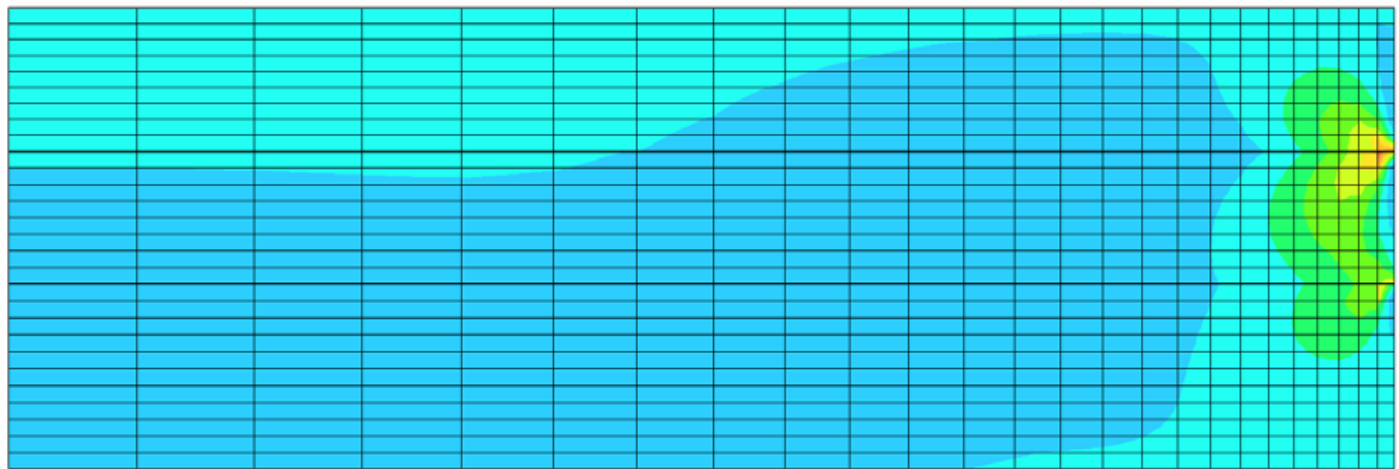

$E_{c}=6 \times 10^{6} \mathrm{psi} ; \alpha_{c}=6 \times 10^{-6} /{ }^{\circ} \mathrm{F} ; 2^{\text {nd }}$ degree gradient; two-mat; steel ratio $=0.5 \%$ 


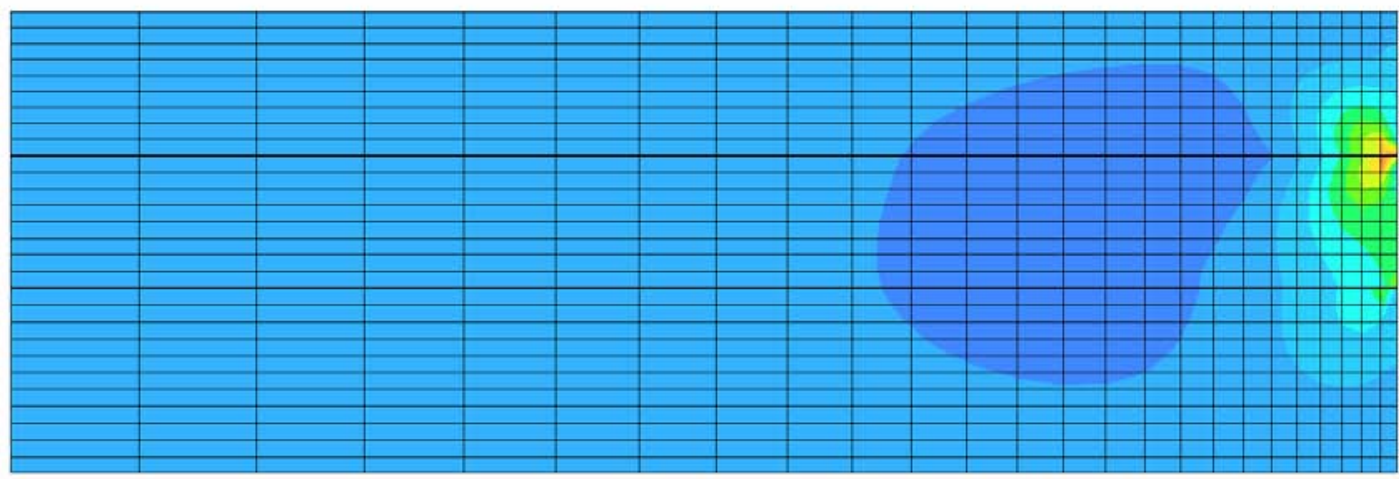

$E_{c}=4 \times 10^{6} \mathrm{psi} ; \alpha_{c}=4 \times 10^{-6} /{ }^{\circ} \mathrm{F} ; 4^{\text {th }}$ degree gradient; two-mat; steel ratio $=0.5 \%$

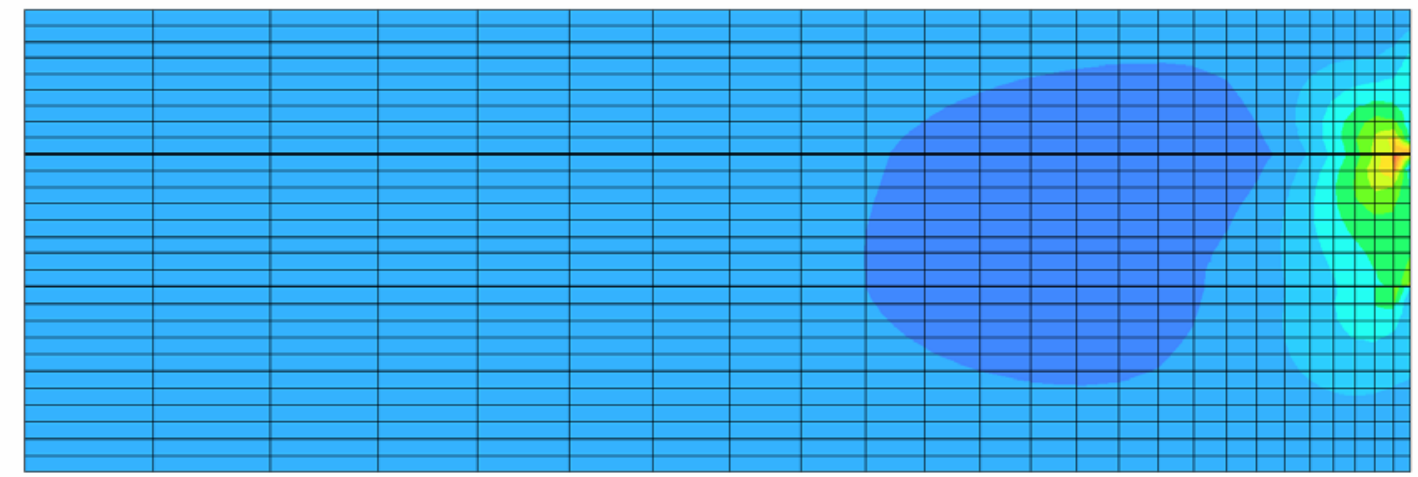

$E_{c}=6 \times 10^{6} \mathrm{psi} ; \alpha_{\mathrm{c}}=4 \times 10^{-6} /{ }^{\circ} \mathrm{F} ; 4^{\text {th }}$ degree gradient; two-mat; steel ratio $=0.5 \%$ 


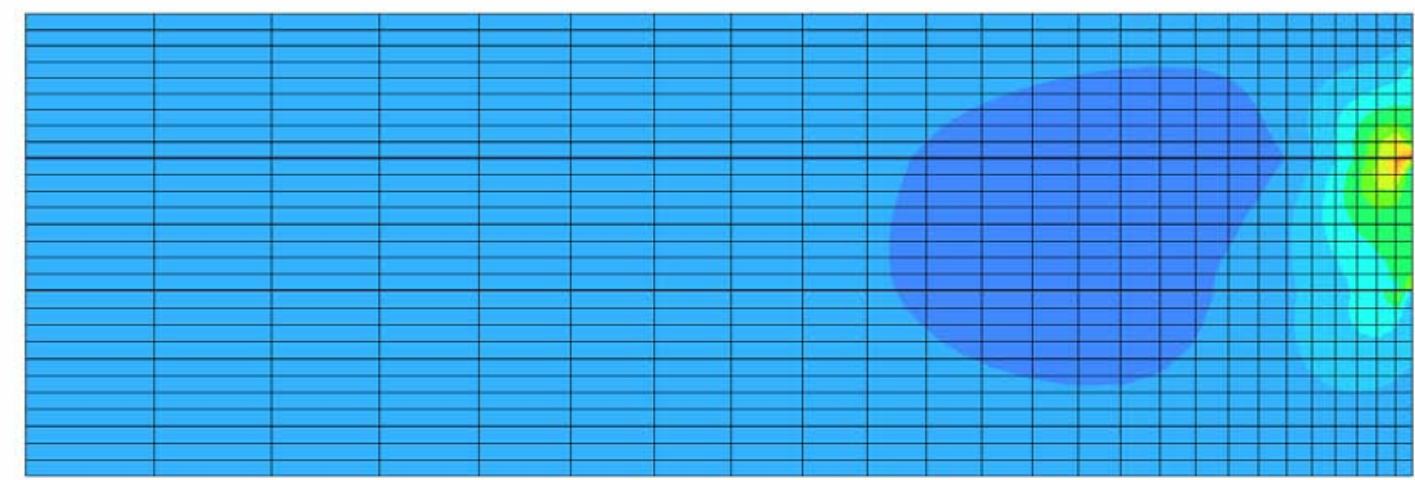

$E_{c}=4 \times 10^{6} \mathrm{psi} ; \alpha_{\mathrm{c}}=6 \times 10^{-6} /{ }^{\circ} \mathrm{F} ; 4^{\text {th }}$ degree gradient; two-mat; steel ratio $=0.5 \%$

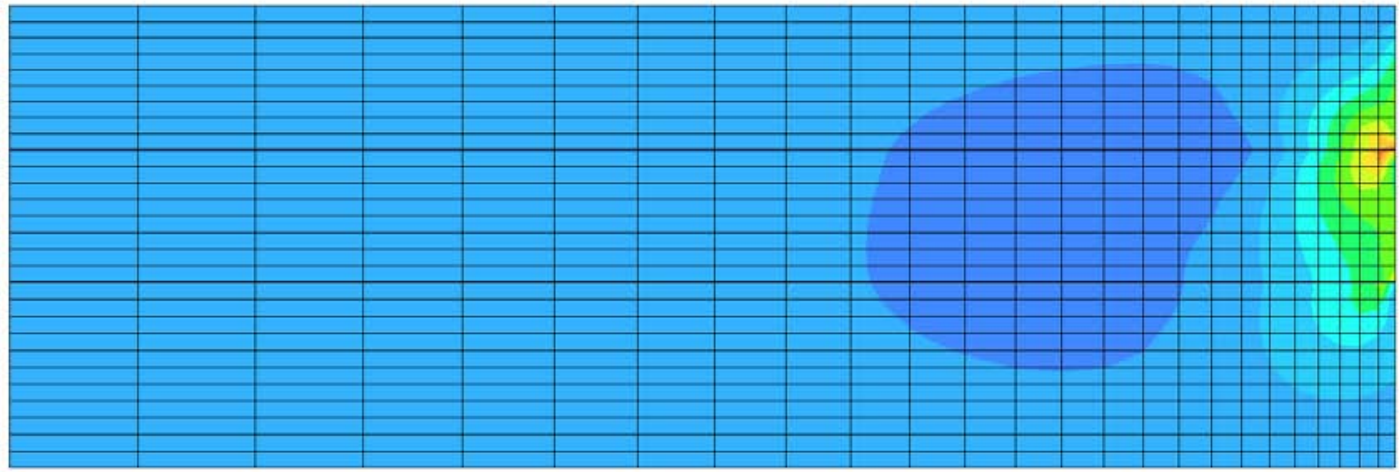

$E_{c}=6 \times 10^{6} \mathrm{psi} ; \alpha_{\mathrm{C}}=6 \times 10^{-6} /{ }^{\circ} \mathrm{F} ; 4^{\text {th }}$ degree gradient; two-mat; steel ratio $=0.5 \%$ 


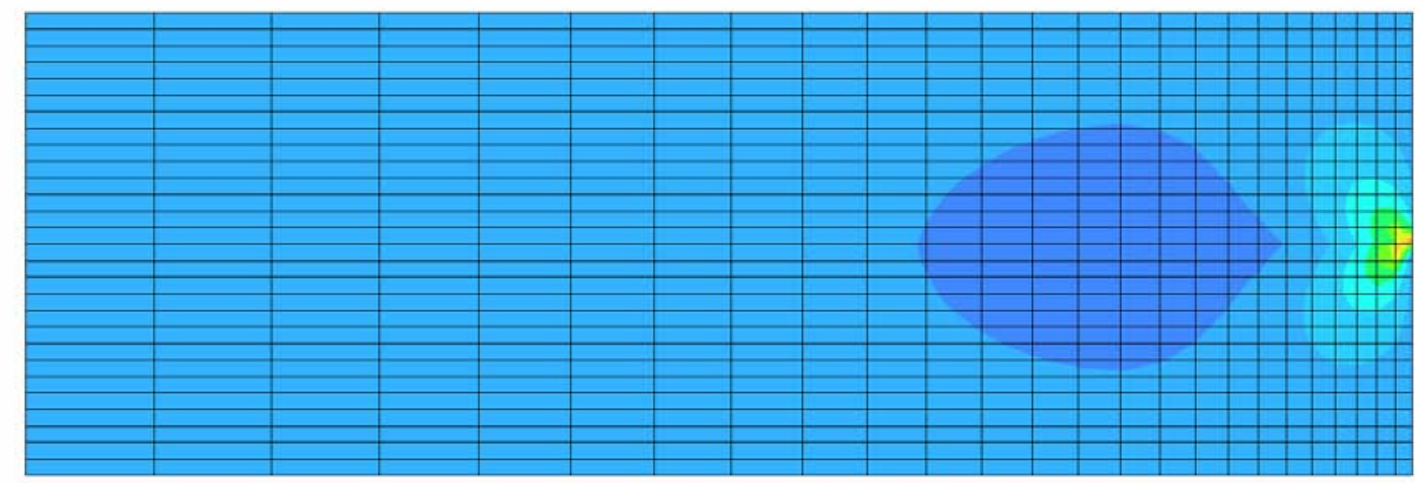

$E_{c}=4 \times 10^{6} \mathrm{psi} ; \alpha_{\mathrm{c}}=4 \times 10^{-6} /{ }^{\circ} \mathrm{F} ; 2^{\text {nd }}$ degree gradient; one-mat; steel ratio $=0.6 \%$

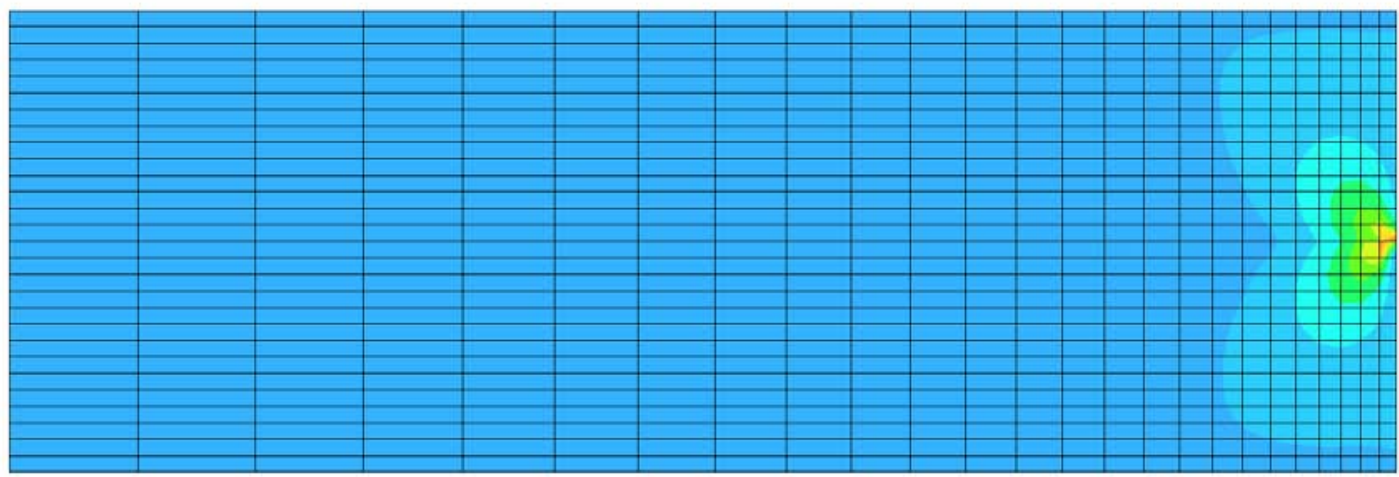

$E_{c}=6 \times 10^{6} \mathrm{psi} ; \alpha_{\mathrm{C}}=4 \times 10^{-6} /{ }^{\circ} \mathrm{F} ; 2^{\text {nd }}$ degree gradient; one-mat; steel ratio $=0.6 \%$ 


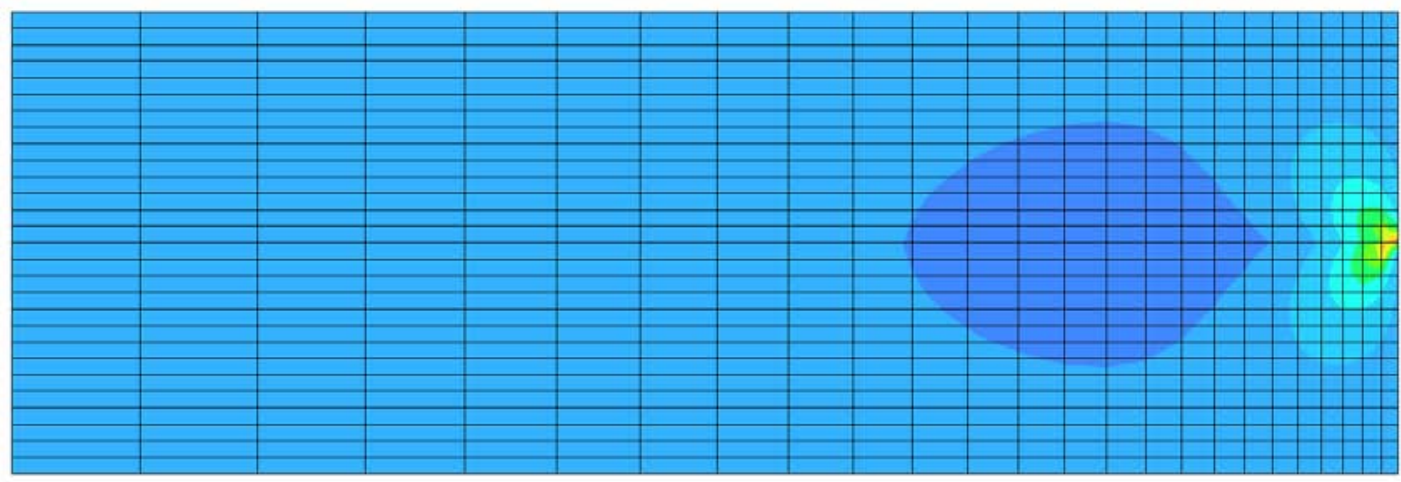

$E_{c}=4 \times 10^{6} \mathrm{psi} ; \alpha_{\mathrm{c}}=6 \times 10^{-6} /{ }^{\circ} \mathrm{F} ; 2^{\text {nd }}$ degree gradient; one-mat; steel ratio $=0.6 \%$

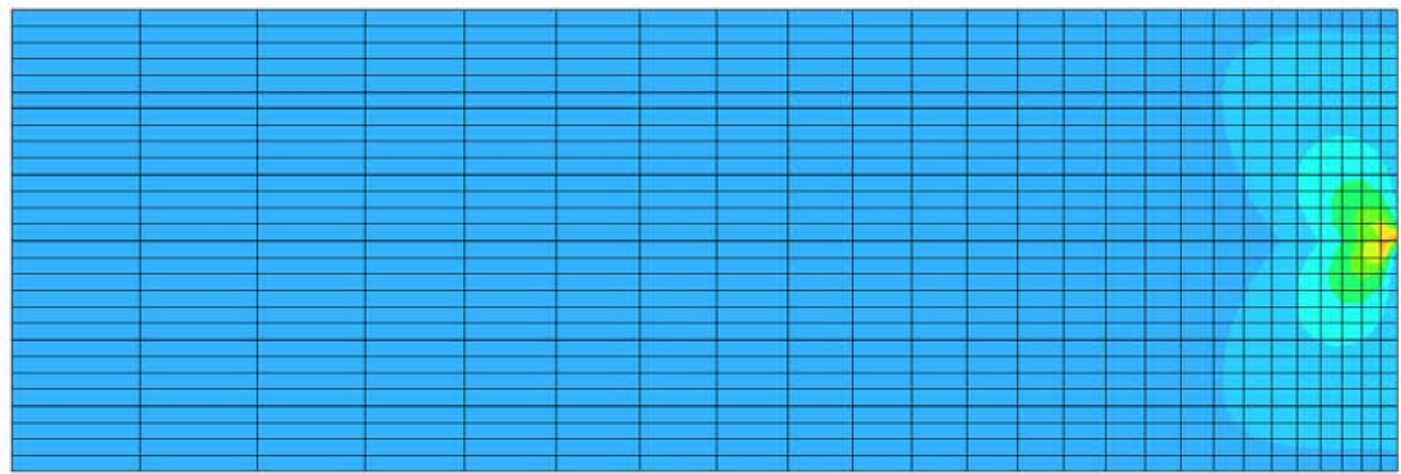

$E_{c}=6 \times 10^{6} \mathrm{psi} ; \alpha_{c}=6 \times 10^{-6} /{ }^{\circ} \mathrm{F} ; 2^{\text {nd }}$ degree gradient; one-mat; steel ratio $=0.6 \%$ 


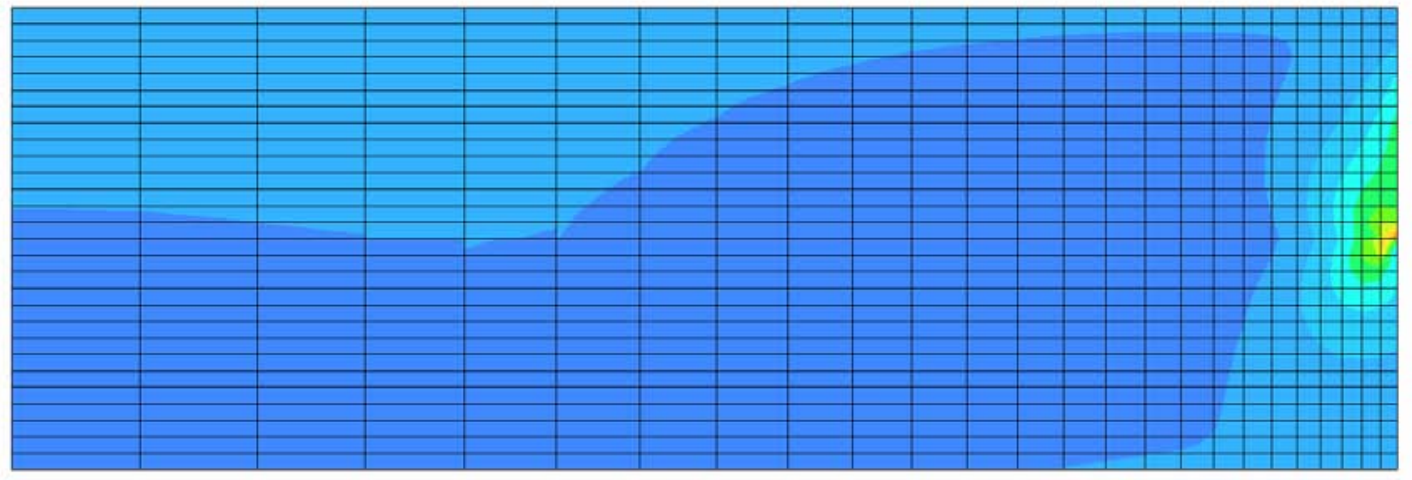

$E_{c}=4 \times 10^{6} \mathrm{psi} ; \alpha_{\mathrm{C}}=4 \times 10^{-6} /{ }^{\circ} \mathrm{F} ; 4^{\text {th }}$ degree gradient; one-mat; steel ratio $=0.6 \%$

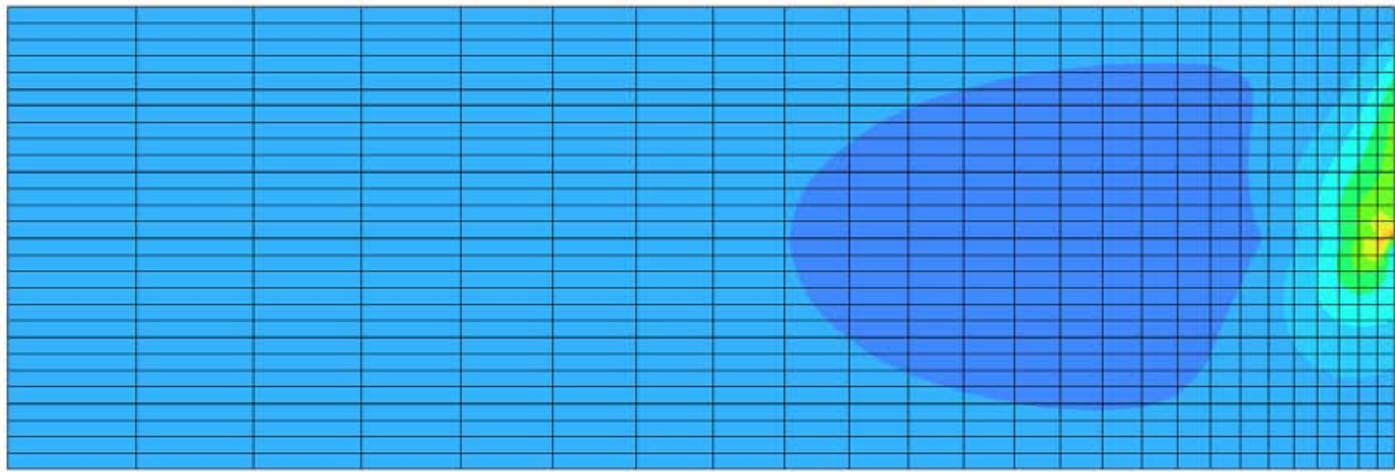

$E_{c}=6 \times 10^{6} \mathrm{psi} ; \alpha_{\mathrm{c}}=4 \times 10^{-6} /{ }^{\circ} \mathrm{F} ; 4^{\text {th }}$ degree gradient; one-mat; steel ratio $=0.6 \%$ 


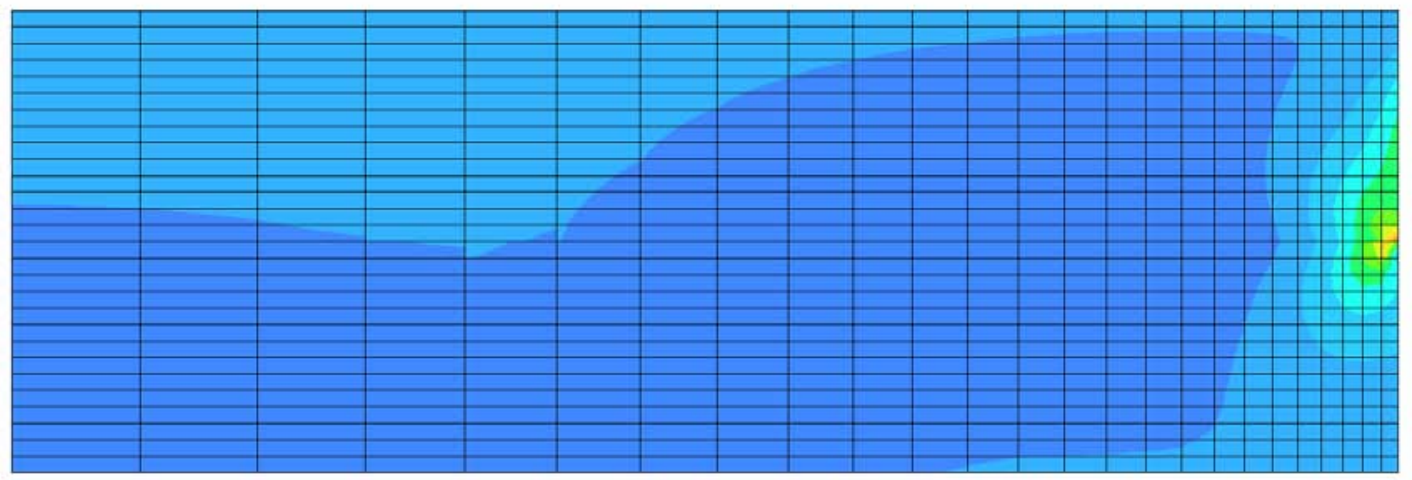

$E_{c}=4 \times 10^{6} \mathrm{psi} ; \alpha_{\mathrm{C}}=6 \times 10^{-6} /{ }^{\circ} \mathrm{F} ; 4^{\text {th }}$ degree gradient; one-mat; steel ratio $=0.6 \%$

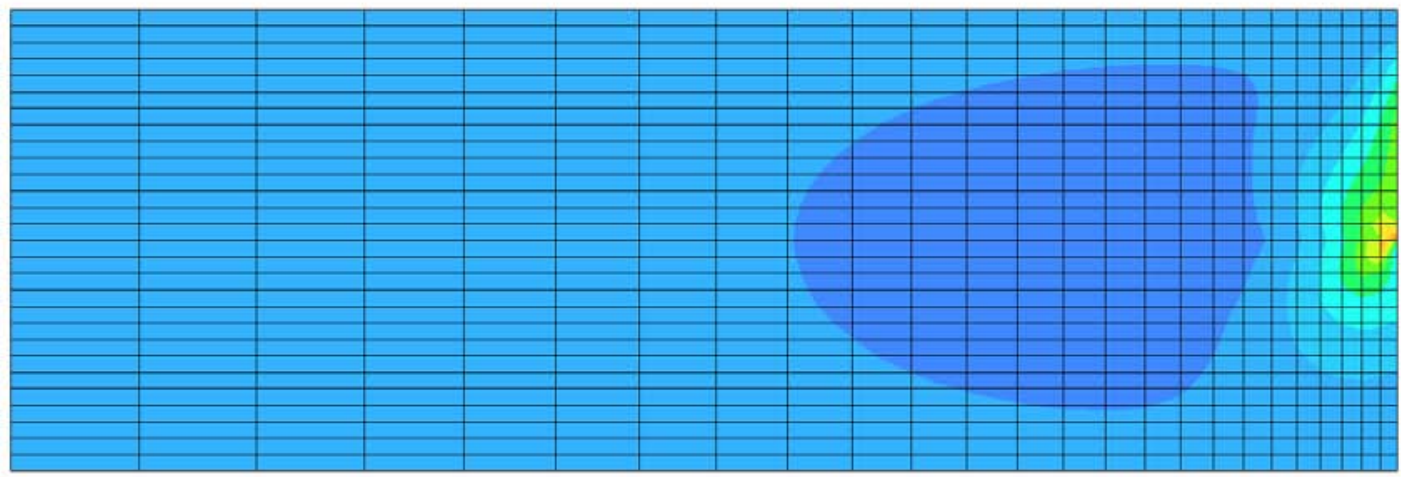

$E_{c}=6 \times 10^{6} \mathrm{psi} ; \alpha_{\mathrm{C}}=6 \times 10^{-6} /{ }^{\circ} \mathrm{F} ; 4^{\text {th }}$ degree gradient; one-mat; steel ratio $=0.6 \%$ 


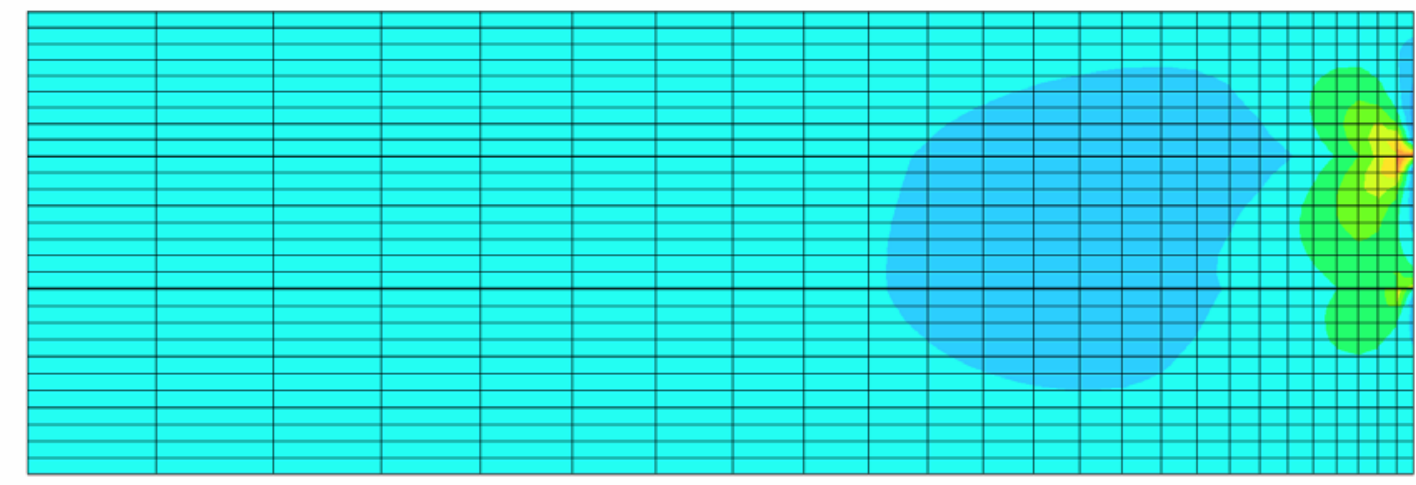

$E_{c}=4 \times 10^{6} \mathrm{psi} ; \alpha_{\mathrm{C}}=4 \times 10^{-6} /{ }^{\circ} \mathrm{F} ; 2^{\text {nd }}$ degree gradient; two-mat; steel ratio $=0.6 \%$

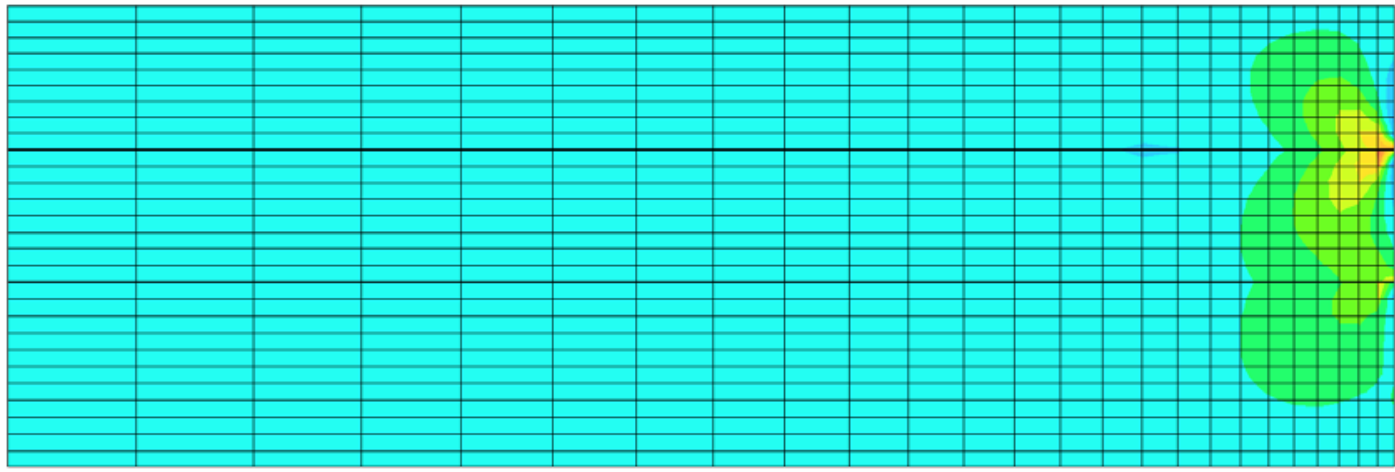

$E_{c}=6 \times 10^{6} \mathrm{psi} ; \alpha_{c}=4 \times 10^{-6} /{ }^{\circ} \mathrm{F} ; 2^{\text {nd }}$ degree gradient; two-mat; steel ratio $=0.6 \%$ 


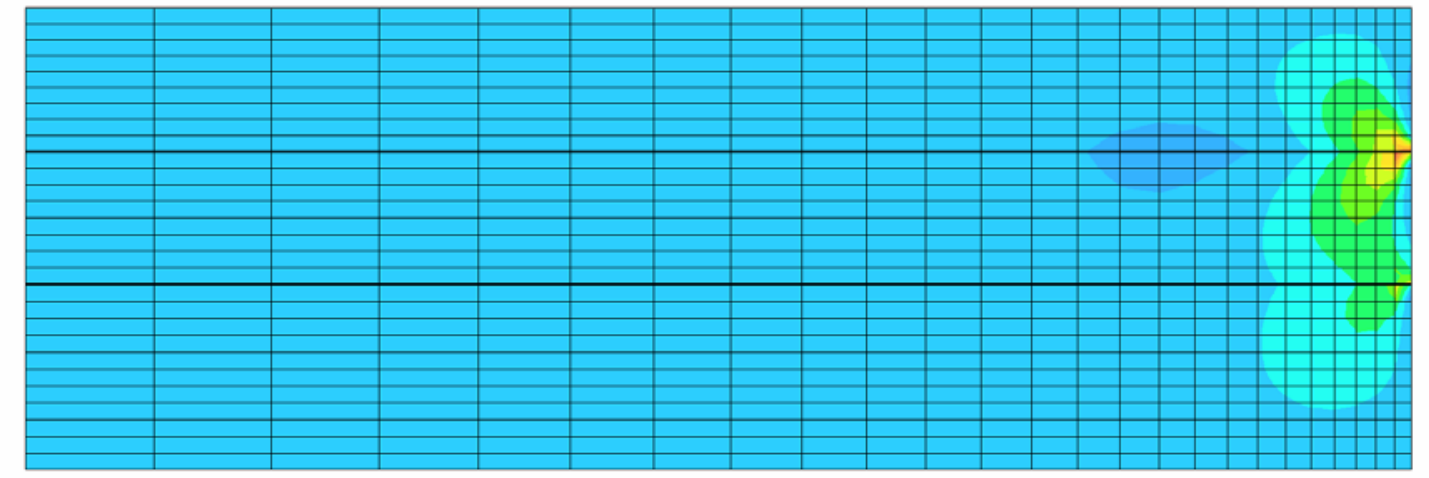

$E_{c}=4 \times 10^{6} \mathrm{psi} ; \alpha_{\mathrm{c}}=6 \times 10^{-6} /{ }^{\circ} \mathrm{F} ; 2^{\text {nd }}$ degree gradient; two-mat; steel ratio $=0.6 \%$

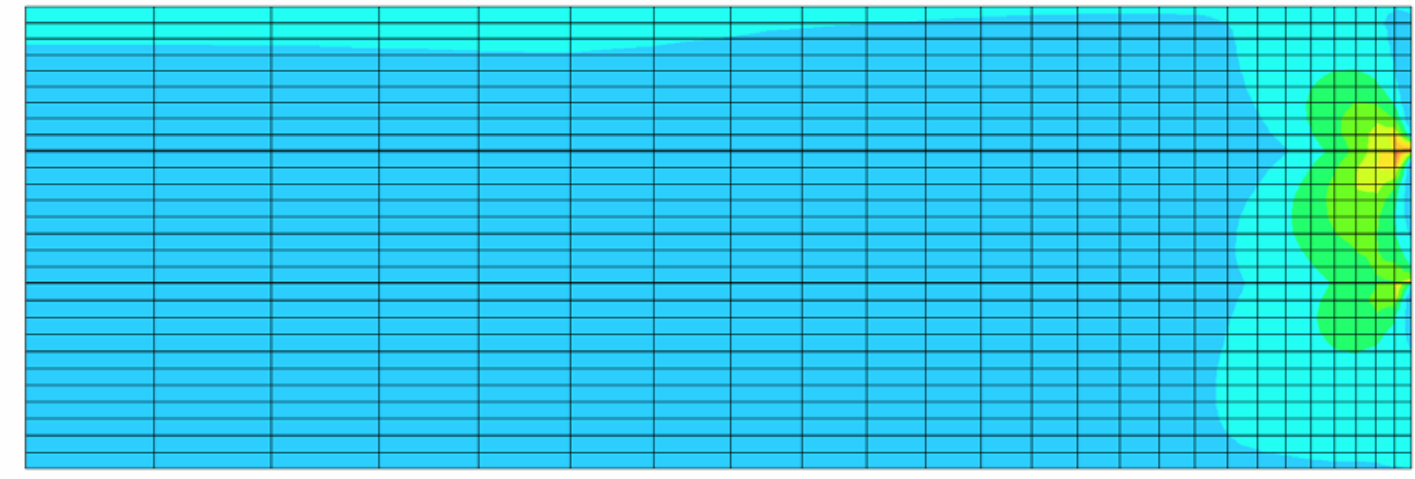

$E_{c}=6 \times 10^{6} \mathrm{psi} ; \alpha_{\mathrm{c}}=6 \times 10^{-6} /{ }^{\circ} \mathrm{F} ; 2^{\text {nd }}$ degree gradient; two-mat; steel ratio $=0.6 \%$ 


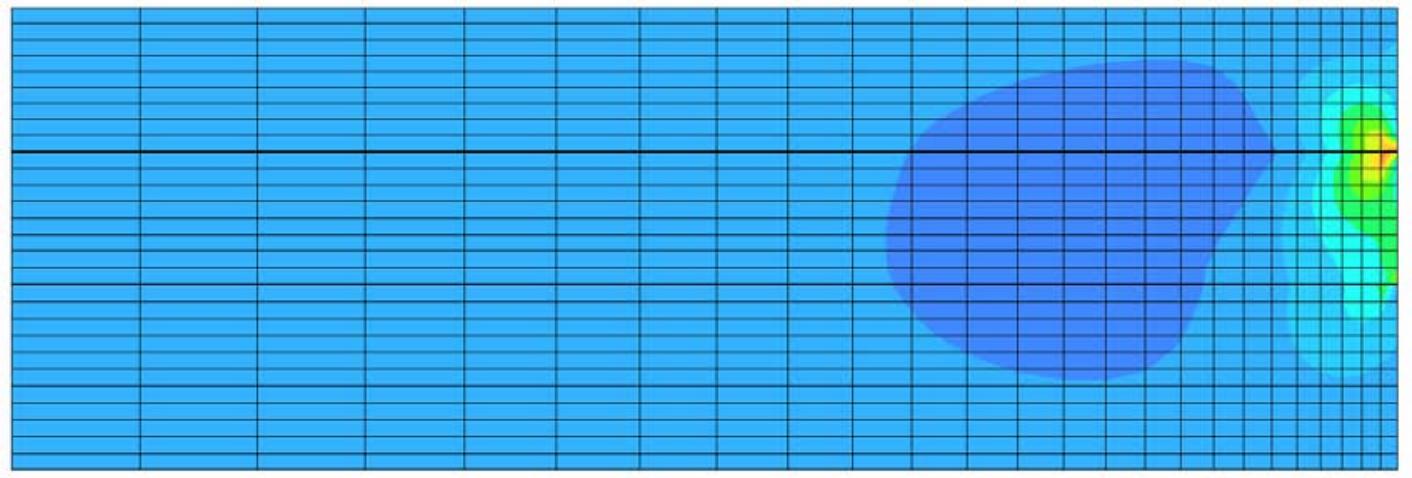

$E_{c}=4 \times 10^{6} \mathrm{psi} ; \alpha_{\mathrm{C}}=4 \times 10^{-6} /{ }^{\circ} \mathrm{F} ; 4^{\text {th }}$ degree gradient; two-mat; steel ratio $=0.6 \%$

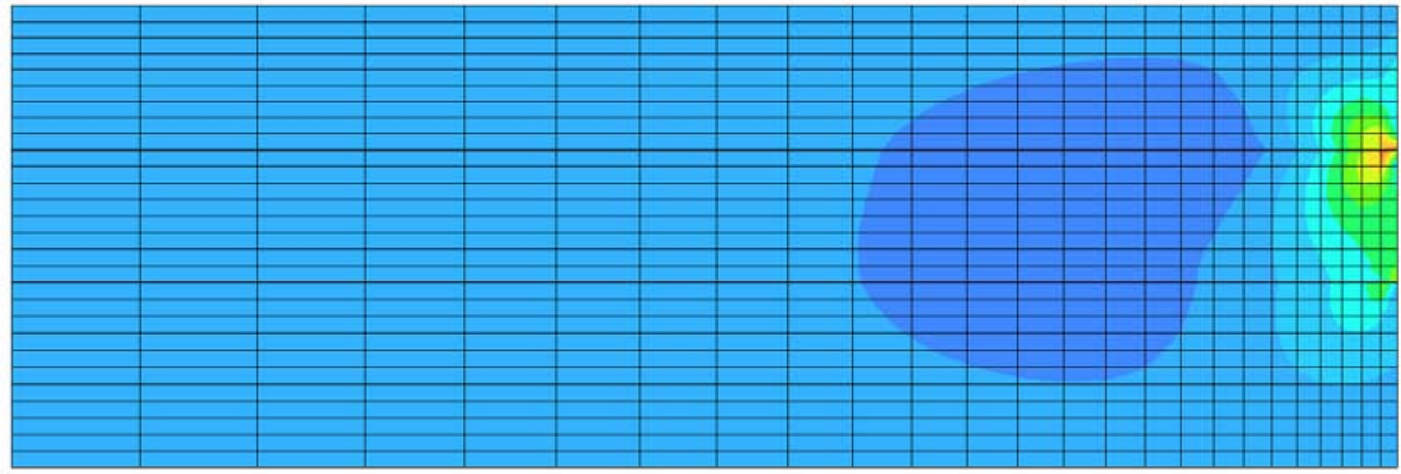

$E_{c}=6 \times 10^{6} \mathrm{psi} ; \alpha_{\mathrm{c}}=4 \times 10^{-6} /{ }^{\circ} \mathrm{F} ; 4^{\text {th }}$ degree gradient; two-mat; steel ratio $=0.6 \%$ 


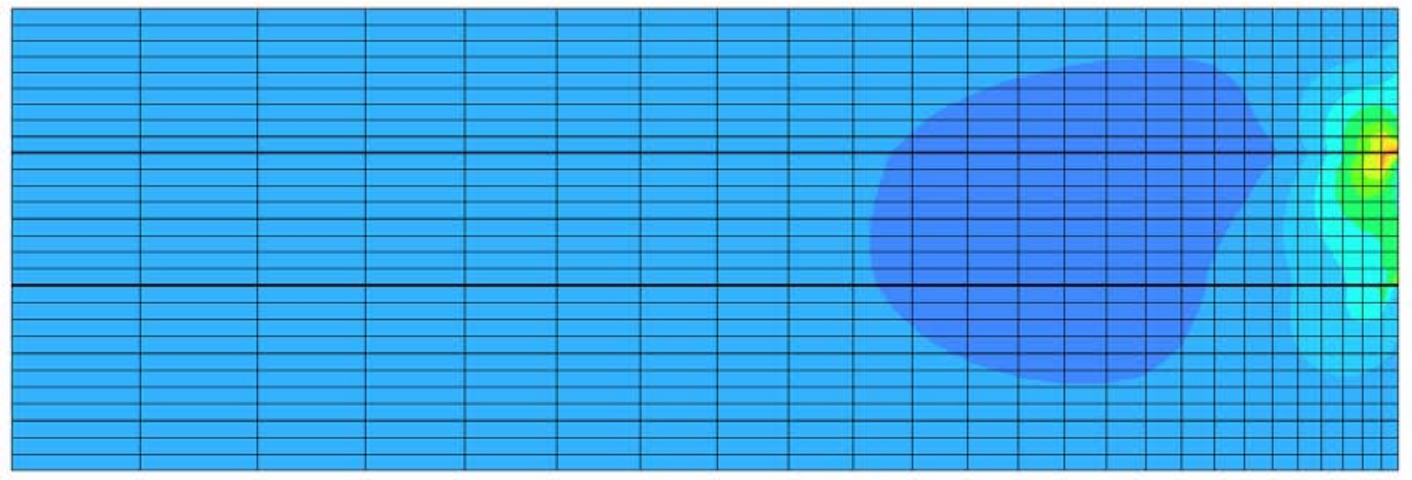

$E_{c}=4 \times 10^{6} \mathrm{psi} ; \alpha_{\mathrm{C}}=6 \times 10^{-6} /{ }^{\circ} \mathrm{F} ; 4^{\text {th }}$ degree gradient; two-mat; steel ratio $=0.6 \%$

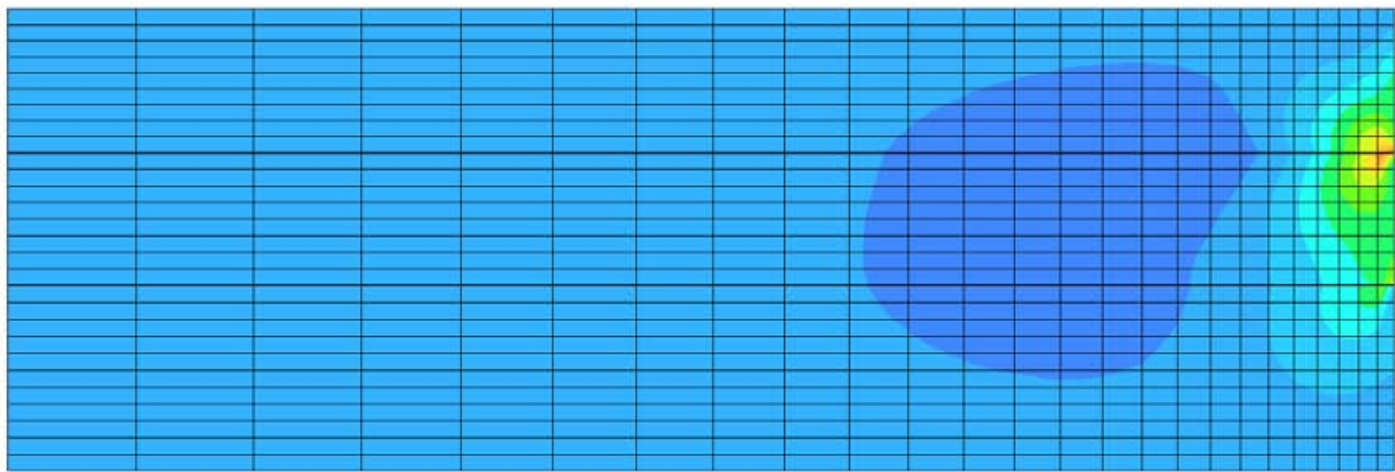

$E_{c}=6 \times 10^{6} \mathrm{psi} ; \alpha_{\mathrm{c}}=6 \times 10^{-6} /{ }^{\circ} \mathrm{F} ; 4^{\text {th }}$ degree gradient; two-mat; steel ratio $=0.6 \%$ 


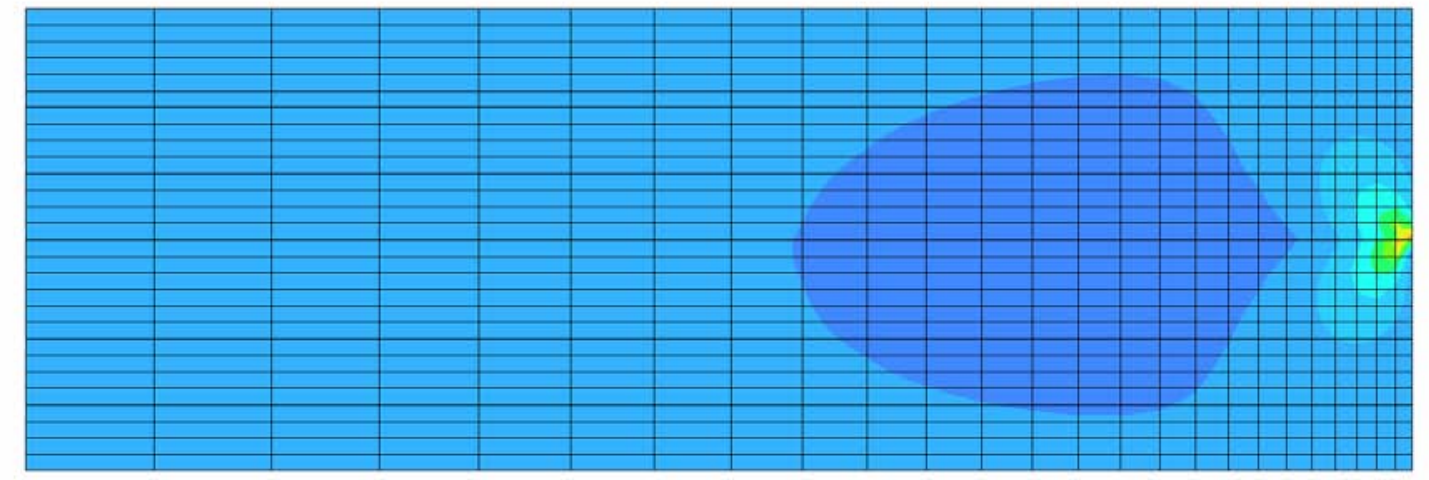

$E_{c}=4 \times 10^{6} \mathrm{psi} ; \alpha_{\mathrm{C}}=4 \times 10^{-6} /{ }^{\circ} \mathrm{F} ; 2^{\text {nd }}$ degree gradient; one-mat; steel ratio $=0.7 \%$

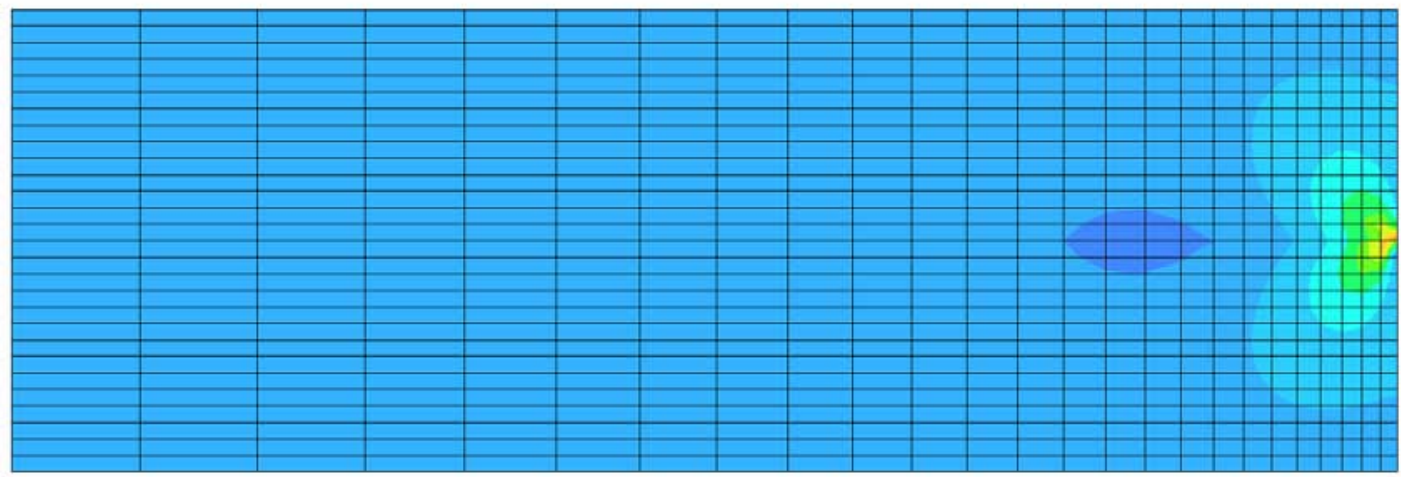

$E_{c}=6 \times 10^{6} \mathrm{psi} ; \alpha_{c}=4 \times 10^{-6} /{ }^{\circ} \mathrm{F} ; 2^{\text {nd }}$ degree gradient; one-mat; steel ratio $=0.7 \%$ 


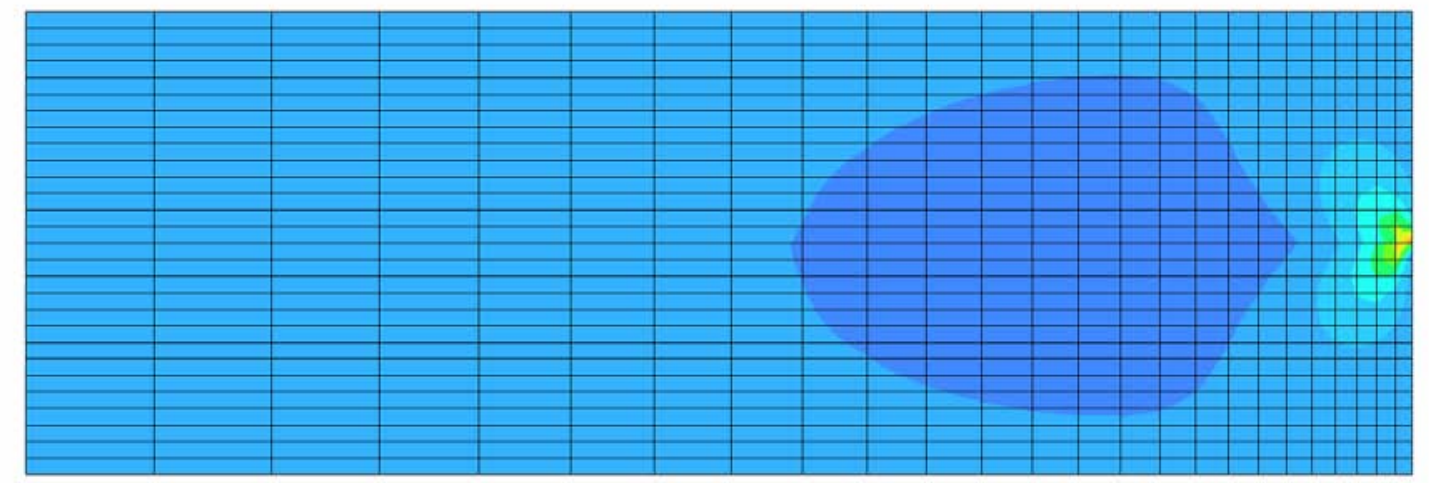

$E_{c}=4 \times 10^{6} \mathrm{psi} ; \alpha_{c}=6 \times 10^{-6} /{ }^{\circ} \mathrm{F} ; 2^{\text {nd }}$ degree gradient; one-mat; steel ratio $=0.7 \%$

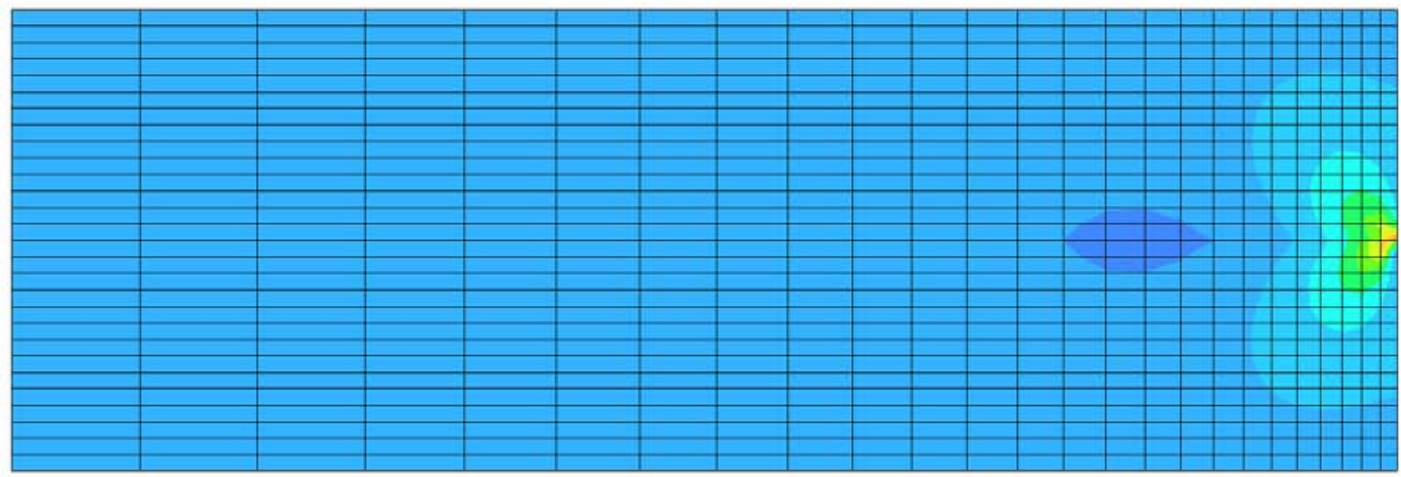

$E_{c}=6 \times 10^{6} \mathrm{psi} ; \alpha_{\mathrm{C}}=6 \times 10^{-6} /{ }^{\circ} \mathrm{F} ; 2^{\mathrm{nd}}$ degree gradient; one-mat; steel ratio $=0.7 \%$ 


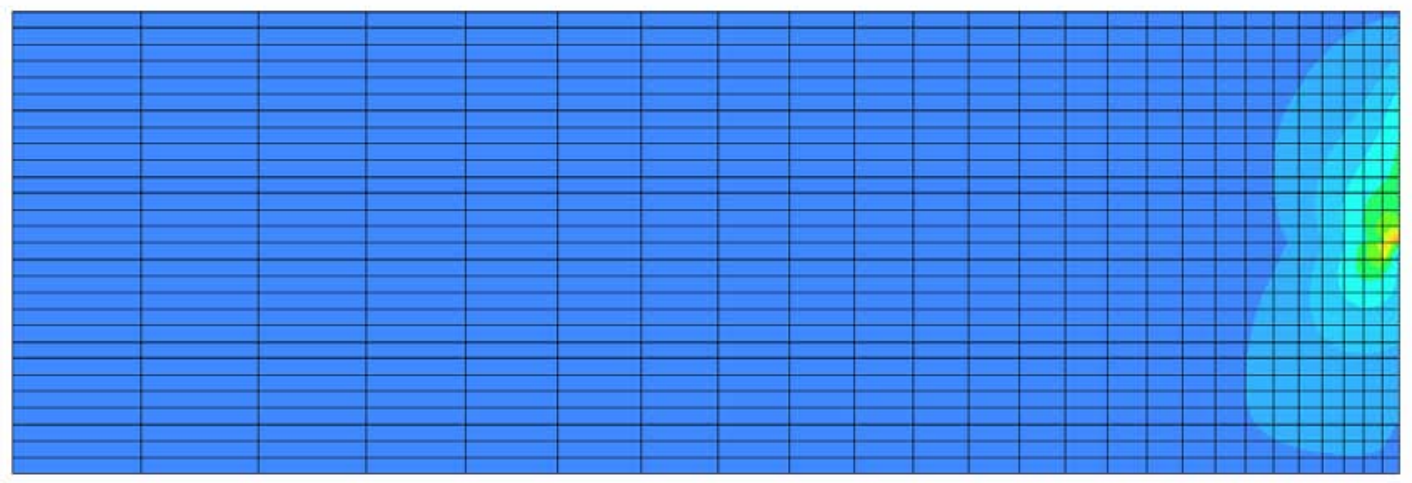

$E_{c}=4 \times 10^{6} \mathrm{psi} ; \alpha_{\mathrm{C}}=4 \times 10^{-6} /{ }^{\circ} \mathrm{F} ; 4^{\text {th }}$ degree gradient; one-mat; steel ratio $=0.7 \%$

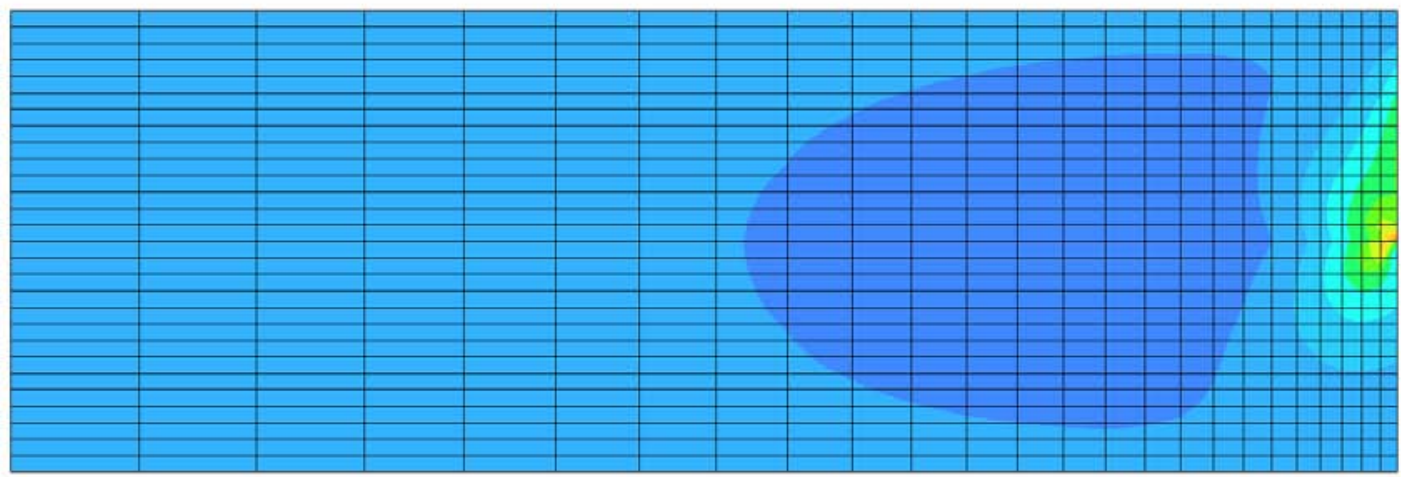

$E_{c}=6 \times 10^{6} \mathrm{psi} ; \alpha_{\mathrm{C}}=4 \times 10^{-6} /{ }^{\circ} \mathrm{F} ; 4^{\text {th }}$ degree gradient; one-mat; steel ratio $=0.7 \%$ 


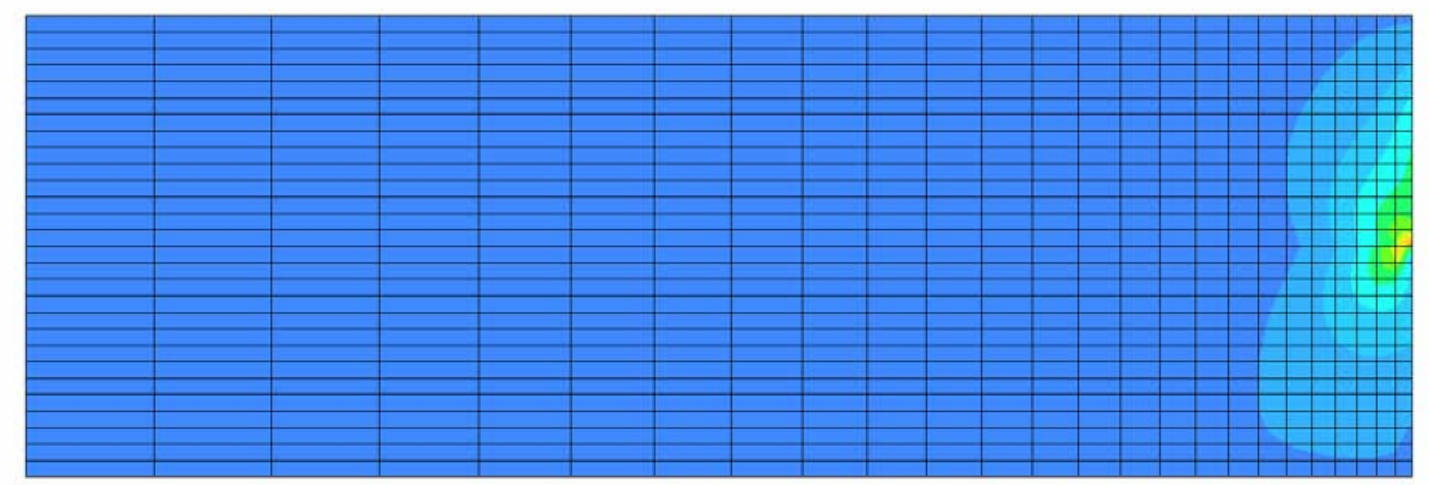

$E_{c}=4 \times 10^{6} \mathrm{psi} ; \alpha_{\mathrm{C}}=6 \times 10^{-6} /{ }^{\circ} \mathrm{F} ; 4^{\text {th }}$ degree gradient; one-mat; steel ratio $=0.7 \%$

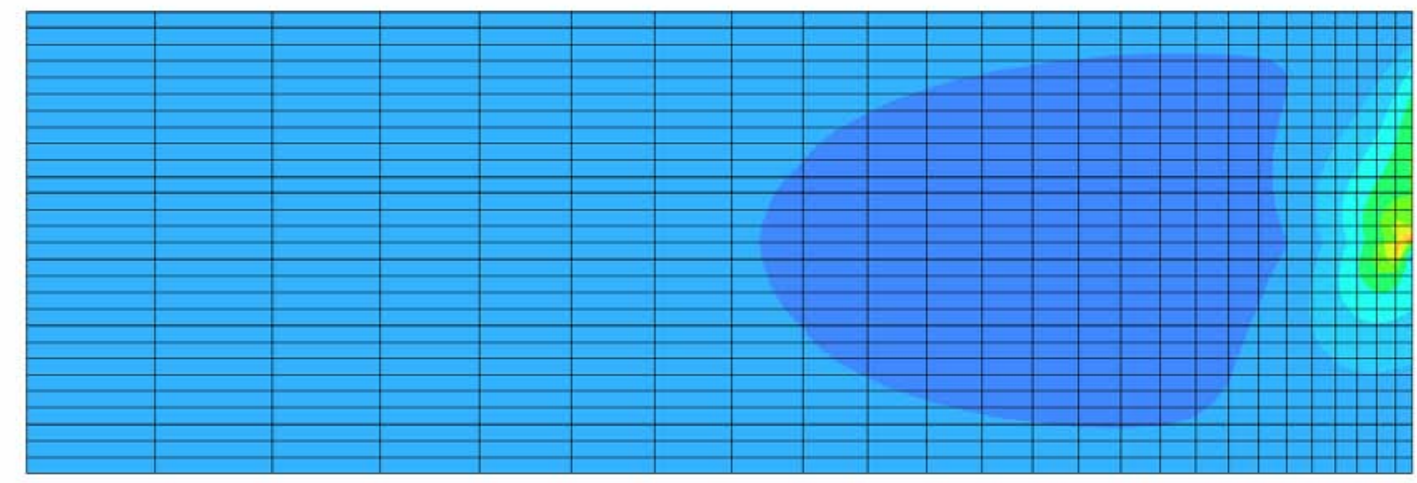

$E_{c}=6 \times 10^{6} \mathrm{psi} ; \alpha_{\mathrm{C}}=6 \times 10^{-6} /{ }^{\circ} \mathrm{F} ; 4^{\text {th }}$ degree gradient; one-mat; steel ratio $=0.7 \%$ 


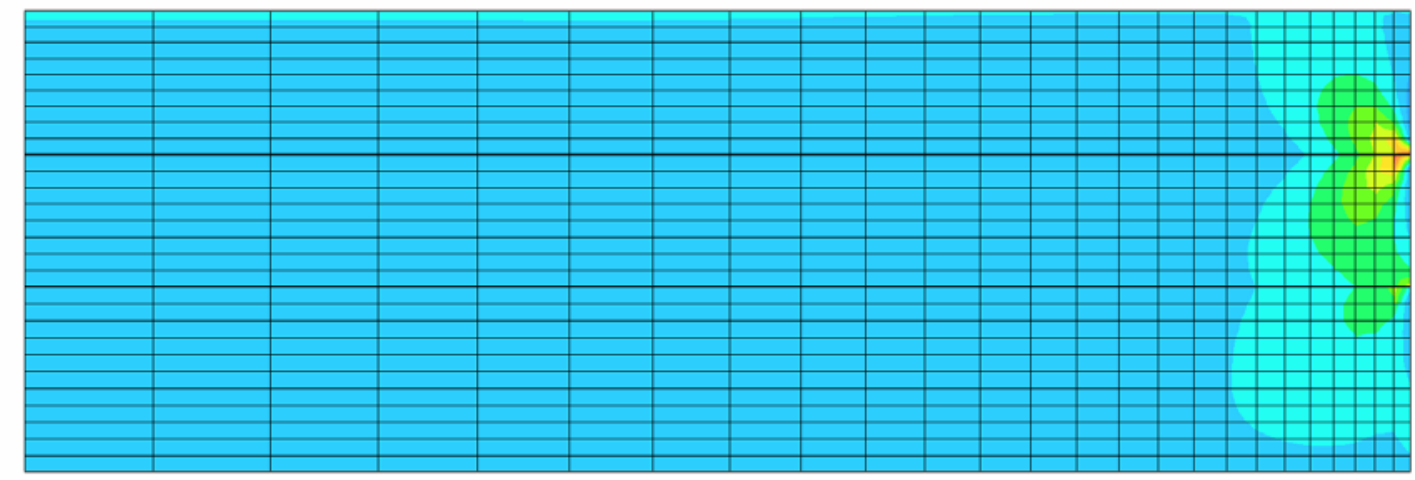

$E_{c}=4 \times 10^{6} \mathrm{psi} ; \alpha_{\mathrm{c}}=4 \times 10^{-6} /{ }^{\circ} \mathrm{F} ; 2^{\text {nd }}$ degree gradient; two-mat; steel ratio $=0.7 \%$

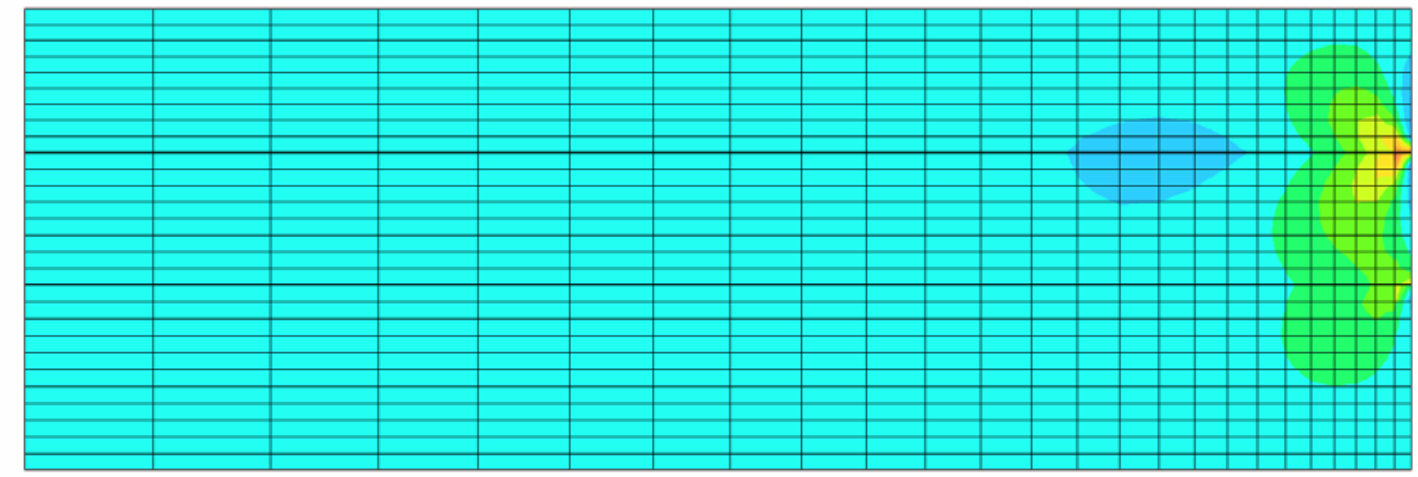

$E_{c}=6 \times 10^{6} \mathrm{psi} ; \alpha_{c}=4 \times 10^{-6} /{ }^{\circ} \mathrm{F} ; 2^{\text {nd }}$ degree gradient; two-mat; steel ratio $=0.7 \%$ 


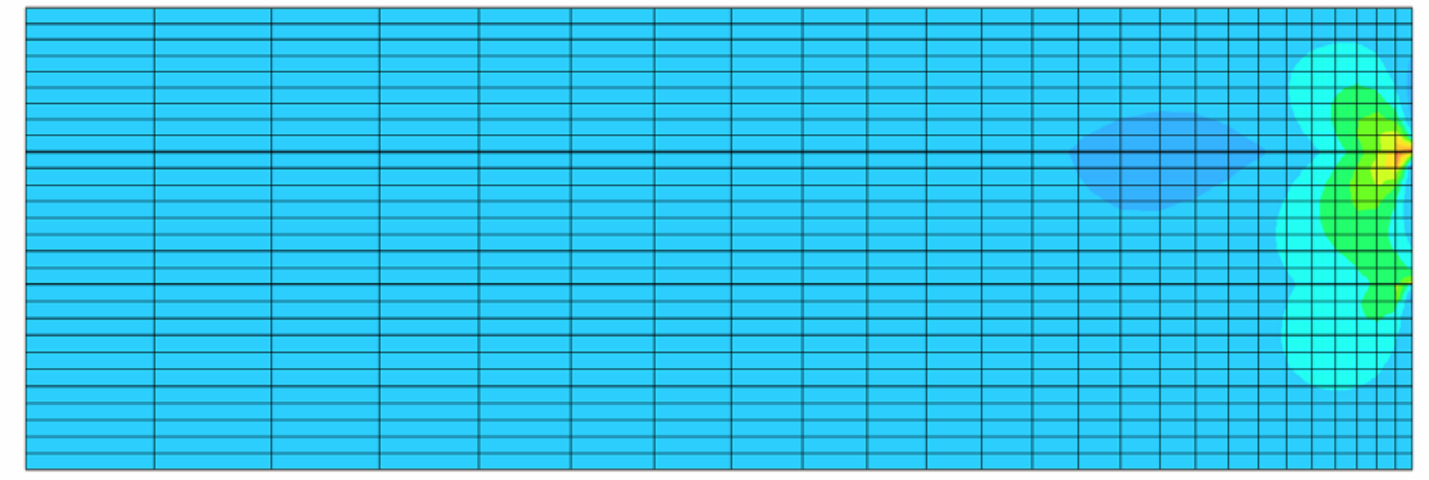

$E_{c}=4 \times 10^{6} \mathrm{psi} ; \alpha_{\mathrm{C}}=6 \times 10^{-6} /{ }^{\circ} \mathrm{F} ; 2^{\text {nd }}$ degree gradient; two-mat; steel ratio $=0.7 \%$

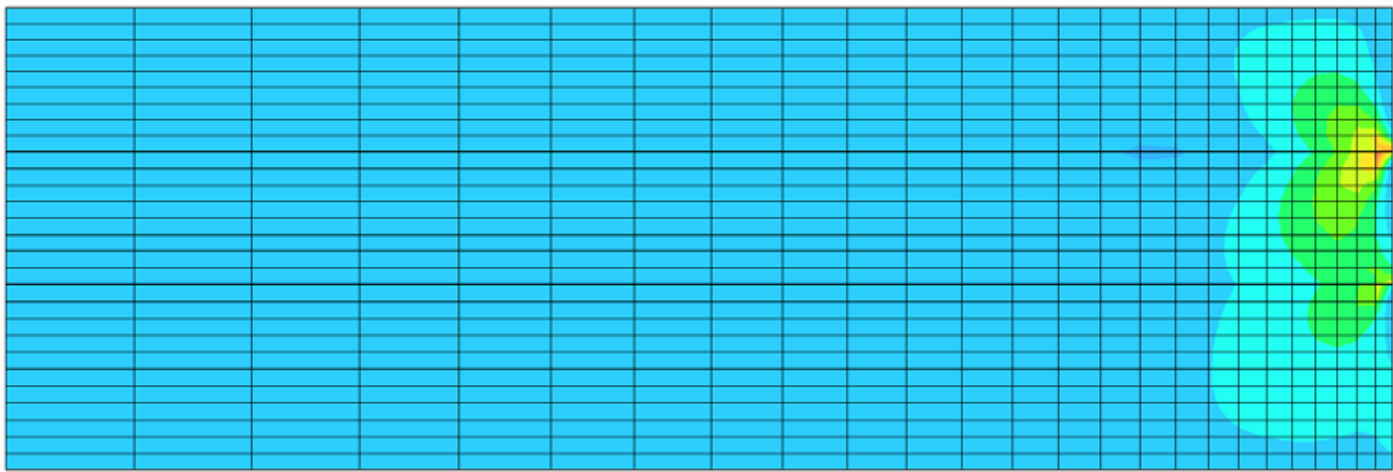

$E_{c}=6 \times 10^{6} \mathrm{psi} ; \alpha_{\mathrm{C}}=6 \times 10^{-6} /{ }^{\circ} \mathrm{F} ; 2^{\text {nd }}$ degree gradient; two-mat; steel ratio $=0.7 \%$ 


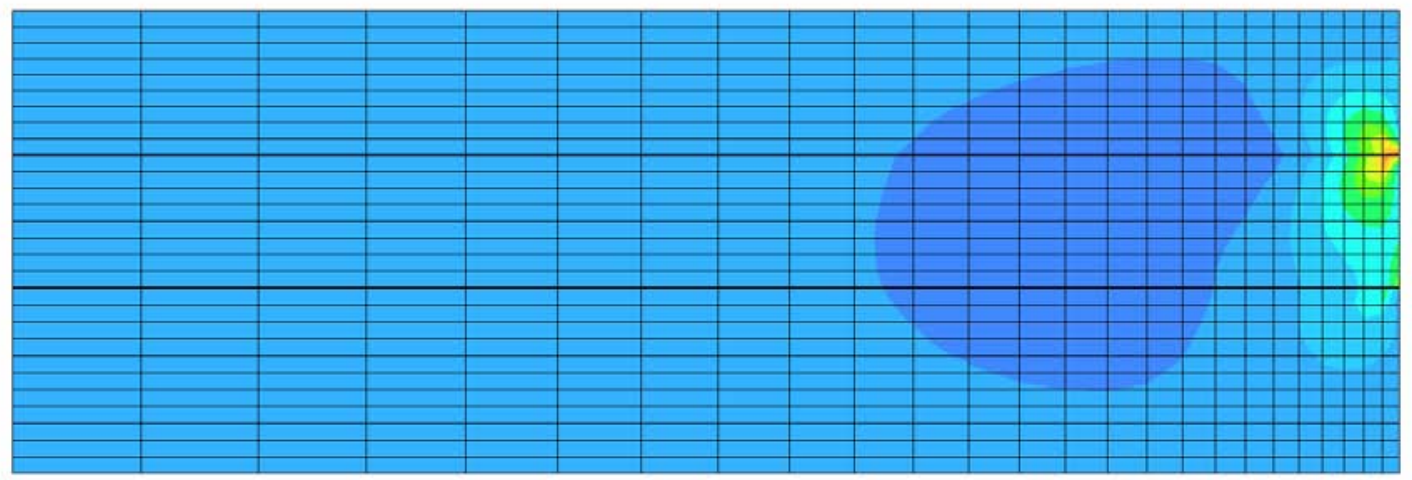

$E_{c}=4 \times 10^{6} \mathrm{psi} ; \alpha_{\mathrm{c}}=4 \times 10^{-6} /{ }^{\circ} \mathrm{F} ; 4^{\text {th }}$ degree gradient; two-mat; steel ratio $=0.7 \%$

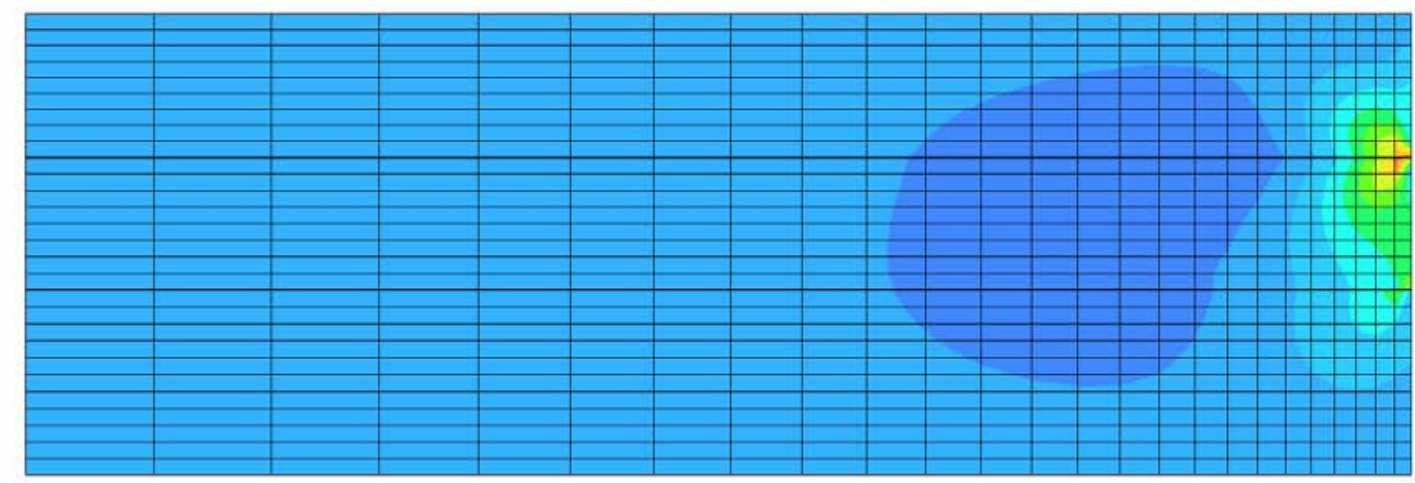

$E_{c}=6 \times 10^{6} \mathrm{psi} ; \alpha_{\mathrm{c}}=4 \times 10^{-6} /{ }^{\circ} \mathrm{F} ; 4^{\text {th }}$ degree gradient; two-mat; steel ratio $=0.7 \%$ 


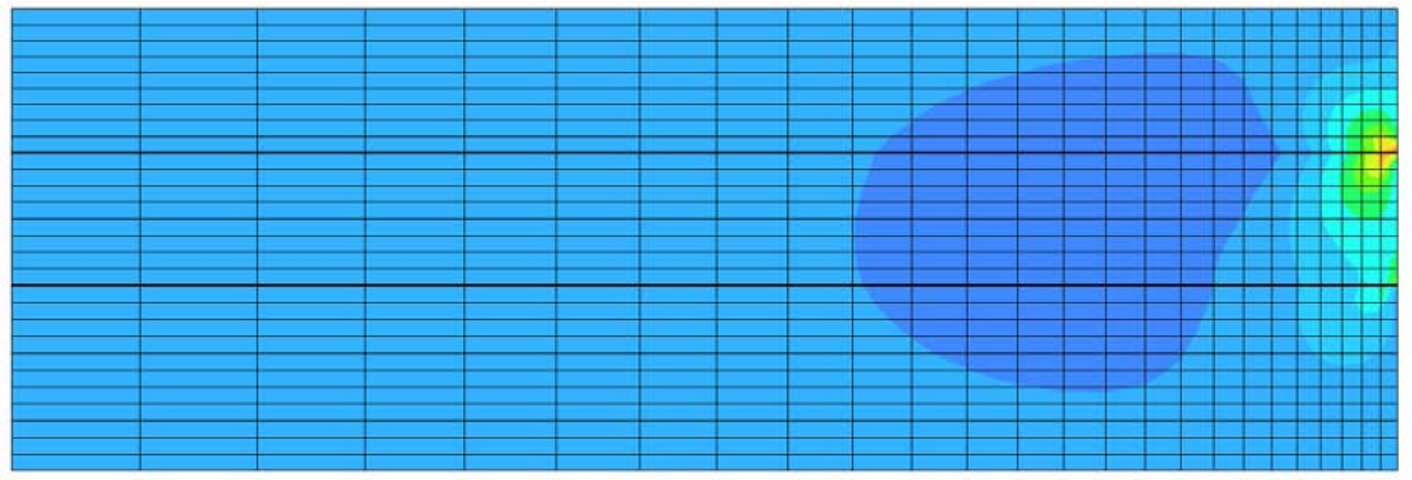

$E_{c}=4 \times 10^{6} \mathrm{psi} ; \alpha_{\mathrm{C}}=6 \times 10^{-6} /{ }^{\circ} \mathrm{F} ; 4^{\text {th }}$ degree gradient; two-mat; steel ratio $=0.7 \%$

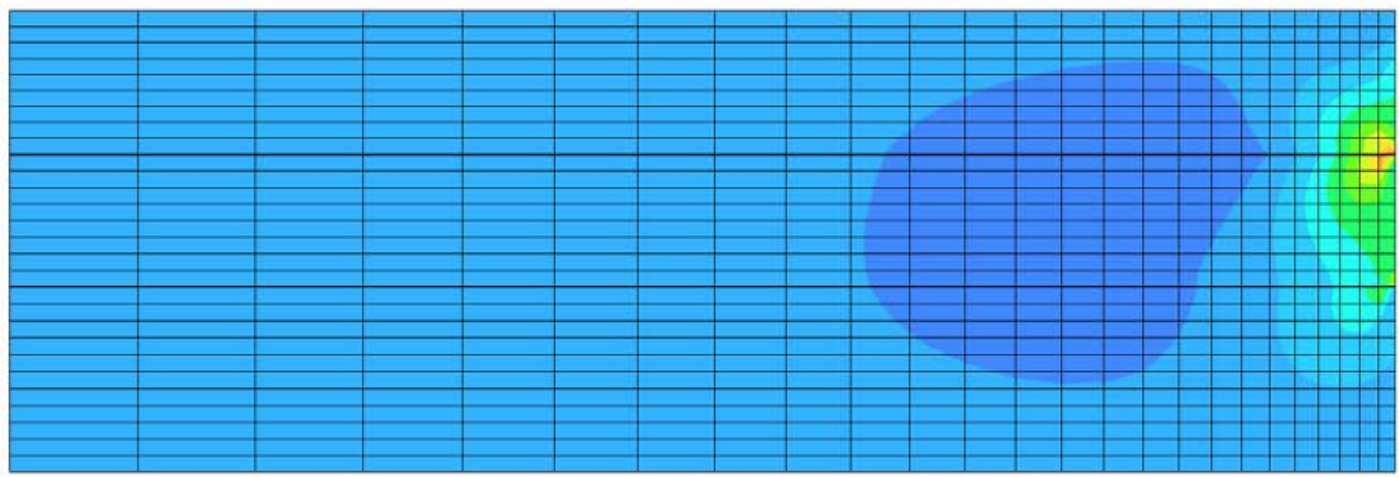

$E_{c}=6 \times 10^{6} \mathrm{psi} ; \alpha_{\mathrm{c}}=6 \times 10^{-6} /{ }^{\circ} \mathrm{F} ; 4^{\text {th }}$ degree gradient; two-mat; steel ratio $=0.7 \%$ 


\section{APPENDIX B}

Special Specifications for Partial-Depth Repair 


\section{SPECIAL SPECIFICATION}

\section{XXXX \\ Partial Depth Repair of Concrete Pavement}

1. Description. Repair concrete pavement to partial depth in accordance with the details shown on the plans and the requirements of this Item.

2. Materials. Provide materials that meet the pertinent requirements of the following:

- Item 360, "Concrete Pavement"

- Item 421, "Hydraulic Cement Concrete"

- Item 440, "Reinforcing Steel"

- DMS 6100, "Epoxies and Adhesives."

If material in Item 421 does not meet the strength requirement, provide material that meets the requirements in DMS-4655, "Rapid-Hardening Cementing Materials for Concrete Repair"

3. Equipment. Provide tools and equipment necessary for proper execution of the work that meet the pertinent requirements of the following:

- Item 360, "Concrete Pavement"

- Item 429, "Concrete Structure Repair"

In addition, provide following equipment:

A. Drill. Use a maximum $40 \mathrm{lb}$. hydraulic drill with tungsten carbide bits.

B. Air Compressor. Provide compressor capable of delivering air at $120 \mathrm{cu}$. ft. per minute and with a minimum 90 psi nozzle pressure.

4. Construction. Obtain approval for all materials and methods of application at least 2 weeks before beginning any repair work. Repair locations will be indicated on the plans or by the Engineer.

A. Remove Concrete. Use jackhammer and other equipment to remove concrete from repair area designated by the Engineer. Use caution not to damage the sound concrete during this operation. Make sure that all loose concrete materials are removed. Obtain approval of the completed concrete removal before proceeding to drilling holes. 
B. Drill Holes. Use drilling operations that do not damage the surrounding concrete. Drill holes in a slab vertically at the depth shown on the plans. Ensure that the holes diameters are no more than $1 / 8$ in. larger than tie bar diameter.

C. Clean Holes. Clean holes with oil-free and moisture-free compressed air and a wire brush to remove all cuttings, dust, and other deleterious material. Check the compressed air stream purity with a clean white cloth. Insert the nozzle to the bottom of the hole to force out all dust and debris. Alternate use of the wire brush and compressed air as necessary until all loose material has been removed.

D. Insertion of Epoxy Material and Tie Bar. Inject epoxy material into hole at adequate amount so that there will be no excess epoxy material on the surface of existing concrete when a tie bar is inserted fully to the depth of the hole. Place the tie bars into the hole. Remove any excess epoxy material from the concrete that comes out when a tie bar is fully inserted.

E. Surface Cleaning. Clean the area to be repaired by abrasive blasting or other approved methods. Remove all loose particles, dirt, deteriorated concrete, or other substances that would impair the bond of the repair material. Follow this with a highpressure air blast for final cleaning.

F. Repair Material Application. Mix, place, cure, and test concrete to the requirements of Item 360, "Concrete Pavement," and Item 421, "Hydraulic Cement Concrete." Broom-finish the concrete surface unless otherwise shown on the plans. Match the grade and alignment of existing concrete pavement. For repair areas to be opened to traffic before $72 \mathrm{hr}$., use curing mats to maintain a minimum concrete surface temperature of $70^{\circ} \mathrm{F}$ when air temperature is less than $70^{\circ} \mathrm{F}$.

G. Repairs. Repair damages to concrete pavement caused by Contractor's operation without any additional compensation. Perform repairs as directed.

5. Measurement. This Item will be measured by the square foot, in place, as measured on the surface of the completed repair.

6. Payment. The work performed and materials furnished in accordance with this Item and measured as provided under "Measurement" will be paid for at the unit price bid for "Partial Depth Repair of Concrete Pavement." This price shall be full compensation for furnishing all materials, tools, equipment, labor, and incidentals necessary to complete the work. No payment will be made for extra work required to repair damage to the adjacent pavement that occurred during concrete removing or cleaning operations. 


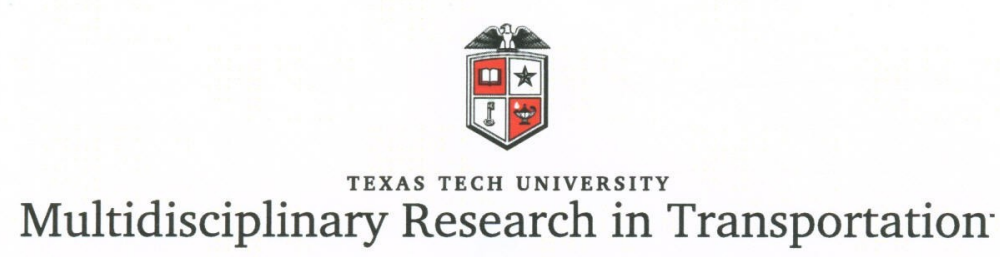

Texas Tech University | Lubbock, Texas 79409

P 806.742.3503 | F 806.742.4168 